NBS MONOGRAPH 18 ARIZONA LIBRARY Documents Collection OCT 171960

\title{
Heat Treatment and Properties of Iron and Steel
}

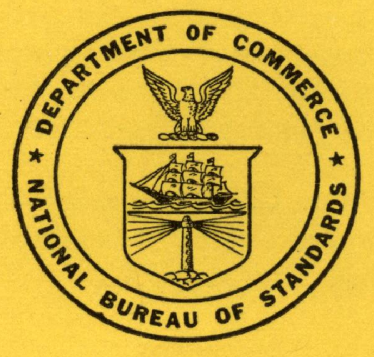

\section{U.S. DEPARTMENT OF COMMERCE NATIONAL BUREAU OF STANDARDS}




\section{THE NATIONAL BUREAU OF STANDARDS}

\section{Functions and Activities}

The functions of the National Bureau of Standards are set forth in the Act of Congress, March 3, 1901, as amended by Congress in Public Law 619, 1950. These include the development and maintenance of the national standards of measurement and the provision of means and methods for making measurements consistent with these standards; the determination of physical constants and properties of materials; the development of methods and instruments for testing materials, devices, and structures; advisory services to government agencies on scientific and technical problems; invention and development of devices to serve special needs of the Government; and the development of standard practices, codes, and specifications. The work includes basic and applied research, development, engineeriff, instrumentation, testing, evaluation, calibration services, and various consultation and information services. Research projects are also performed for other government agencies when the work relates to and supplements the basic program of the Bureau or when the Bureau's unique competence is required. The scope of activities is suggested by the listing of divisions and sections on the inside of the back cover.

\section{Publications}

The results of the Bureau's work take the form of either actual equipment and devices or published papers. These papers appear either in the Bureau's own series of publications or in the journals of professional and scientific societies. The Bureau itself publishes three periodicals available from the Government Printing Office: The Journal of Research, published in four separate sections, presents complete scientific and technical papers; the Technical News Bulletin presents summary and proliminary reports on work in progress; and Basic Radio Propagation Predictions provides data for determining the best frequencies to use for radio communications throughout the world. There are also five series of nonperiodical publications: Monographs, Applied Mathematics Series, Handbooks, Miscellaneous Publications, and Technical Notes.

Information on the Bureau's publications can be found in NBS Circular 460, Publications of the National Bureau of Standards $(\$ 1.25)$ and its Supplement $(\$ 1.50)$, available from the Superintendent of Documents, Government Printing Office, Washington 25, D.C. 
UNITED STATES DEPARTMENT OF COMMERCE - Frederick H. Mueller, Secretary NATIONAL BUREAU OF STANDARDS - A. V. Astin, Director

\section{Heat Treatment and Properties of Iron and Steel}

Thomas G. Digges and Samuel J. Rosenberg

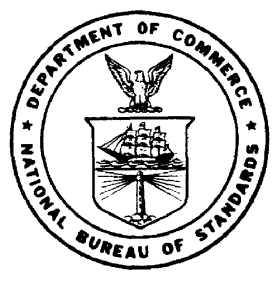

National Bureau of Standards Monograph 18

Issued October 3, 1960

Supersedes Circular 495

For sale by the Superintendent of Documents, U.S. Government Printing Office, Washington 25, D.C. - Price 35 cents 


\section{Contents}

Introduction

2. Properties of iron ......................... 1

2.1. Transformation temperatures .......... 1

2.2. Mechanical properties ................ 2

3. Alloys of iron and carbon _................. 2

3.1. Iron-carbon phase diagram _........... 2

3.2. Correlation of mechanical properties with microstructures of slowly cooled carbon stee's.

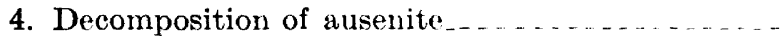

4.1. Isothermal transformation

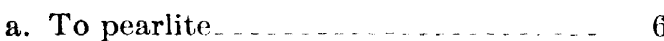

b. To bainite .................... 7

c. To martensite _................. 7

4.2. Continuous cooling _.................. 7

5. Heat treatment of steels _.................... 8

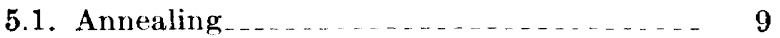

a. Full annealing ................. 9

b. Process annealing .............. 9

c. Spheroidizing ................... 10

5.2. Normalizing ............................... 11

5.3. Hardening .......................... 11

a. Effect of mass ................. 11

5.4. Tempering .......................... 12

5.5 Case hardening ....................... 13

a. Carburizing ........................ 13

b. Cyaniding ............................ 14

c. Carbonitriding ....................... 15

d. Nitriding ............................... 15

5.6. Surface hardening .................. 15

a. Induction hardening .............. 15

b. Flame hardening .............. 16

5.7. Special treatments .................. 16

a. Austempering ................. 16

b. Martempering ................. 16

c. Cold treatment ................... 16

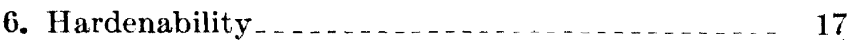

7. Heat treatment of cast irons................ 18

7.1. Relieving residual stresses (aging) _..... 20

7.2. Annealing ......................... 20

a. Malleabilizing ..................... 20

7.3. Normalizing, quenching, and tempering _- 20

7.4. Special heat treatments.............. 21

II
8. Practical considerations $r$ Page

8.1. Furnaces and salt baths............. 21

a. Protective atmospheres_......... 21

b. Temperature measurement and control ............................ 21

8.2. Quenching media and accessories_...... 22

8.3. Relation of design to heat treatment_... 23

9. Nomenclature and chemical compositions of steels -23

9.1. Structural steels_..................... 23

9.2. Tool steels _........................ 29

9.3. Stainless and heat resisting steels_...... 30

10. Recommended heat treatments_............. 30

10.1. Structural steels_................... 30

10.2. Tool steels _.............................. 33

10.3. Stainless and heat resisting steels_..... 33

a. Group I-Hardenable chromium steels (martensitic and magnetic) _ 33

b. Group II-Nonhardenable chromium steels (ferritic and mag-

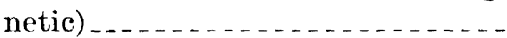

c. Group III-Nonhardenable chromium-nickel and chromiumnickel-manganese steels (austenitic and nonmagnetic) ..........

11. Properties and uses of steels _............... 36

11.1. Structural steels_................. 36

a. Plain carbon structural steels_... 36

b. Alloy structural steels_.......... 36

11.2. Tool steels _........................ 37

11.3. Stainless and heat resisting steels _..... 38

a. Group I-Hardenable chromium steels (martensitic and magnetic)

b. Group II-Nonhardenable chromium steels (ferritic and mag-

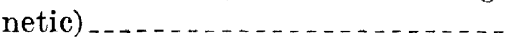

c. Group III-Nonhardenable chromium-nickel and chromiumnickel-manganese steels (austenitic and nonmagnetic)

d. Semi-austenitic stainless steels.....

12. Selected references . . . . . . . . . . . . . . . . . . e

1

(1)

1

3

9

3

3

6

6

6

38




\title{
Heat Treatment and Properties of Iron and Steel
}

\author{
Thomas G. Digges and Samuel J. Rosenberg
}

This Monograph has been prepared to give an understanding of heat treatment principally to those unacquainted with this subject. To this end, the basic theoretical and practical principles involved in the heat treatment of iron and steel are presented in simplified form.

\section{Introduction}

The National Bureau of Standards receives many requests for general information concerning the heat treatment of iron and steel and for directions and explanations of such processes. This Monograph has been prepared to answer such inquiries and to give in simplified form a working knowledge of the basic theoretical and practical principles involved in the heat treatment of iron and steel. The effects of various treatments on the structures and mechanical properties of these materials are described. Many theoretical aspects are discussed only briefly or omitted entirely, and in some instances, technical details have been neglected for simplicity. The present Monograph supersedes Circular 495, which was published in 1950.

Heat treatment may be defined as an operation or combination of operations that involves the heating and cooling of a solid metal or alloy for the purpose of obtaining certain desirable conditions or properties. It is usually desired to preserve, as nearly as possible, the form, dimensions, and surface of the piece being treated.

Steels and cast irons are essentially alloys of iron and carbon, modified by the presence of other elements. Steel may be defined as an alloy of iron and carbon (with or without other alloying elements) containing less than about 2.0 percent of carbon, usefully malleable or forgeable as initially cast. Cast iron may be defined as an alloy of iron and carbon (with or without other alloying elements) containing more than 2.0 percent of carbon, not usefully malleable or forgeable as initially cast. For reasons that will be apparent later, the dividing line between steels and cast irons is taken at 2.0 percent of carbon, even though certain special steels contain carbon in excess of this amount. In addition to carbon, four other elements are normally present in steels and in cast irons. These are mangnaese, silicon, phosphorus, and sulfur.

Steels may be broadly classified into two types, (1) carbon and (2) alloy. Carbon steels owe their properties chiefly to the carbon. They are frequently called straight or plain carbon steels. Alloy steels are those to which one or more alloying elements are added in sufficient amounts to modify certain properties. The properties of cast iron also may be modified by the presence of alloying elements-such irons are called alloy cast irons.

\section{Properties of Iron}

Since iron is the basic element of steel, a knowledge of some of its properties is a prerequisite to an understanding of the fundamental principles underlying the heat treatment of steels.

\subsection{Transformation Temperatures}

If a molten sample of pure iron were allowed to cool slowly and the temperature of the iron were measured at regular intervals, an idealized (equilibrium) time-temperature plot of the data would appear as shown in figure 1. The discontinuities (temperature arrests) in this curve are caused by physical changes in the iron.

The first arrest at $2,800^{\circ} \mathrm{F}$ marks the temperature at which the iron freezes. The other arrests (known as transformation temperatures or critical points) mark temperatures at which certain internal changes take place in the solid iron. Some of these temperatures are very important in the heat treatment of steel.

The atoms in all solid metals are arranged in some definite geometric (or crystallographic) pattern. The atoms in iron, immediately after freezing, are arranged in what is termed the bodycentered cubic system. In this crystal structure

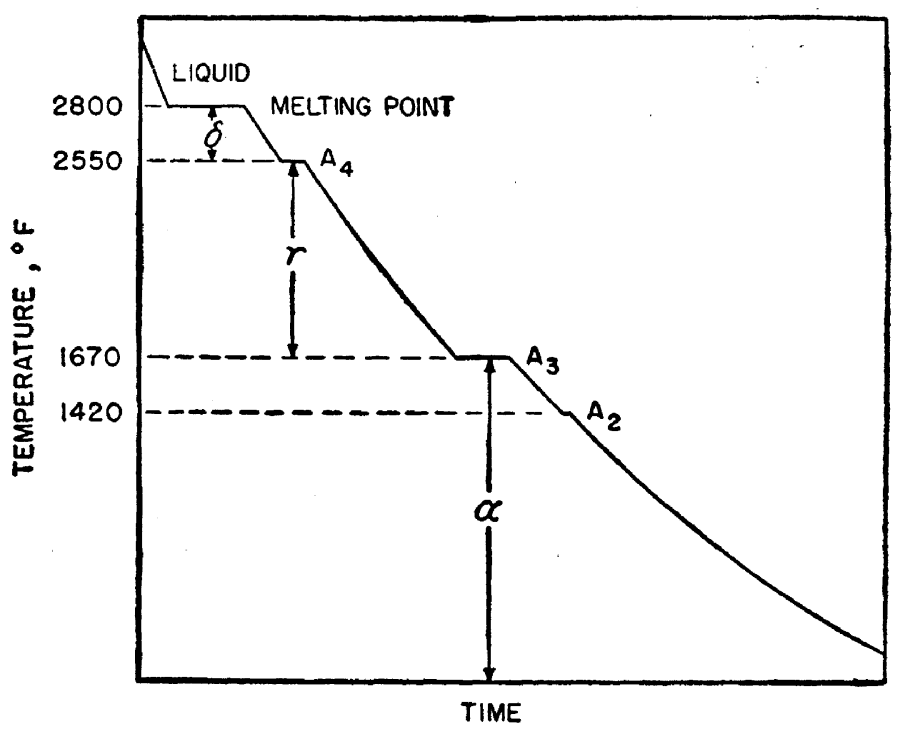

FIGURE 1. Idealized cooling curve for pure iron. 
the unit cell consists of a cube with an iron atom at each of the eight corners and another in the center (fig. 2, a). Each of the many individual grains (crystals) of which the solid metal is composed is built up of a very large number of these unit cells, all oriented alike in the same grain. This high-temperature form of iron is known as delta $(\delta)$ iron.
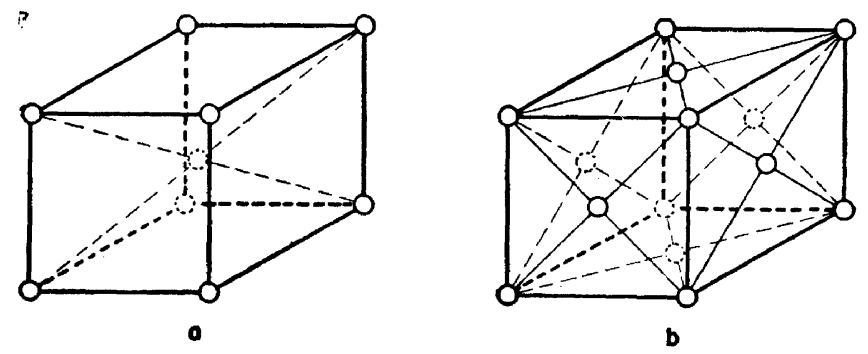

Figure 2. Crystal structure of iron.

(a) Body-centered cubic (aipha and delta iron); (b) Face-centered cubic (gamma iron).

At $2,550^{\circ} \mathrm{F}$ (the $A_{4}$ point), iron undergoes an allotropic transformation (fig. 1); that is, the arrangement of the atoms in the crystal changes. The new crystal structure is face-centered cubic, and the unit cell again consists of a cube with an iron atom at each of the eight corners, but with an iron atom in the center of each of the six faces instead of one in the center of the cube (fig. 2, b). This form is known as gamma $(\gamma)$ iron. At $1,670^{\circ}$ $F$ (the $A_{3}$ point), iron undergoes another allotropic transformation and reverts to the bodycentered cubic system (fig. 2, a). This structure, which is crystallographically the same as delta iron, is stable at all temperatures below the $A_{3}$ point and is known as alpha ( $\alpha$ ) iron (fig. 5, A). The arrest at $1,420^{\circ} \mathrm{F}$ (known as the $A_{2}$ point) is not caused by an allotropic change, that is, a change in crystal structure. It marks the temperature at which iron becomes ferromagnetic and is therefore termed the magnetic transition. Above this temperature iron is nonmagnetic.

These various temperature arrests on cooling are caused by evolutions of heat. On heating, the arrests occur in reverse order and are caused by absorption of heat. The critical points may be detected also by sudden changes in other physical properties, for instance, expansivity or electrical conductivity.

\subsection{Mechanical Properties}

Iron is relatively soft, weak, and ductile and cannot be appreciably hardened by heat treatment. Its tensile strength at room temperature is about $40,000 \mathrm{lb} /$ in. $^{2}$, its yield strength is about $20,000 \mathrm{lb} /$ in. $^{2}$, and its Brinell hardness is about 80 . The modulus of elasticity is about $29,000,000$ $\mathrm{lb} /$ in. ${ }^{2}$. The strength and hardness can be increased, with corresponding decrease in ductility, by cold working.

\section{Alloys of Iron and Carbon}

The properties of iron are affected very markedly by additions of carbon. It should be realized that in discussing iron-carbon alloys, we actually are dealing with plain carbon steels and cast irons.

\subsection{Iron-Carbon Phase Diagram}

The complete iron-carbon phase (or constitutional) diagram represents the relationship between temperatures, compositions, and structures of all phases that may be formed by iron and carbon under conditions of equilibrium (very slow cooling). A portion of this diagram for alloys ranging up to 6.7 percent of carbon is reproduced in figure 3 ; the upper limit of carbon in cast iron is usually not in excess of 5 percent. The lefthand boundary of the diagram represents pure iron (ferrite), and the right-hand boundary represents the compound iron carbide, $\mathrm{Fe}_{3} \mathrm{C}$, commonly called cementite.

The beginning of freezing of the various ironcarbon alloys is given by the curve $A B C D$, termed the liquidus curve. The ending of freezing is given by the curve $A H J E C F$, termed the solidus curve. The freezing point of iron is lowered by the addition of carbon (up to $4.3 \%$ ) and the resultant alloys freeze over a range in temperature instead of at a constant temperature as does the pure metal iron. The alloy containing 4.3 percent of carbon, called the eutectic alloy of iron and cementite, freezes at a constant temperature as indicated by the point $C$. This temperature is $2,065^{\circ} \mathrm{F}$, considerably below the freezing point of pure iron.

Carbon has an important effect upon the transformation temperatures (critical points) of iron. It raises the $A_{4}$ temperature and lowers the $A_{3}$. This effect on the $A_{3}$ temperature is very important in the heat treatment of carbon and alloy structural steels, while that on the $A_{4}$ is important in the heat treatment of certain high alloy steels, particularly of the stainless types.

It is possible for solid iron to absorb or dissolve carbon, the amount being dependent upon the crystal structure of the iron and the temperature. The body-centered (alpha or delta) iron can dissolve but little carbon, whereas the face-centered (gamma) iron can dissolve a considerable amount, the maximum being about 2.0 percent at $2,065^{\circ}$ F (fig. 3). This solid solution of carbon in gamma iron is termed austenite. The solid solution of carbon in delta iron is termed delta ferrite, and the solid solution of carbon in alpha iron is termed alpha ferrite, or, more simply, ferrite.

The mechanism of solidification of iron-carbon alloys, especially those containing less than about 0.6 percent of carbon, is rather complicated and is of no importance in the heat treatment of carbon steels and cast irons. It is sufficient to know that all iron-carbon alloys containing less than 2.0 percent of carbon (that is, steel) will, immediately or soon after solidification is complete, consist of 


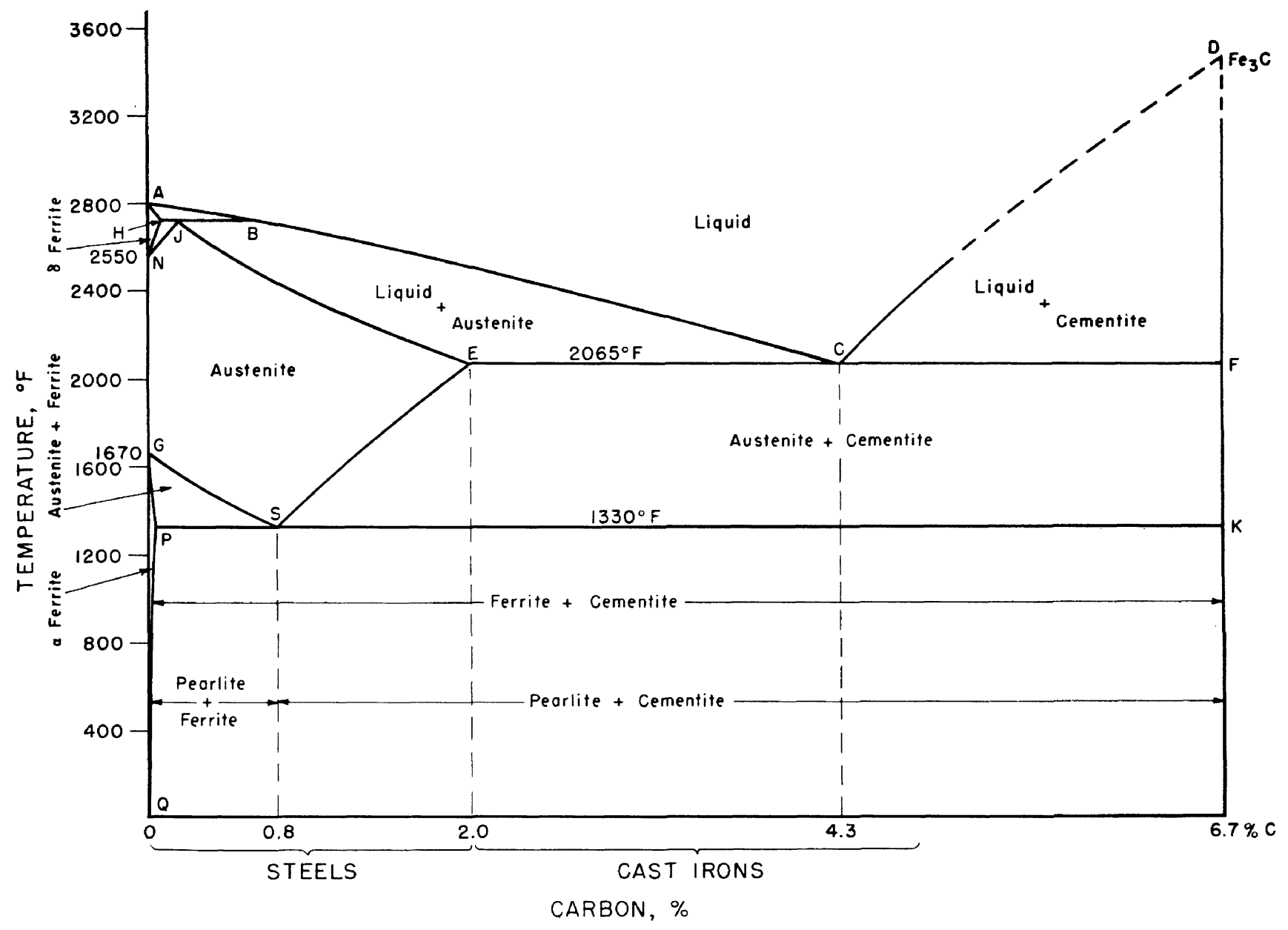

FiglRE 3. Iron-carbon phase diagram.

the single phase austenite. Cast irons will consist of two phases immediately after solidificationaustenite and cementite. Under some conditions this cementite formed on cooling through the temperature horizontal $E C F$ will decompose partly or completely into austenite and graphite.

The part of the iron-carbon diagram that is concerned with the heat treatment of steel is reproduced on an expanded scale in figure 4. Regardless of the carbon content, steel exists as austenite above the line GOSE. Steel of composition $S$ $(0.80 \%$ of carbon) is designated as "eutectoid" steel, and those with lower or higher carbon as "hypoeutectoid" and "hypereutectoid," respectively.

A eutectoid steel, when cooled at very slow rates from temperatures within the austenitic field, undergoes no change until the temperature horizontal $P S K$ is reached. At this temperature (known as the $A_{1}$ temperature), the austenite transforms completely to an aggregate of ferrite and cementite having a typical lamellar structure (fig. 5, D and $\mathrm{E})$. This aggregate is known as pearlite and the $A_{1}$ temperature is, therefore, frequently referred to as the pearlite point. Since the $A_{1}$ transforma- tion involves the transformation of austenite to pearlite (which contains cementite- $-\mathrm{Fe}_{3} \mathrm{C}$ ), pure iron does not possess an $A_{1}$ transformation (fig. 4). Theoretically, iron must be alloyed with a minimum of 0.03 percent of carbon before the first minute traces of pearlite can be formed on cooling (point $\mathrm{P}$, fig. 4). If the steel is held at a temperature just below $A_{1}$, (either during cooling or heating), the carbide in the pearlite tends to coalesce into globules or spheroids. This phenomenon, known as spheroidization, will be discussed subsequently.

Hypoeutectoid steels (less than $0.80 \%$ of carbon), when slowly cooled from temperatures above the $A_{3}$, begin to precipitate ferrite when the $A_{3}$ line ( $G O S$-fig. 4) is reached. As the temperature drops from the $A_{3}$ to $A_{1}$, the precipitation of ferrite increases progressively and the amount of the remaining austenite decreases progressively, its carbon content being increased. At the $A_{1}$ temperature the remaining austenite reaches eutectoid composition $(0.80 \%$ of carbon-point $S$, fig. 4) and, upon further cooling, transforms completely into pearlite. The microstructures of slowly cooled hypoeutectoid steels thus consist of mixtures of 


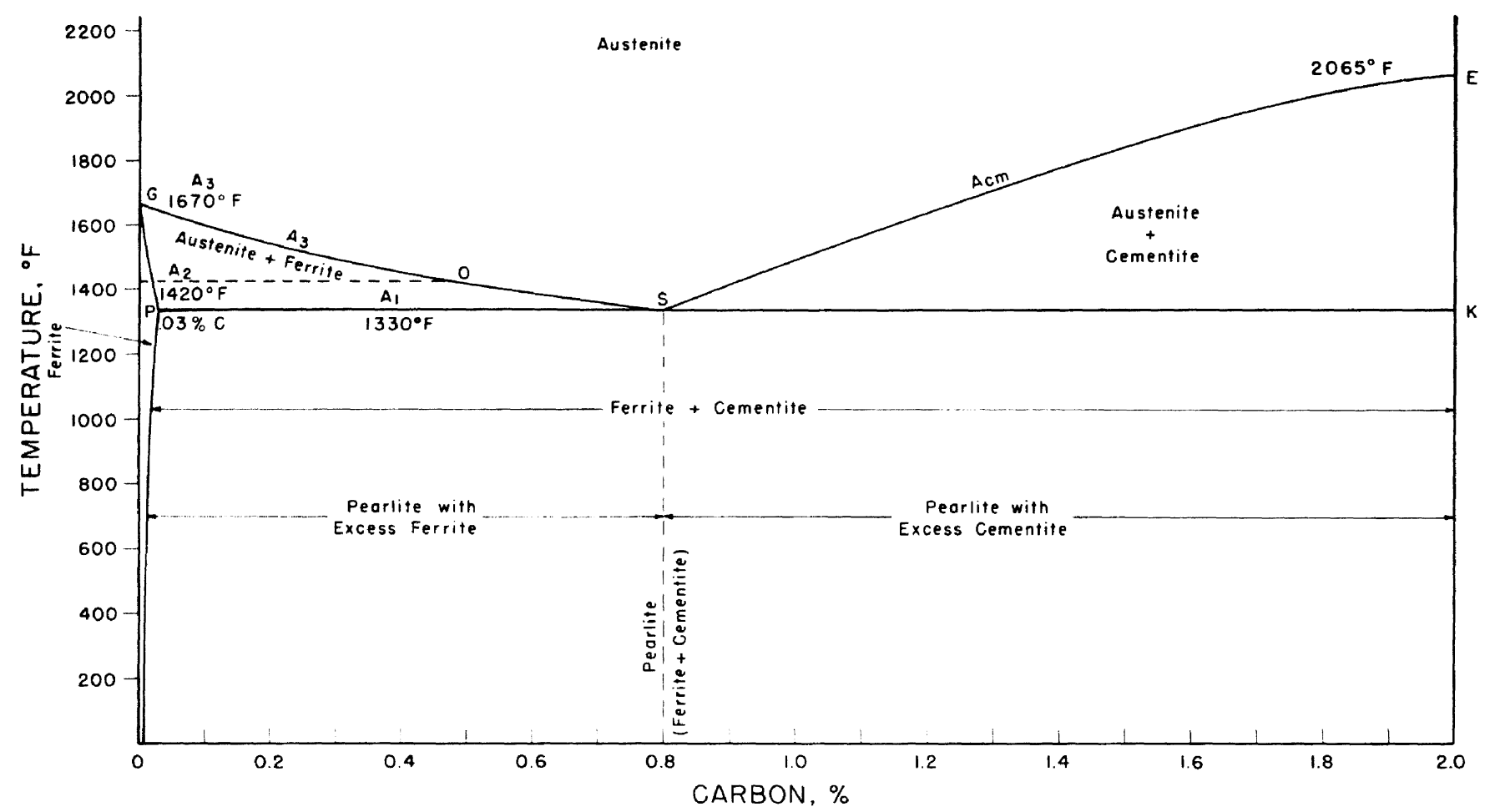

Figure 4. Phase diagram for carbon steels.

ferrite and pearlite (fig. 5, B and C). The lower the carbon content, the higher is the temperature at which ferrite begins to precipitate and the greater is the amount in the final structure.

Hypereutectoid steels (more than $0.80 \%$ of carbon), when slowly cooled from temperatures above the $A_{\mathrm{cm}}$, begin to precipitate cementite when the $A_{\mathrm{cm}}$ line ( $S E$ - fig. 4) is reached. As the temperature drops from the $A_{\mathrm{cm}}$ to $A_{1}$, the precipitation of cementite increases progressively and the amount of the remaining austenite decreases progressively, its carbon content being depleted. At the $A_{1}$ temperature the remaining austenite reaches eutectoid composition $(0.80 \%$ of carbon) and, upon further cooling, transforms completely into pearlite. The microstructures of slowly cooled hypereutectoid steels thus consist of mixtures of cementite and pearlite (fig. 5, F). The higher the carbon content, the higher is the temperature at which cementite begins to precipitate and the greater is the amount in the final structure.

The temperature range between the $A_{1}$ and $A_{3}$ points is called the critical or transformation range. Theoretically, the critical points in any steel should occur at about the same temperatures on either heating or cooling very slowly. Practically, however, they do not since the $A_{3}$ and $A_{1}$ points, affected but slightly by the rate of heating, are affected tremendously by the rate of cooling. Rapid rates of heating raise these points only slightly, but rapid rates of cooling lower the temperatures of transformation considerably. To differentiate between the critical points on heating and cooling, the small letters "c" (for "chauffage" from the French, meaning heating) and " $\mathrm{r}$ " (for "refroidissement" from the French, meaning cooling) are added. The terminology of the critical points thus becomes $\mathrm{Ac}_{3}, \mathrm{Ar}_{3}, \mathrm{Ac}_{1}, \mathrm{Ar}_{1}$, etc. The letter " $\mathrm{e}$ " is used to designate the occurrence of the points under conditions of extremely slow cooling on the assumption that this represents equilibrium conditions (" $\mathrm{e}$ " for equilibrium); for instance, the $\mathrm{Ae}_{3}, \mathrm{Ae}_{1}$, and $\mathrm{Ae}_{\mathrm{cm}}$.

\subsection{Correlation of Mechanical Properties With Microstructures of Slowly Cooled Carbon Steels}

Some mechanical properties of pearlite formed during slow cooling of a eutectoid ( $0.80 \%$ of carbon) steel are approximately as follows:

Tensile strength $-115,000 \mathrm{lb} / \mathrm{in}^{2}$.

Yield strength-60,000 lb/in ${ }^{2}$.

Brinell hardness number-200.

The amount of pearlite present in a slowly cooled hypoeutectoid steel is a linear function of the carbon content, varying from no pearlite, when no carbon is present (the very slight amount of carbon soluble in alpha iron may be neglected), to all pearlite at 0.80 percent of carbon. The balance of the structure of hypoeutectoid steels is composed of ferrite, the mechanical properties of which were given in a preceding section. Since the mechanical properties of aggregates of ferrite and pearlite are functions of the relative amounts of these two constitutents, the mechanical properties of slowly cooled hypoeutectoid steels are also 

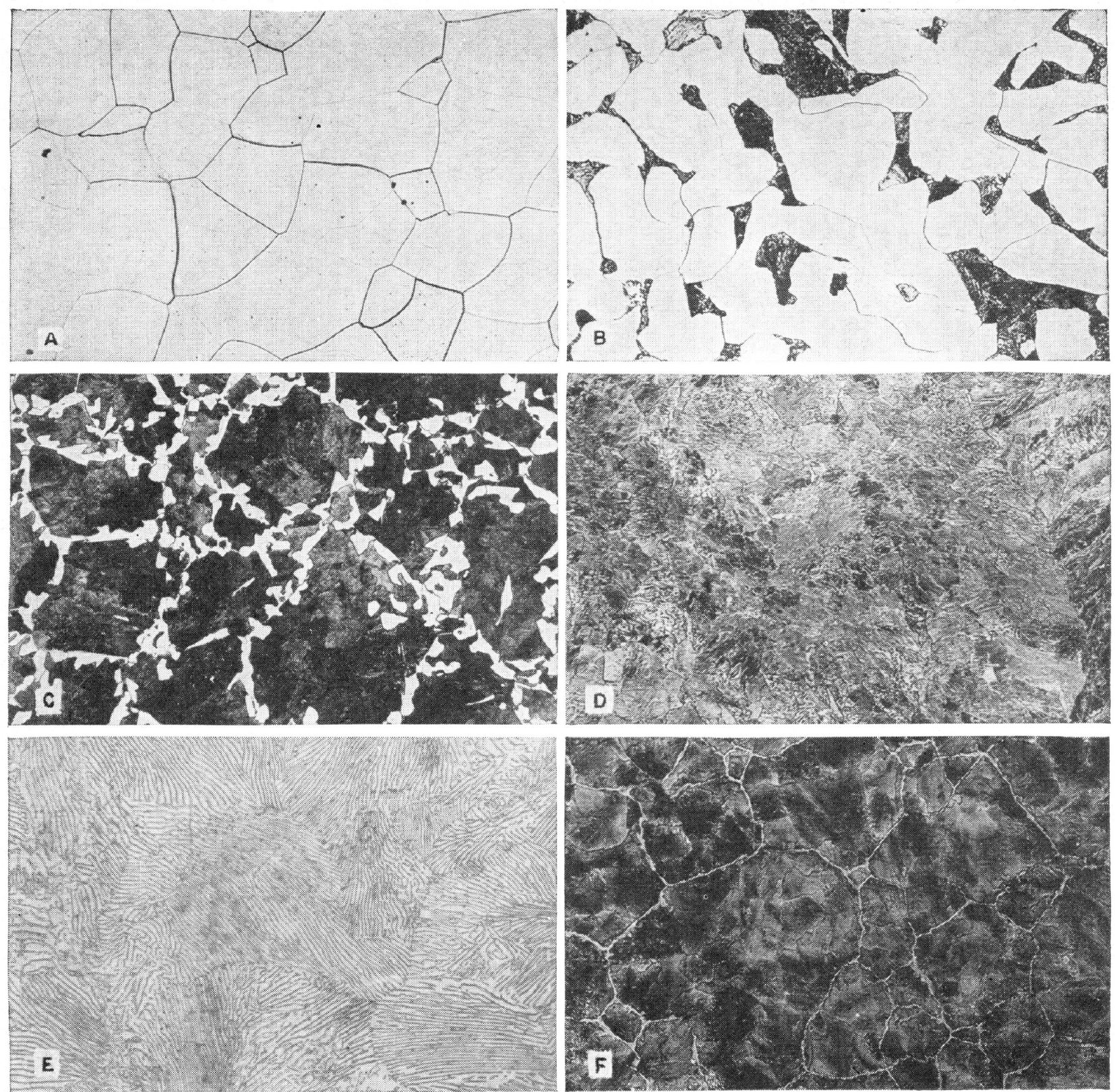

Figure 5. Microstructural constituents of slowly cooled carbon steels.

A, Ferrite ( $\alpha$ iron). All grains are of the same composition. $\times 100$.

B, $0.25 \%$ carbon. Light areas are ferrite grains. Dark areas are pearlite. $\times 100$.

C, $0.5 \%$ carbon. Same as B but higher carbon content results in more pearlite and less ferrite. $\times 100$

$\mathrm{D}, 0.8 \%$ carbon. All pearlite. $\times 100$

$\mathrm{E}$, Same as D. At higher magnification the lamellar structure of pearlite is readily observed. $\times 500$

$\mathrm{F}, 1.3 \%$ carbon. Pearlite plus excess cementite as network. $\times 100$.

All etched with either picral or nital.

linear functions of the carbon content, varying between those of iron at no carbon to those of pearlite at 0.80 percent of carbon (fig. 6).

\section{Decomposition of Austenite}

In alloys of iron and carbon, austenite is stable only at temperatures above the $\mathrm{Ae}_{1}\left(1,330^{\circ} \mathrm{F}\right)$. Below this temperature it decomposes into mixtures of ferrite ( $\alpha$ iron) and cementite (iron carbide). The end product or final structure is greatly influenced by the temperature at which the transformation occurs, and this, in turn, is influ- enced by the rate of cooling. Since the mechanical properties may be varied over a wide range, depending on the decomposition products of the parent austenite, a knowledge of how austenite decomposes and the factors influencing it is necessary for a clear understanding of the heat treatment of steel. The progressive transformation of austenite under conditions of equilibrium (extremely slow cooling) has been described. Practically, however, steel is not cooled under equilibrium conditions, and consequently the critical points on cooling always occur at lower temperatures than indicated in figure 4. 

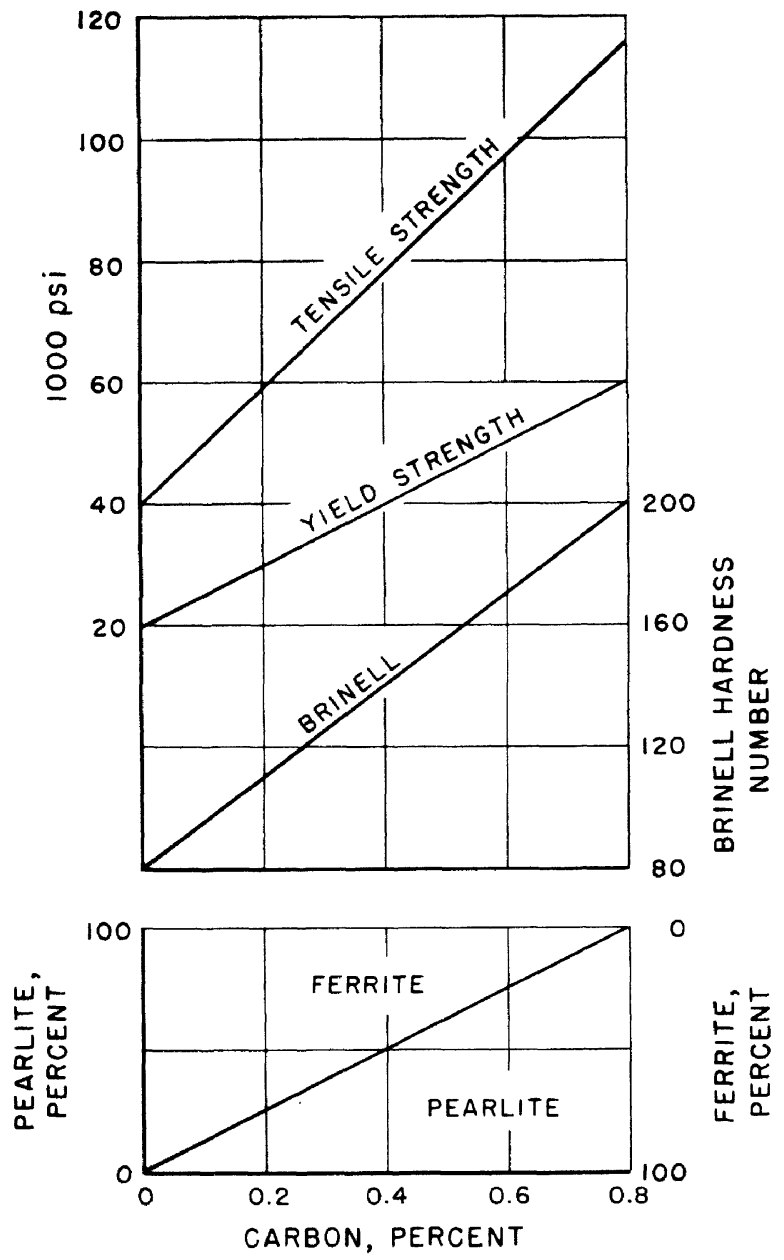

Frgure 6. Relation of mechanical properties and structure to carbon content of slowly cooled carbon steels.

If samples of steel, say of eutectoid carbon content for the sake of simplicity, are cooled from above the $A_{1}$ at gradually increasing rates, the corresponding Ar transformation occurs at lower and lower temperatures (fig. 7). This transformation is distinguished from that occurring under extremely slow rates of cooling $\left(\mathrm{Ar}_{\mathrm{f}}\right)$ by the designation $\mathrm{Ar}^{\prime}$. As the rate of cooling of this steel is increased, an additional transformation (termed the $\mathrm{Ar}^{\prime \prime}$ or $\mathrm{M}_{\mathrm{s}}$ ) appears at relatively low temperatures (about $430^{\circ} \mathrm{F}$ ). If the rate of cooling is still further increased, the $\mathrm{Ar}^{\prime}$ transformation is suppressed entirely and only the $\mathrm{Ar}^{\prime \prime}$ transformation is evident. It should be noted that the temperature of the $\mathrm{Ar}^{\prime \prime}$ is not affected by the rate of cooling, whereas the temperature of the $\mathrm{Ar}^{\prime}$ may be depressed to as low as about $1,050^{\circ} \mathrm{F}$ in this particular steel.

The product of the $\mathrm{Ar}^{\prime}$ transformation is fine pearlite. As the temperature of the $\mathrm{Ar}^{\prime}$ is gradually lowered, the lamellar structure of the resulting pearlite becomes correspondingly finer and the steel becomes harder and stronger. The product of the $\mathrm{Ar}^{\prime \prime}$ transformation is martensite (fig. $9, A$, and $15, A$ ), which is the hardest and most

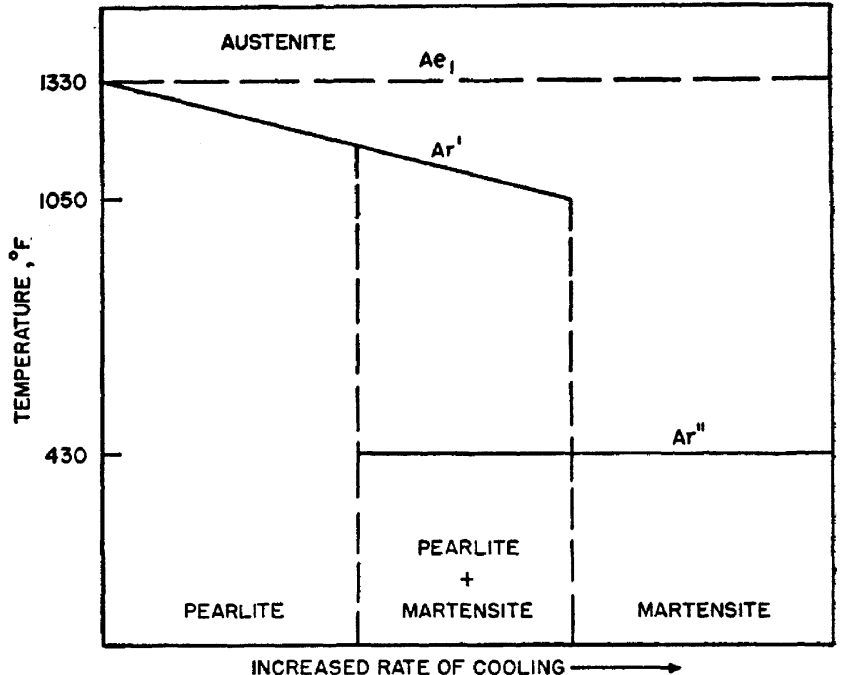

FIGURE 7. Schematic illustration showing the effect of rate of cooling on the transformation temperatures and decomposition products of austenite of eutectoid carbon steel.

brittle of the transformation products of austenite and is characterized by a typical acicular structure.

The phenomenon of the occurrence of both the $\mathrm{Ar}^{\prime}$ and $\mathrm{Ar}^{\prime \prime}$ transformations is known as the split transformation. The resultant microstructures of steels cooled at such rates as to undergo a split transformation consist of varying amounts of fine pearlite and martensite (fig. 9, C). The actual amounts of these two constitutents are functions of the rates of cooling, the slower rates resulting in more pearlite and less martensite, and the faster rates resulting in more martensite and less pearlite.

\subsection{Isothermal Transformation}

The course of transformation of austenite when the steel is quenched to and held at various constant elevated temperature levels (isothermal transformation) is conveniently shown by a diagram known as the $\mathrm{S}$-curve (also termed the $T T T$ diagram-for time, temperature, and transformation). Such a diagram for eutectoid carbon steel is shown in figure 8 and the discussion of this figure will be confined to steel of this particular composition.

\section{a. To Pearlite}

Austenite containing 0.80 percent of carbon, cooled quickly to and held at $1,300^{\circ} \mathrm{F}$, does not begin to decompose (transform) until after about $15 \mathrm{~min}$, and does not completely decompose until after about $5 \mathrm{hr}$ (fig. 8). Thus, at temperatures just below the $\mathrm{Ae}_{1}$, austenite is stable for a considerable length of time. The product of the decomposition of austenite at this temperature is coarse pearlite of relatively low hardness. If the austenite is quickly cooled to and held at a somewhat lower temperature, say $1,200^{\circ} \mathrm{F}$, decomposition begins in about 5 sec and is completed after 


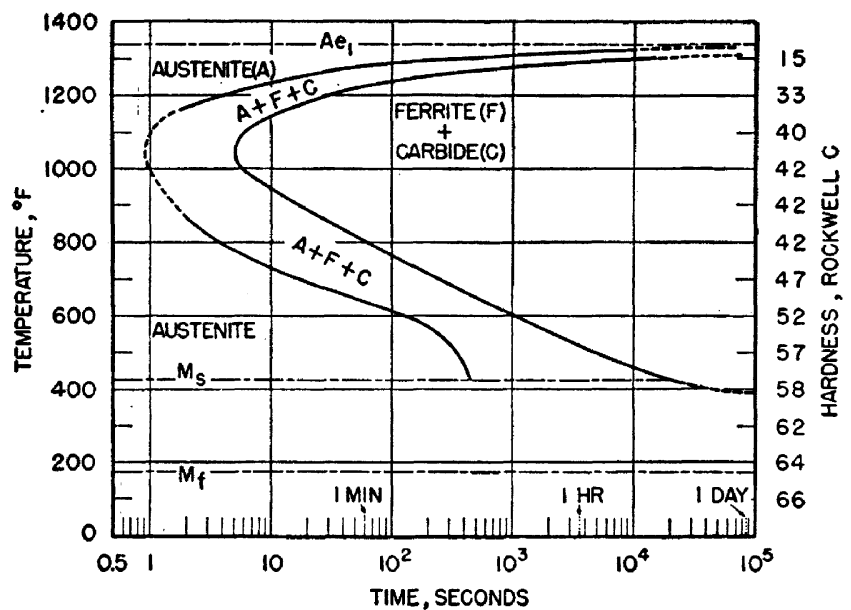

FIGURE 8. Isothermal transformation diagram (S-curve) for eutectoid carbon steel.

(Metals Handbook, 1948 edition, page 608.) The hardness of the structures formed at the various temperatures is given by the scale on the right.

about 30 sec, the resultant pearlite being finer and harder than that formed at $1,300^{\circ} \mathrm{F}$. At a temperature of about $1,050^{\circ} \mathrm{F}$, the austenite decomposes extremely rapidly, only about 1 sec elapsing before the transformation starts and 5 sec before it is completed. The resultant pearlite is extremely fine and its hardness is relatively high. This region of the S-curve where decomposition of austenite to fine pearlite proceeds so rapidly is termed the "nose" of the curve.

\section{b. To Bainite}

If the austenite is cooled unchanged to temperatures below the nose of the S-curve $\left(1,050^{\circ} \mathrm{F}\right)$, the time for its decomposition begins to increase (fig. 8). The final product of decomposition now is not pearlite, but a new acicular constituent called bainite (fig. 15, E) possessing unusual toughness with hardness even greater than that of very fine pearlite.

Depending on the temperature, then, a certain finite interval of time is necessary before austenite starts to transform into either pearlite or bainite. Additional time is necessary before the transformations are completed.

\section{c. To Martensite}

If the austenite is cooled unchanged to relatively low temperatures (below about $430^{\circ} \mathrm{F}$ for the eutectoid carbon steel under consideration), partial transformation takes place instantaneously; the product of transformation is martensite. Austenite transforms into martensite over a temperature range and the amount that transforms is a function of the temperature. Only minute amounts will so transform at about $430^{\circ} \mathrm{F}$; practically all of the austenite will be transformed at about $175^{\circ} \mathrm{F}$. The beginning of this transformation range is termed the $\mathrm{M}_{\mathrm{s}}$ (martensitestart) and the end of the range is termed the $M_{t}$ (martensite-finish). As long as the temperature is held constant within the $\mathbf{M}_{\mathrm{B}}-\mathrm{M}_{\mathrm{f}}$ range, that portion of the austenite that does not transform instantaneously to martensite remains untransformed for a considerable length of time, eventually transforming to bainite.

In ordinary heat treatment of the plain carbon steels, austenite does not transform into bainite. Transformation of the austenite takes place either above or at the nose of the S-curve, forming pearlite, or in passing through the $M_{8}-M_{t}$ range, forming martensite, or both. It is evident that in order for austenite to be transformed entirely into martensite, it must be cooled sufficiently rapidly so that the temperature of the steel is lowered past the nose of the S-curve in less time than is necessary for transformation to start at this temperature. If this is not accomplished, part of the steel transforms into pearlite at the high temperature $\left(\mathrm{Ar}^{\prime}\right)$, and the remainder transforms into martensite at the low temperature $\left(\mathrm{Ar}^{\prime \prime}\right.$ or $\mathrm{M}_{\mathrm{s}}-\mathrm{M}_{\mathrm{f}}$ temperature range). This explains the phenomenon of the split transformation described previously.

\subsection{Continuous Cooling}

Figure 9 represents a theoretical S-curve on which are superimposed five theoretical cooling curves. Curves $A$ to $E$ represent successively slower rates of cooling, as would be obtained, for instance, by cooling in iced brine, water, oil, air, and in the furnace, respectively.

The steel cooled according to curve $E$ begins to transform at temperature $t_{1}$ and completes transformation at $t_{2}$; the final product is coarse pearlite with relatively low hardness. When cooled according to curve $D$, transformation begins at $t_{3}$ and is completed at $t_{4}$; the final product is fine pearlite and its hardness is greater than the steel cooled according to curve $E$. When cooled according to curve $C$, transformation begins at $t_{5}$ and is only partially complete when temperature $t_{6}$ is reached; the product of this partial transformation is very fine pearlite. The remainder of the austenite does not decompose until the $M_{s}$ temperature is reached, when it begins to transform to martensite, completing this transformation at the $\mathrm{M}_{\mathrm{f}}$ temperature. The final structure is then a mixture of fine pearlite and martensite (typical of incompletely hardened steel-frequently termed "slack quenched" steel) with a higher hardness than was obtained with the steel cooled according to curve $D$. The rate of cooling represented by curve $B$ is just sufficient to intersect the nose of the S-curve, consequently only a minute amount of the austenite decomposes into fine pearlite at temperature $t_{7}$; the remainder of the austenite is unchanged until the martensite transformation range is reached. If the steel is cooled at a slightly faster rate, so that no transformation takes place at the nose of the S-curve, the steel is completely hardened. This particular rate is termed the critical cooling rate and is defined as the slowest rate at which the steel can be cooled and yet be completely hardened. Since this rate cannot be di- 

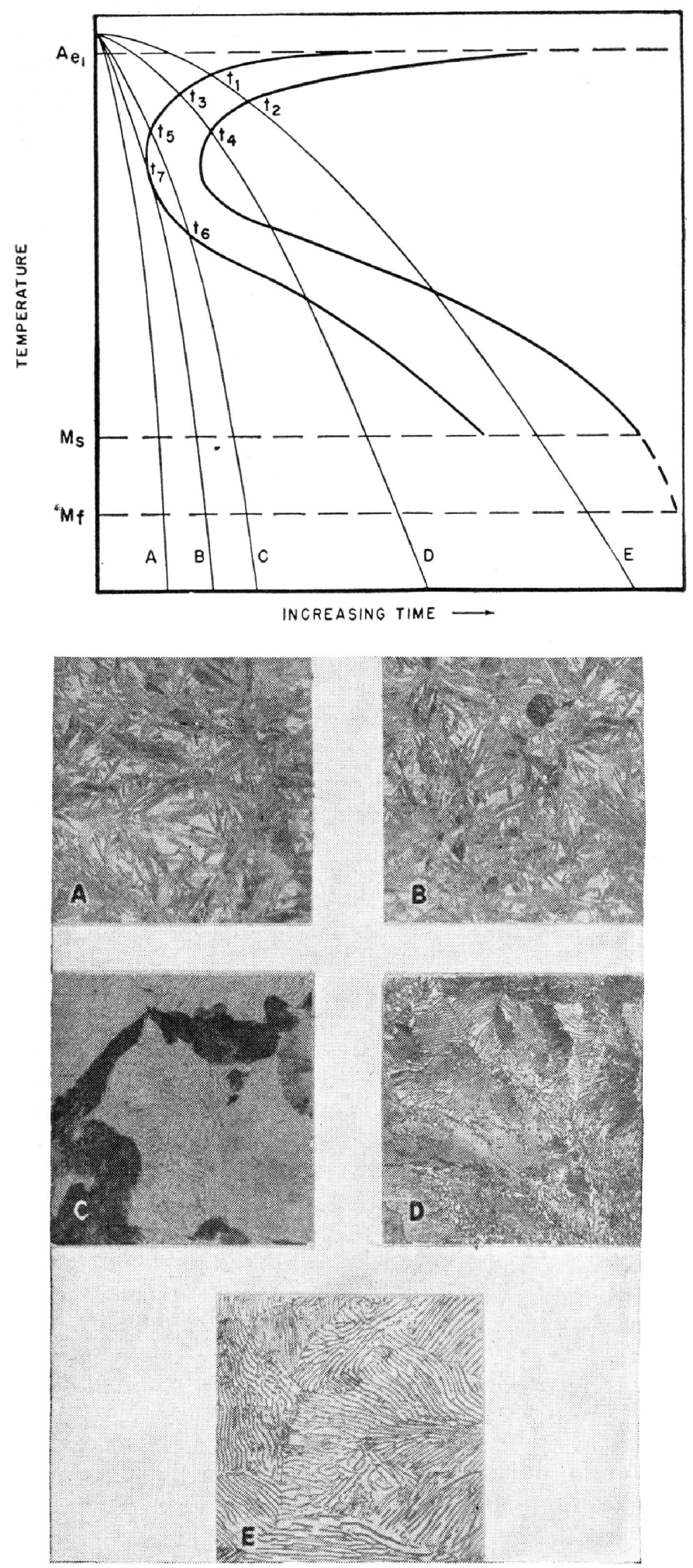

FiguRE 9. Schematic diagram. illustrating the relation between the S-curve, continuous cooling curves, and resulting microstructures of eutectoid carbon steel.

Microstructures: A, martensite; B, martensite with a trace of very fine pearlite (dark); C, martensite and very fine pearlite; D, fine pearlite; $\mathrm{E}$, coarse pearlite. All etched with nital. $\times 500$.

rectly determined, the rate indicated by curve $B$, producing only a trace of fine pearlite (fig. 9, B), is frequently used as the critical cooling rate. The hardness of the resultant martensite is equivalent to the maximum that can be obtained. Samples cooled at a faster rate, such as that indicated by curve $A$, are also completely martensitic but no harder than the sample cooled according to the critical cooling rate.

It will be noted that the rate at which a steel cools through the temperature range in the vicinity of the nose of the S-curve is of critical importance. Somewhat slower rates of cooling above and below this temperature range can be tolerated and yet obtain a completely hardened steel, provided that the cooling through the temperature interval at the nose of the S-curve is sufficiently fast. In practice, however, steels are usually cooled rapidly from the quenching temperature to relatively low temperatures (about $500^{\circ} \mathrm{F}$ ) and then allowed to cool in air.

Although the above discussions of the decomposition of austenite have been limited to a steel of eutectoid composition, other steels behave in a similar manner, the temperatures and times of reactions being different. In hypoeutectoid steels, free ferrite plus pearlite are formed if transformation begins above the temperature range of the nose of the S-curve; the amount of free ferrite decreases as the temperature of transformation approaches the nose of the curve. In hypereutectoid steels, free cementite plus pearlite are formed if transformation occurs above the nose. The time for the start of the transformation at the nose increases as the carbon increases up to the eutectoid composition, and then decreases with further increase in carbon. That is, the nose is shifted to the right (with respect to the time axis, fig. 8) as the carbon is increased to 0.8 percent and to the left with further increase in carbon content.

The temperature of formation of bainite is not appreciably affected by carbon content, but the time for its formation increases with the carbon.

Both the $\mathrm{M}_{\mathrm{s}}$ and $\mathrm{M}_{\mathrm{f}}$ temperatures are markedly lowered by increasing carbon content, as is shown for $\mathrm{M}_{\mathrm{s}}$ in figure 10. The $\mathrm{M}_{\mathrm{f}}$ temperatures of the plain carbon steels have not been adequately determined; available information indicates that the $\mathrm{M}_{\mathrm{f}}$ of high carbon steels is actually below room temperature. Slight amounts of austenite are frequently retained in quenched steels, especially in the higher carbon grades, even when cooled to room temperature.

\section{Heat Treatment of Steels}

All heat-treating operatures consist of subjecting a metal to a definite time-temperature cycle, which may be divided into three parts: (1) Heating, (2) holding at temperature (soaking), and (3) cooling. Individual cases vary, but certain fundamental objectives may be stated.

The rate of heating is not particularly important unless a steel is in a highly stressed condition, such as is imparted by severe cold working or prior hardening. In such instances the rate of heating should be slow. Frequently this is impracticable, since furnaces may be at operating temperatures, but placing the cold steel in the hot furnace may cause distortion or even cracking. This danger 


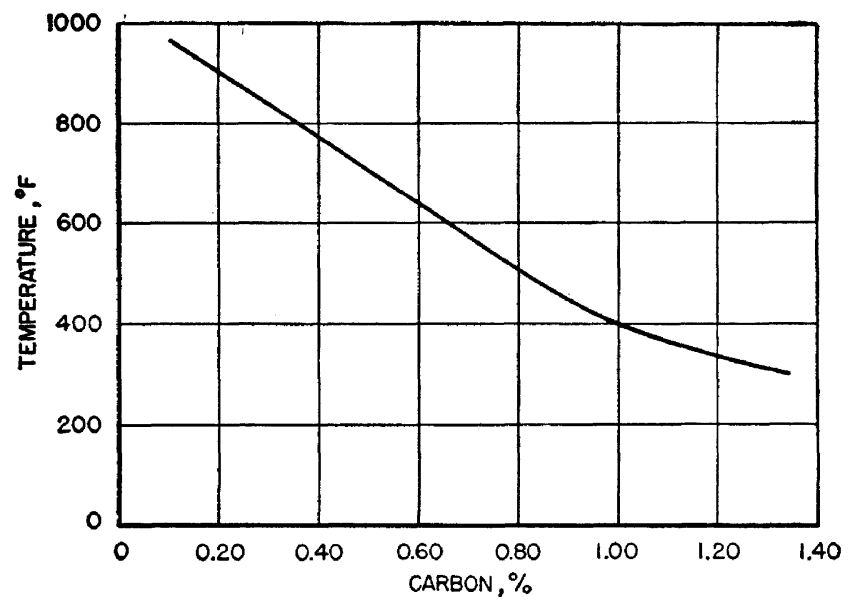

FiguRE 10. Influence of carbon on the start of the martensite $\left(M_{8}\right)$ transformation of high-purity iron-carbon alloys.

(Digges, Trans. Am. Soc. Metals 28, 597 (1940).)

can be minimized by the use of a preheating furnace maintained at a temperature below the $A_{1}$. The steel, preheated for a sufficient period, then can be transferred to the furnace at operating temperature. This procedure is also advantageous when treating steels having considerable variations in section thickness or very low thermal conductivity.

The object of holding a steel at heat-treating temperature is to assure uniformity of temperature throughout its entire volume. Obviously, thin sections need not be soaked as long as thick sections, but if different thicknesses exist in the same piece, the period required to heat the thickest section uniformly governs the time at temperature. A rule frequently used is to soak $1 / 2 \mathrm{hr} / \mathrm{in}$. of thickness.

The structure and properties of a steel depend upon its rate of cooling and this, in turn, is governed by such factors as mass, quenching media, etc. It must be realized that the thicker the section, the slower will be the rate of cooling regardless of the method of cooling used except in such operations as induction hardening to be discussed later.

\subsection{Annealing}

Annealing is a process involving heating and cooling, usually applied to produce softening. The term also refers to treatments intended to alter mechanical or physical properties, produce a definite microstructure, or remove gases. The temperature of the operation and the rate of cooling depend upon the material being annealed and the purpose of the treatment.

\section{a. Full Annealing}

Full annealing is a softening process in which a steel is heated to a temperature above the transformation range $\left(\mathrm{Ac}_{3}\right)$ and, after being held for a sufficient time at this temperature, is cooled slowly to a temperature below the transformation range $\left(A r_{1}\right)$. The steel is ordinarily allowed to cool slowly in the furnace, although it may be removed and cooled in some medium such as mica, lime, or ashes, that insures a slow rate of cooling.

Since the transformation temperatures are affected by the carbon content, it is apparent that the higher carbon steels can be fully annealed at lower temperatures than the lower carbon steels. In terms of the diagram shown in figure 4, steels must be heated to above the line GOSK. The temperature range normally used for full annealing is 25 to $50 \mathrm{deg} F$ above this line (the upper critical), as shown in figure 11 .

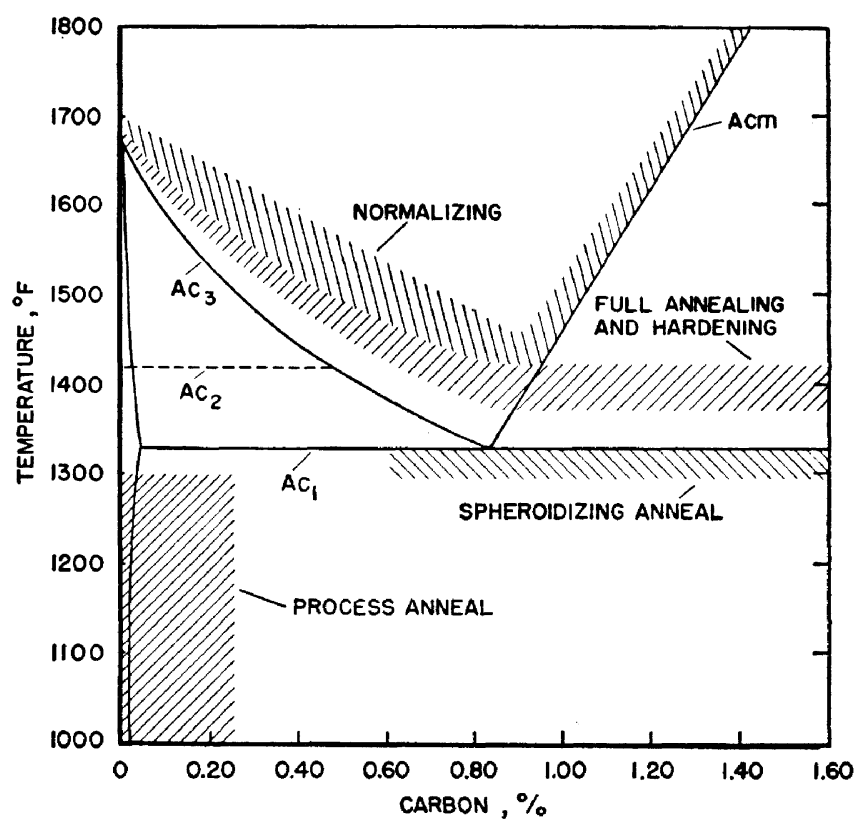

Figlre 11. Recommended temperature ranges for heat treating plain carbon steels.

The microstructures of the hypoeutectoid steels that result after full annealing are quite similar to those shown for the equilibrium conditions (fig. 5, B and (). Eutectoid and hypereutectoid steels frequently spheroidize partially or completely on full annealing (see later section and fig. 12, D).

\section{b. Process Annealing}

Process annealing, frequently termed stressrelief annealing, is usually applied to cold-worked low carbon steels (up to about $0.25 \%$ of carbon) to soften the steel sufficiently to allow further coldworking. The steel is usually heated close to, but below, the $A c_{1}$ temperature (fig. 11). If the steel is not to be further cold-worked, but relief of internal stresses is desired, a lower range of temperature will suffice (about $1,000^{\circ} \mathrm{F}$ ). Rate of cooling is immaterial.

This type of anneal will cause recrystallization and softening of the cold-worked ferrite grains, but usually will not affect the relatively small amounts of cold-worked pearlite. Typical structures of cold-worked, process-annealed, and fully annealed low-carbon steel are shown in figure 12, $A, B$, and $C$, respectively. 

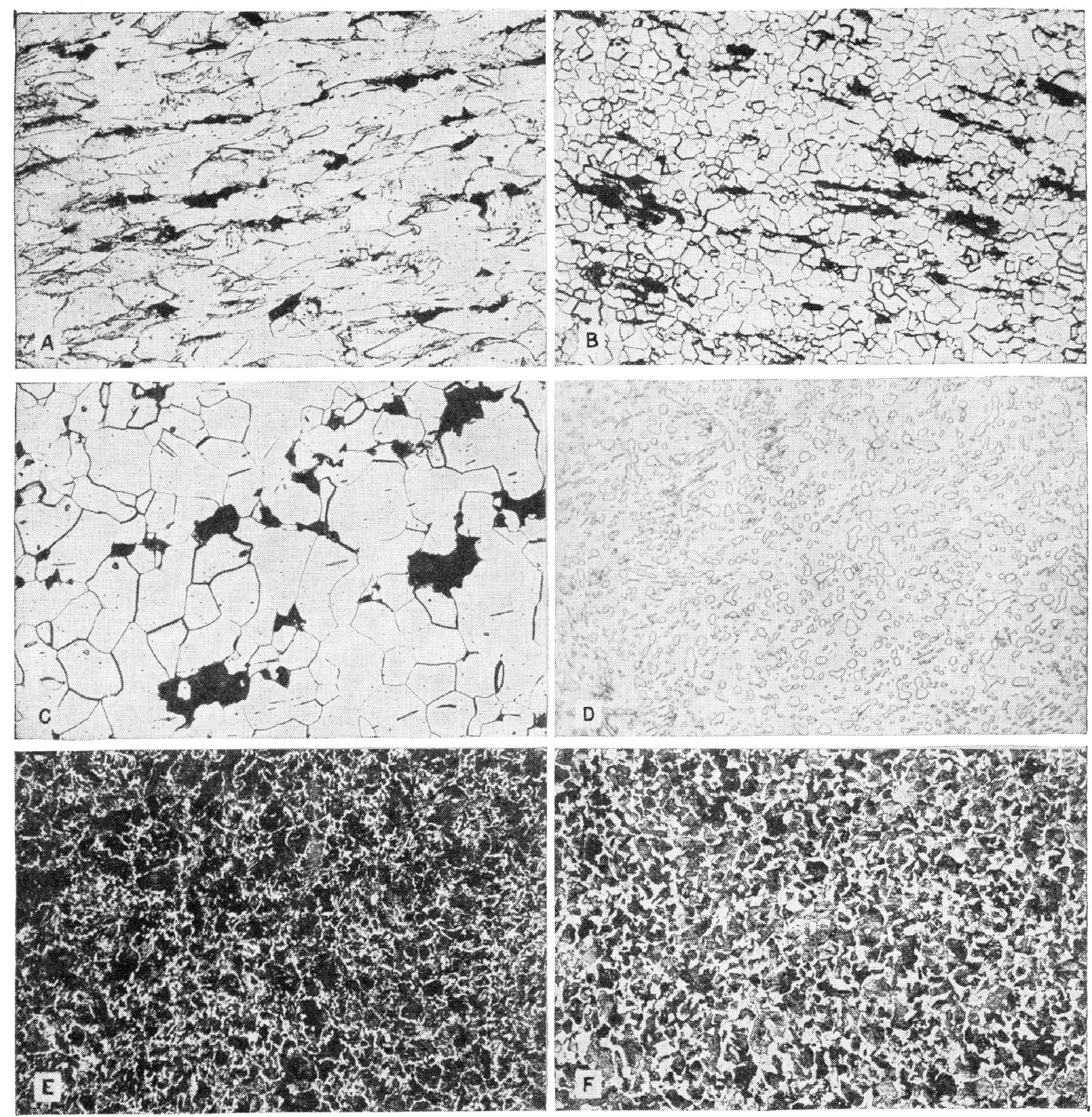

Figure 12. Representative microstructures of carbon steels.

A, Low carbon steel $(0.1 \% \mathrm{C}$ ) as cold-worked. Both ferrite (light) and pearlite (dark) are severely deformed. $\times 100$.

B, Same as (A) after process annealing at $1,200^{\circ} \mathrm{F}$. The ferrite is recrystallized (grains are equi-axed), but pearlite is not affected by this treatment $\times 100$.

, Same all traces of cold working are eliminated, and the ferrite grains are larger than in (B). $\times 100$. ferrite,

E. Hypoeutectoid steel $(0.5 \% \mathrm{C})$ as normalized at $1,600^{\circ} \mathrm{F}$ in $1 / 4$-in. round (center area). Because of the rapid rate of air cooling such a small section, the pearlite is quite fine and relatively little free ferrite is formed. $\times 500$.

F, Same steel as (E) but normalized in 21/2-in. round (center area). The slower rate of cooling due to the larger section results in coarser pearlite and more free ferrite. $\times 500$

All etched in picral.

\section{c. Spheroidizing}

Spheroidizing is a process of heating and cooling steel that produces a rounded or globular form of carbide in a matrix of ferrite. It is usually accomplished by prolonged heating at temperatures just below the $\mathrm{Ac}_{1}$ (fig. 11), but may be facilitated by alternately heating to temperatures just above the $A c_{1}$ and cooling to just below the $A_{1}$. The final step, however, should consist of holding at a temperature just below the critical $\left(\mathrm{Ar}_{1}\right)$. The rate of cooling is immaterial after slowly cooling to about $1,000^{\circ} \mathrm{F}$

The rate of spheroidization is affected by the initial structure. The finer the pearlite, the more readily spheroidization is accomplished. A martensitic structure is very amenable to spheroidization.

This treatment is usually applied to the high carbon steels $(0.60 \%$ of carbon and higher). The purpose of the treatment is to improve machinability and it is also used to condition high-carbon steel for cold-drawing into wire. A typical microstructure of spheroidized high carbon steel is shown in figure $12, \mathrm{D}$. 


\subsection{Normalizing}

Normalizing is a process in which a steel is heated to a temperature above the $\mathrm{Ac}_{3}$ or the $\mathrm{A}_{\mathrm{cm}}$ (fig. 11) and then cooled in still air. The purpose of the treatment is to obliterate the effects of any previous heat treatment (including the coarsegrained structure sometimes resulting from high forging temperatures) or cold-working and to insure a homogeneous austenite on reheating for hardening or full annealing. The resultant structures are pearlite or pearlite with excess ferrite or cementite, depending upon the composition of the steel. They are different from the structures resulting after annealing in that, for steels of the same carbon content in the hypo- or hypereutectoid ranges, there is less excess ferrite or cementite and the pearlite is finer. These are the results of the more rapid cooling.

Since the type of structure, and, therefore, the mechanical properties, are affected by the rate of cooling, considerable variations may occur in normalized steels because of differences in section thickness of the shapes being normalized. The effect of section thickness on the structure of a normalized 0.5-percent-carbon steel is shown in figure $12, \mathrm{E}$ and $\mathrm{F}$.

\subsection{Hardening}

Steels can be hardened by the simple expedient of heating to above the $\mathrm{Ac}_{3}$ transformation, holding long enough to insure the attainment of uniform temperature and solution of carbon in the austenite, and then cooling rapidly (quenching). Complete hardening depends on cooling so rapidly (fig. 9, A and B) that the austenite, which otherwise would decompose on cooling through the $\mathrm{Ar}_{1}$, is maintained to relatively low temperatures. When this is accomplished, the austenite transforms to martensite on cooling through the $M_{s}$ $M_{i}$ range. Rapid cooling is necessary only to the extent of lowering the temperature of the steel to well below the nose of the S-curve. Once this has been accomplished, slow cooling from then on, either in oil or in air, is beneficial in avoiding distortion and cracking. Special treatments, such as time quenching and martempering, are designed to bring about these conditions. As martensite is quite brittle, steel is rarely used in the as-quenched condition, that is, without tempering.

The maximum hardness that can be obtained in completely hardened low-alloy and plain carbon structural steels depends primarily on the carbon content. The relationship of maximum hardness to carbon content is shown in figure 13 .

\section{a. Effect of Mass}

Previous discussion of the formation of martensite has neglected the influence of mass. It must be realized that even with a sample of relatively small dimensions, the rate of abstraction of heat is not uniform. Heat is always abstracted from the surface layers at a faster rate than from the interior. In a given cooling medium the cooling rate of both the surface and interior decreases as the dimensions of a sample increase and the pos-

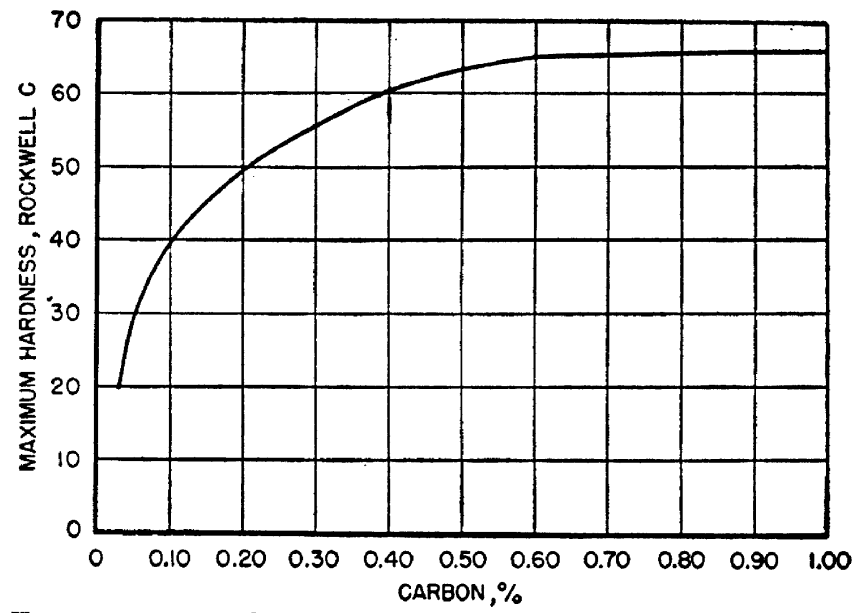

FIGURE 13. Relation of maximum attainable hardness of quenched steels to carbon content.

(Burns, Moore, and Archer, Trans. Am. Soc. Metals 26, 14 (1938)).

sibility of exceeding the critical cooling rate (fig. 9 , B) becomes less. To overcome this, the steel may be quenched in a medium having a very high rate of heat abstraction, such as iced brine, but, even so, many steels have a physical restriction on the maximum size amenable to complete hardening regardless of the quenching medium.

The marked effect that mass has upon the hardness of quenched steel may be illustrated by measuring the hardness distribution of different size rounds of the same steel quenched in the same medium. Curves showing the distribution of hardness in a series of round bars of different sizes of 0.5-percent-carbon steel are shown in figure 14 .

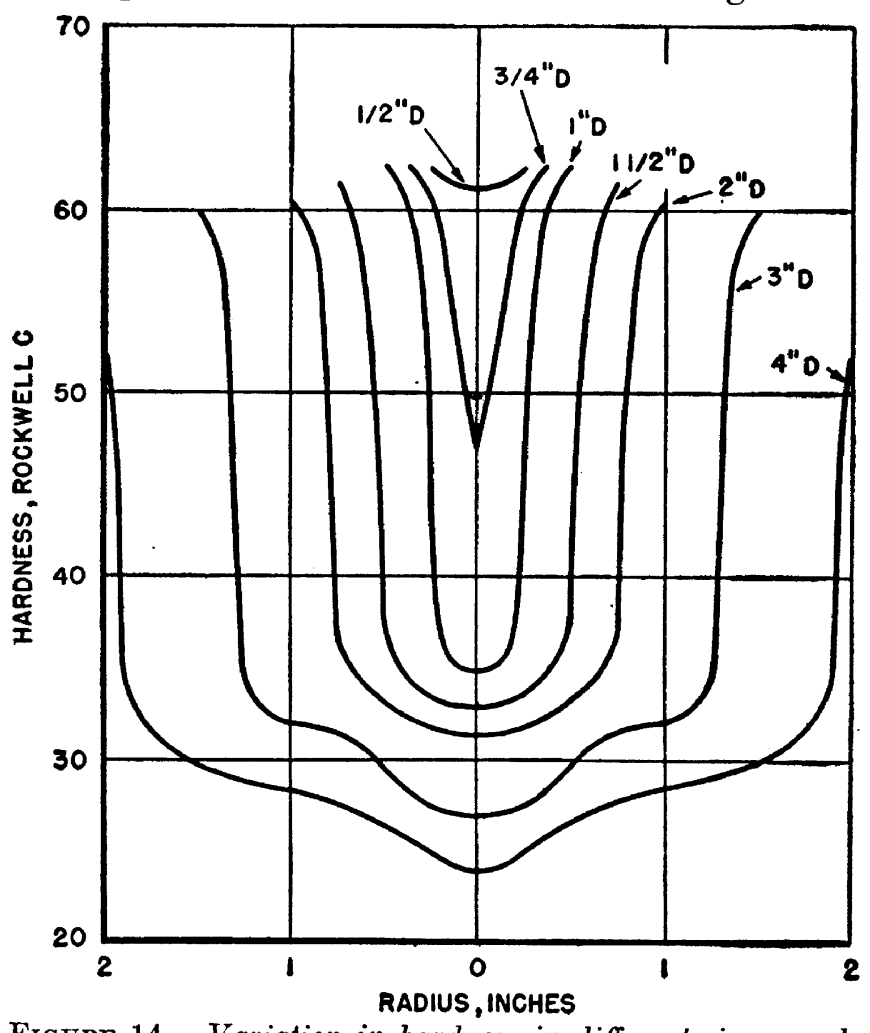

FIGURE 14. Variation in hardness in different size rounds of 0.5 -percent-carbon steels as quenched from $1,530^{\circ} F$ in water.

(Jominy, Hardenability of alloy steels, Am. Soc. Metals, p. 75, 1939.) 
The quenching medium used was water; the quenching temperature was $1,530^{\circ} \mathrm{F}$. The rate of cooling decreased as the diameters of the bars increased. Only the 1/2-in. round hardened completely through the cross section, whereas with the 4-in. round the critical cooling rate was not attained even at the surface.

\subsection{Tempering}

Tempering (sometimes called drawing) is the process of reheating hardened (martensitic) or normalized steels to some temperature below the lower critical $\left(\mathrm{Ac}_{1}\right)$. The rate of cooling is immaterial except for some steels that are susceptible to temper brittleness. ${ }^{1}$
As the tempering temperature is increased, the martensite (fig. 15, A) of hardened steel passes through stages of tempered martensite (fig. 15, B and C) and is gradually changed into a structure consisting of spheroids of cementite in a matrix of ferrite, formerly termed sorbite (fig. 15, D). These changes are accompanied by a decreasing hardness and increasing toughness. The tempering temperature depends upon the desired properties and the purpose for which the steel is to be used. If con-
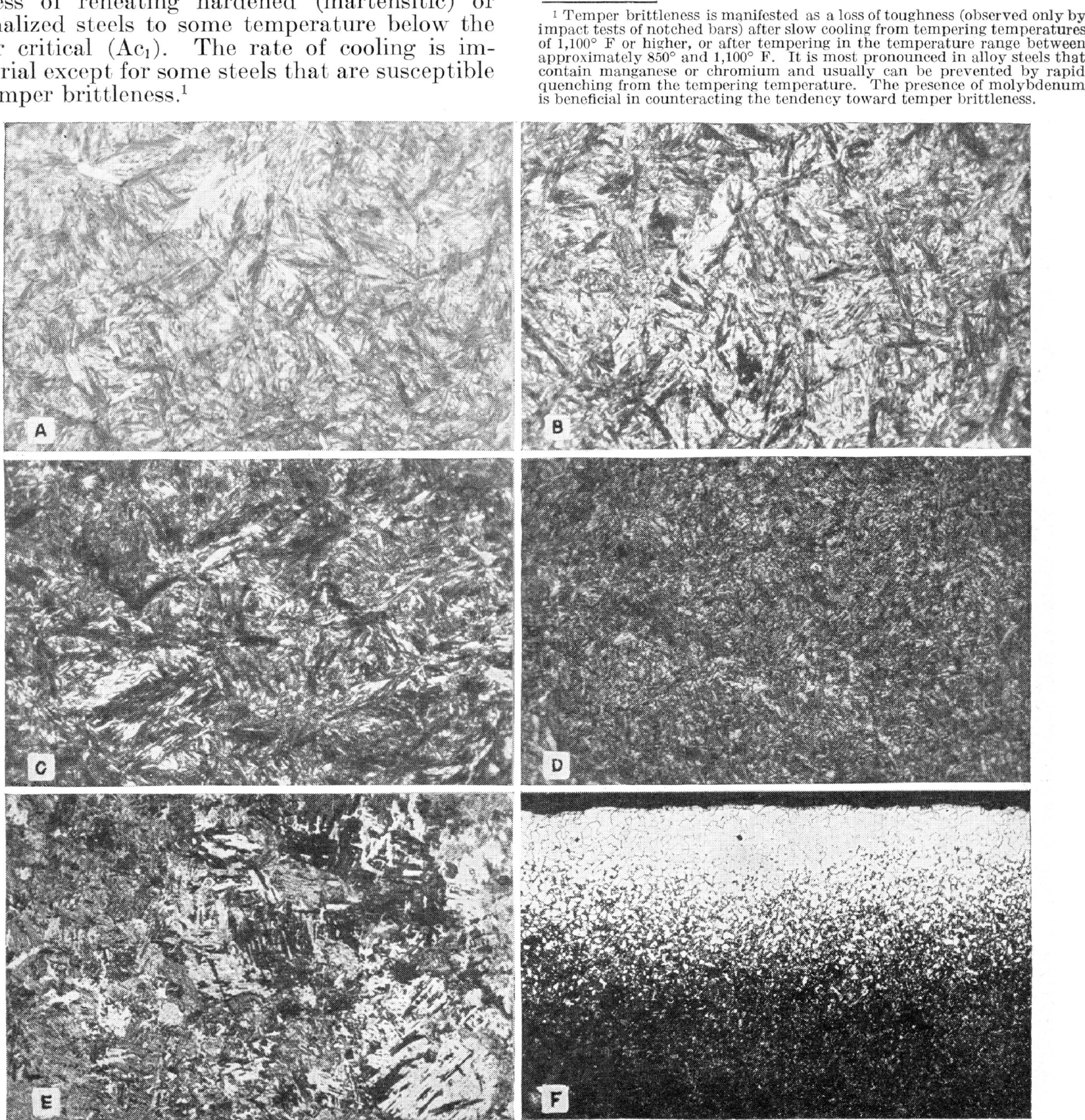

FIGURE 15. Microstructures and corresponding hardness of heat-treated high carbon steel.

A, As quenched in brine; martensite, Rockwell $\mathrm{C}$ hardness $=67 . \quad \times 500$

B, Same as A after tempering at $400^{\circ} \mathrm{F}$; tempered martensite, Rockwell $\mathrm{C}$ hardness $=61 . \times 500$.

$\mathrm{C}$, Same as (A) after tempering at $800^{\circ} \mathrm{F}$; tempered martensite, Rockwell $\mathrm{C}$ hardness $=45$. $\quad \times 500$.

$\mathrm{D}$, Same as (A) after tempering at $1,200^{\circ} \mathrm{F}$; tempered martensite, Rockwell $\mathrm{C}$ hardness $=25 . \times 500$.

$\mathrm{E}$, Quenched in lead at $650^{\circ} \mathrm{F}$; bainite, Rockwell $\mathrm{C}$ hardness $=49 . \times 500$.

F, Heat-treated steel showing decarburized surface layer (light area) that did not respond to hardening. $\times 100$ 
siderable hardness is necessary, the tempering temperature should be low; if considerable toughness is required, the tempering temperature should be high. The effect of tempering on the hardness of fully hardened carbon steels is shown in figure 16.

Proper tempering of a hardened steel requires a certain amount of time. At any selected tempering temperature, the hardness drops rapidly at first, gradually decreasing more slowly as the time is prolonged. The effect of time at different tempering temperatures upon the resultant hardness of a eutectoid carbon steel is shown in figure 17 . Short tempering periods are generally undesirable

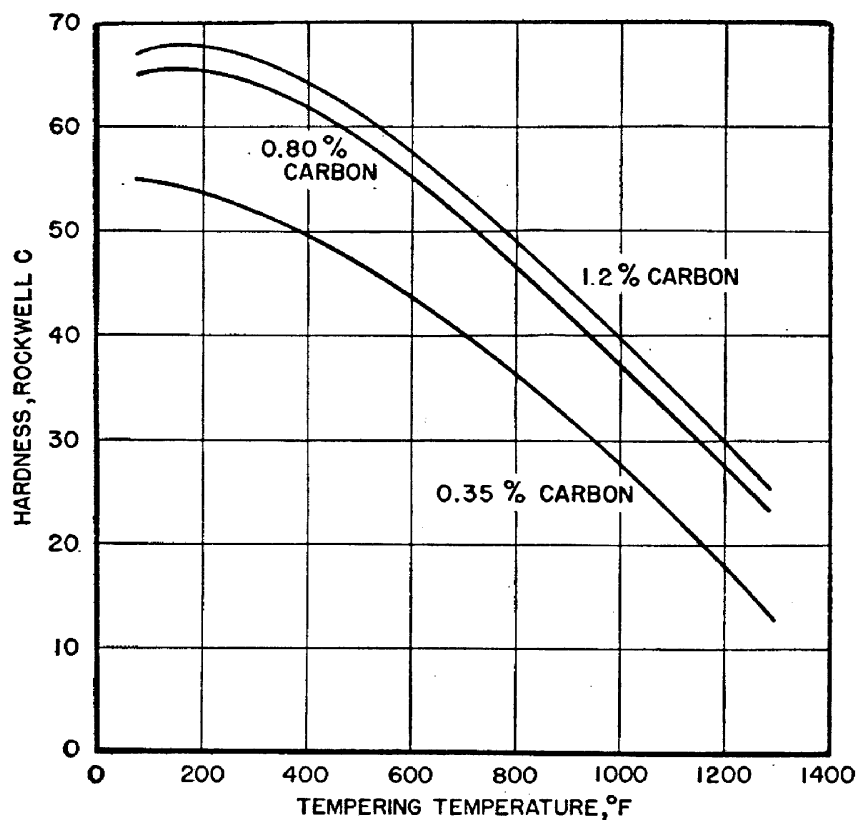

Figure 16. Effect of tempering temperature on the hardness of carbon steels of different carbon content.

Specimens were tempered for $1 \mathrm{hr}$. (Bain, Functions of the alloying elements in steel, Am. Soc. Metals, p. 38, 1939.)

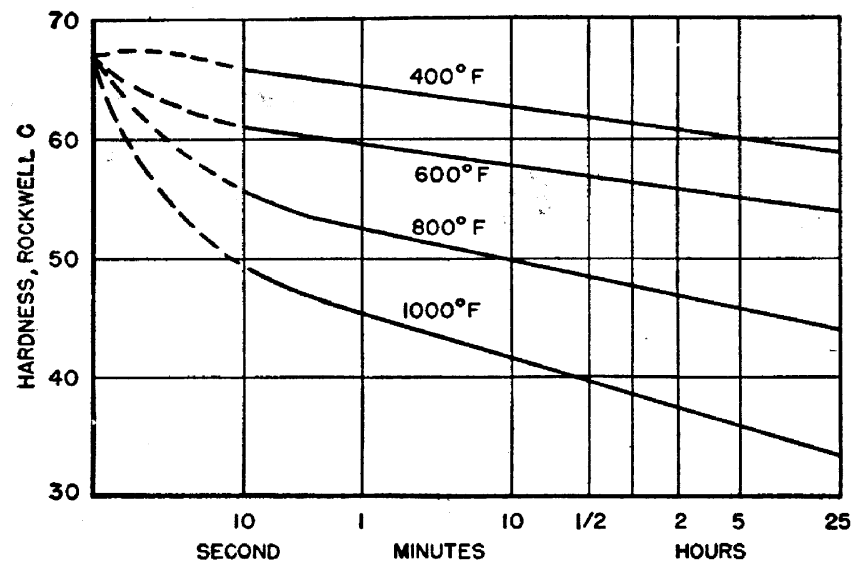

TIME AT TEMPERING TEMPERATURE

FrgURE 17. Effect of time at tempering temperature on the hardness of 0.8-percent-carbon steel. (Logarithmic time scale.) 1939.) and should be avoided. Good practice requires at least $1 / 2 \mathrm{hr}$ (or, preferably, 1 to $2 \mathrm{hr}$ ) at tempering temperature for any hardened steel.

The necessity for tempering a steel promptly after hardening cannot be overemphasized. If fully hardened steel is allowed to cool to room temperature during hardening there is danger that the steel may crack. Carbon steels and most of the low alloy steels should be tempered as soon as they are cool enough to be held comfortably in the bare hands. Steels should not be tempered before they cool to this temperature because in some steels the $\mathrm{M}_{\mathrm{f}}$ temperature is quite low and untransformed austenite may be present. Part of all of this residual austenite will transform to martensite on cooling from the tempering temperature so that the final structure will consist of both tempered and untempered martensite. The brittle untempered martensite, together with the internal stresses caused by its formation, can easily cause failure of the heat-treated part. When it is possible that such a condition exists, a second tempering treatment (double tempering) should be given to temper the fresh martensite formed on cooling after the initial tempering treatment.

If structural steels are to be used in the normalized condition, the normalizing operation is frequently followed by heating to a temperature of about $1,200^{\circ}$ to $1,300^{\circ} \mathrm{F}$. The purpose of this treatment, which is also designated as tempering, is to relieve internal stresses resulting on cooling from the normalizing temperature and to improve the ductility.

\subsection{Case Hardening}

Case hardening is a process of hardening a ferrous alloy so that the surface layer or case is made substantially harder than the interior or core. The chemical composition of the surface layer is altered during the treatment by the addition of carbon, nitrogen, or both. The most frequently used case-hardening processes are carburizing, cyaniding, carbonitriding, and nitriding.

\section{a. Carburizing}

Carburizing is a process that introduces carbon inte a solid ferrous alloy by heating the metal in contact with a carbonaceous material to a temperature above the $\mathrm{Ac}_{3}$ of the steel and holding at that temperature. The depth of penetration of carbon is dependent on temperature, time at temperature, and the composition of the carburizing agent. As a rough indication, a carburized depth of about 0.030 to 0.050 in. can be obtained in about $4 \mathrm{hr}$ at $1,700^{\circ} \mathrm{F}$, depending upon the type of carburizing agent, which may be a solid, liquid, or gas.

Since the primary object of carburizing is to secure a hard case and a relatively soft, tough core, only low-carbon steels (up to a maximum of about $0.25 \%$ of carbon), either with or without alloying elements (nickel, chromium, manganese, 
molybdenum), are normally used. After carburizing, the steel will have a high-carbon case graduating into the low-carbon core (fig. 18).

A variety of heat treatments may be used subsequent to carburizing, but all of them involve quenching the steel to harden the carburized surface layer. The most simple treatment consists of quenching the steel directly from the carburizing temperature; this treatment hardens both the case and core (insofar as the core is capable of being hardened). Another simple treatment, and perhaps the one most frequently used, consists of slowly cooling from the carburizing temperature, reheating to above the $\mathrm{Ac}_{3}$ of the case (about $\left.1,425^{\circ} \mathrm{F}\right)$, and quenching; this treatment hardens the case only. A more complex treatment is to double quench - first from above the $\mathrm{Ac}_{3}$ of the core (about $1,650^{\circ} \mathrm{F}$ for low-carbon steel) and then from above the $\mathrm{Ac}_{3}$ of the case (about 1,425 $\mathrm{F})$; this treatment refines the core and hardens the case. The plain carbon steels are almost always quenched in water or brine; the alloy steels are usually quenched in oil. Although tempering following hardening of carburized steel is sometimes omitted, a low-temperature tempering treatment at about $300^{\circ} \mathrm{F}$ is good practice.

It is sometimes desirable to carburize only certain parts of the surface. This can be accomplished by covering the surface to be protected against carburizing with some material that prevents the passage of the carburizing agent. The most widely used method is copper plating of the surfaces to be protected. Several proprietary solutions or pastes, which are quite effective in preventing carburization, are also available.

The commercial compounds commonly used for pack (solid) carburizing contain mixtures of carbonate (usually barium carbonate), coke (diluent), and hardwood charcoal, with oil, tar, or molasses as a binder. Mixtures of charred leather, bone, and charcoal are also used.

The carburizing action of these compounds is diminished during use and it is necessary to add new material before the compound is reused. Ad- dition of one part of unused to three to five parts of used compound is common practice. The parts to be carburized are packed in boxes (or other suitable containers) made of heat-resistant alloys, although rolled or cast steel may be used where long life of the box is not important. The lid of the box should be sealed with fire clay or some other refractory to help prevent escape of the carburizing gas generated at the carburizing temperature. The depth and uniformity of case is affected by the method of packing and design of the container.

Liquid carburizing consists of case hardening steel or iron in molten salt baths that contain mixtures principally of cyanides (violently poisonous), chlorides, and carbonates. The case produced by this method contains both carbon and nitrogen, but principally the former. The temperatures used range from about $1,550^{\circ}$ to $1,650^{\circ} \mathrm{F}$ or higher, depending upon the composition of the bath and the desired depth of case. At $1,650^{\circ} \mathrm{F}$ a case depth of about 0.010 to 0.015 in. can be obtained in $1 \mathrm{hr}$; about 0.020 to $0.030 \mathrm{in}$. can be obtained in $4 \mathrm{hr}$. Considerably deeper cases can be obtained at higher temperatures with longer periods of time. After carburizing, the parts must be quenched just as in solid carburizing, but it is usual to do this directly from the molten bath.

In all present-day commercial gas carburizing, two or more hydrocarbons are used in combination for supplying the carbon to the steel. The hydrocarbons used are methane, ethane, propane, and oil vapors. The steel parts are placed in sealed containers through which the carburizing gases are circulated; the temperatures used are in the neighborhood of $1,700^{\circ} \mathrm{F}$. Average expectation for depth of case in gas-carburized steel is illustrated in figure 19. After carburizing, the parts must be quench hardened.

\section{b. Cyaniding}

A hard, superficial case can be obtained rapidly on low-carbon steels by cyaniding. This process involves the introduction of both carbon and nitro-

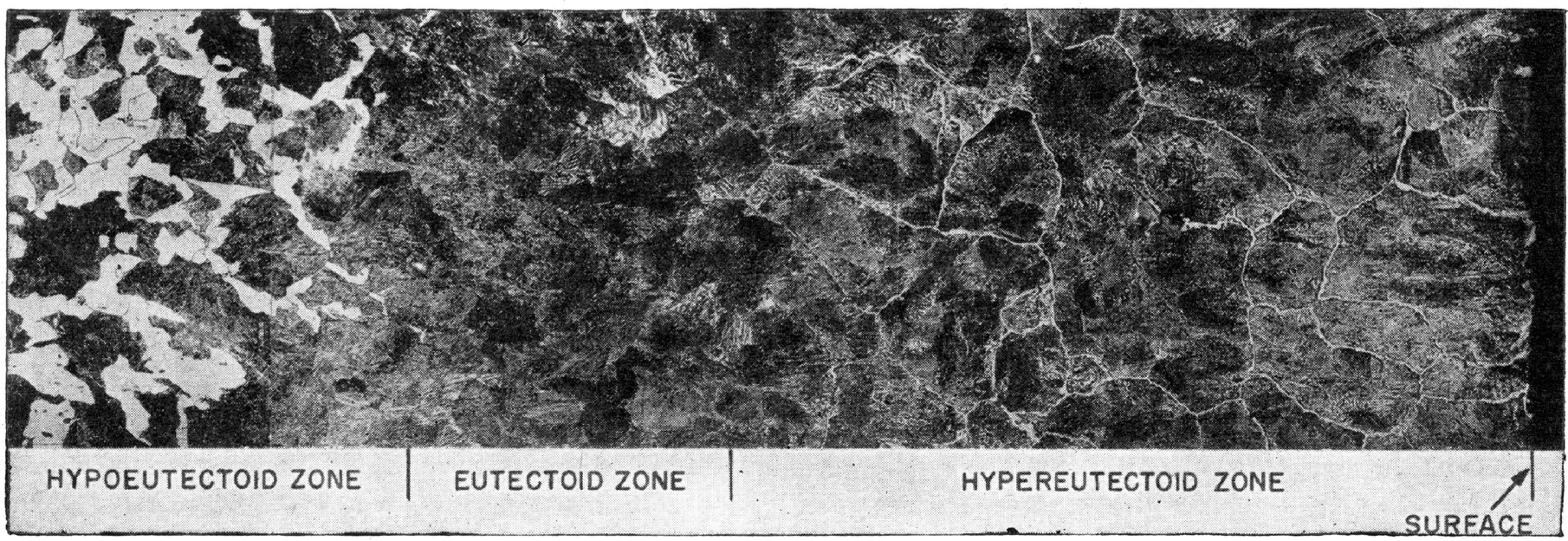

Figure 18. Structure of a carburized steel.

The specimen was cooled slowly from the carburizing temperature. Etched with nital. $\times 75$. 


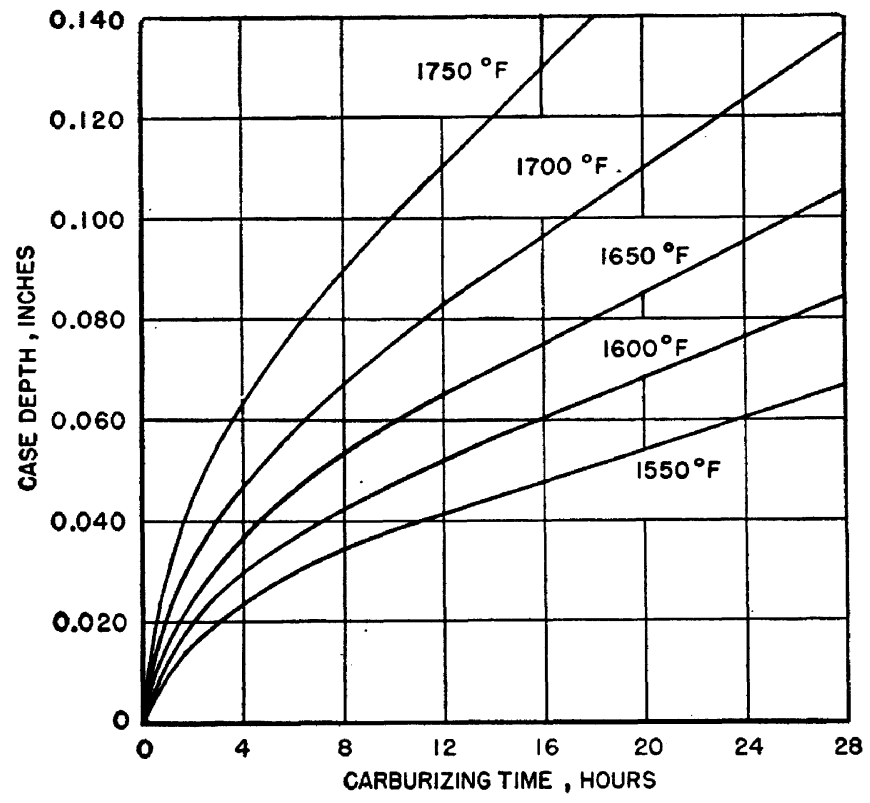

Figure 19. Relation of time and temperature to carbon penetration in gas carburizing.

(Metals Handbook, 1939 edition, p. 1041.)

gen into the surface layers of the steel. Steels to be cyanided normally are heated in a molten bath of cyanide-carbonate-chloride salts (usually containing 30 to $95 \%$ of sodium cyanide) and then quenched in brine, water, or mineral oil; the ten!perature of operation is generally within the range of $1,550^{\circ}$ to $1,600^{\circ} \mathrm{F}$. 'The depth of case is a function of time, temperature, and composition of the cyanide bath; the time of immersion is quite short as compared with carburizing, usually varying from about $15 \mathrm{~min}$ to $2 \mathrm{hr}$. The maximum case depth is rarely more than about $0.020 \mathrm{in}$. and the average depth is considerably less.

Steels can be cyanided also by heating to the proper temperature and dipping in a powdered cyanide mixture or sprinkling the powder on the steel, followed by quenching. The case thus formed is extremely thin.

Cyaniding salts are violent poisons if allowed to come in contact with scratches or wounds; they are fatally poisonous if taken internally. Fatally poisonous fumes are evolved when cyanides are brought into contact with acids. Cyaniding baths should be equipped with a hood for venting the gases evolved during heating and the work room should be well ventilated. Molten cyanide should never be permitted to come in contact with sodium or potassium nitrates commonly used for baths for tempering as the mixtures are explosive. Furthermore, care is necessary in preparing a salt bath and the work pieces should be completely dry before placing in the molten bath. The advice of salt manufacturers should be obtained and followed in the operation and maintenance of salt baths.

\section{c. Carbonitriding}

Carbonitriding, also termed gas cyaniding, dry cyaniding, and ni-carbing, is a process for case hardening a steel part in a gas-carburizing atmos- phere that contains ammonia in controlled percent-ages. Carbonitriding is used mainly as a low-cost substitute for cyaniding and, as in cyaniding, both carbon and nitrogen are added to the steel. The process is carried on above the $A c_{1}$ temperature of the steel, and is practical up to $1,700^{\circ} \mathrm{F}$. Quenching in oil is sufficiently fast to attain maximum surface hardness; this moderate rate of cooling tends to minimize distortion. The depth to which carbon and nitrogen penetrate varies with temperature and time. The penetration of carbon is approximately the same as that obtained in gas carburizing (fig. 19).

\section{d. Nitriding}

The nitriding process consists in subjecting machined and heat-treated steel, free from surface decarburization, to the action of a nitrogenous medium, usually ammonia gas, at a temperature of about $930^{\circ}$ to $1,000^{\circ} \mathrm{F}$, whereby a very hard surface is obtained. The surface-hardening effect is due to the absorption of nitrogen and subseqeunt heat treatment of the steel is unnecessary. The time required is relatively long, normally being 1 or 2 days. The case, even after 2 days of nitriding, is generally less than $0.020 \mathrm{in}$. and the highest hardness exists in the surface layers to a depth of only a few thousandths of an inch.

Special low-alloy steels have been developed for nitriding. These steels contain elements that readily combine with nitrogen to form nitrides, the most favorable being aluminum, chromium, and vanadium. Molybdenum and nickel are used in these steels to add strength and toughness. The carbon content usually is about 0.20 to 0.50 percent, although in some steels, where high core hardness is essential, it may be as high as 1.3 percent. Stainless steels also can be nitrided.

Because nitriding is carried out at a relatively low temperature, it is advantageous to use quenched and tempered steel as the base material. This gives a strong, tough core with an intensely hard wear-resisting case-much harder, indeed, than can be obtained by quench hardening either carburized or cyanided steel.

$\mathrm{Al}$ hough warpage is not a problem during nitriding, steels increase slightly in size during this treatment. Allowance can be made for this growth in the finished article. Protection against nitriding can be effected by tin, copper, or bronze plating, or by the application of certain paints.

\subsection{Surface Hardening}

It is frequently desirable to harden only the surface of steels without altering the chemical composition of the surface layers. If a steel contains sufficient carbon to respond to hardening, it is possible to harden the surface layers only by very rapid heating for a short period, thus conditioning the surface for hardening by quenching.

\section{a. Induction Hardening}

In induction hardening, a high-frequency current is passed through a coil surrounding the steel, the surface layers of which are heated by electro- 
magnetic induction. The depth to which the heated zone extends depends on the frequency of. the current (the lower frequencies giving the greater depths) and on the duration of the heating cycle. The time required to heat the surface layers to above the $\mathrm{Ac}_{3}$ is surprisingy brief, frequently being a matter of only a few seconds. Selective heating (and therefore hardening) is accomplished by suitable design of the coils or inductor blocks. At the end of the heating cycle, the steel is usually quenched by water jets passing through the inductor coils. Precise methods for controlling the operation, that is, rate of energy input, duration of heating, and rate of cooling, are necessary. These features are incorporated in induction hardening equipment, which is usually entirely automatic in operation. Figure 20 shows the hardened layer in induction hardened steel.

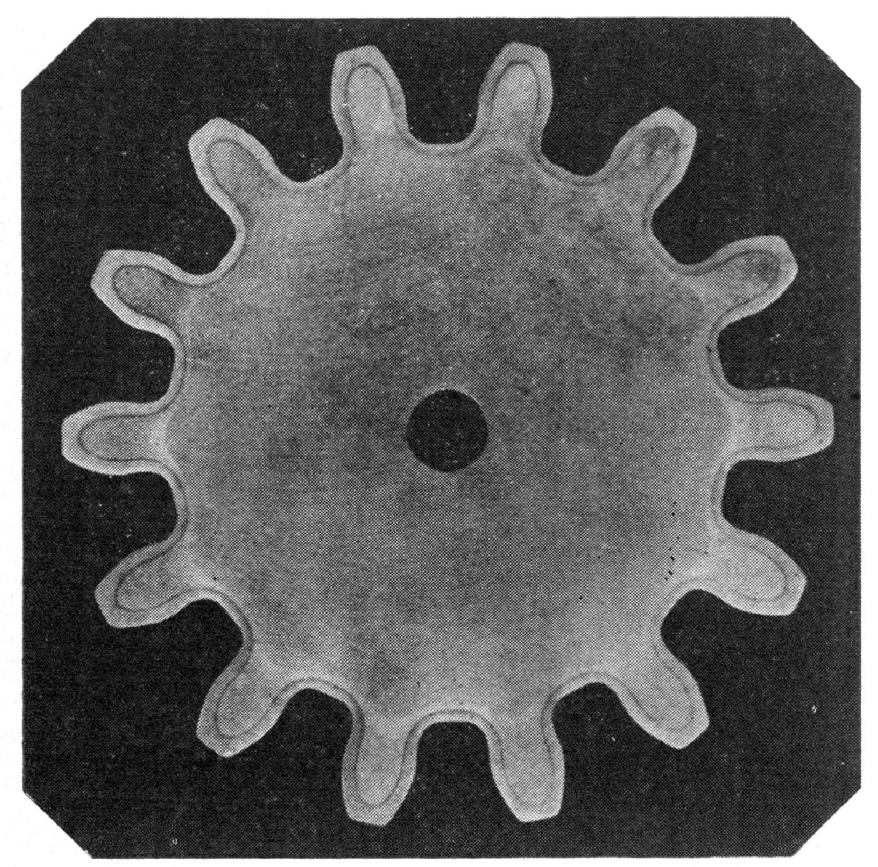

Figure 20. Macrograph of induction hardened gear teeth. Original size, 4-in. diameter (Osborn).

\section{b. Flame Hardening}

Flame hardening is a process of heating the surface layers of steel above the transformation temperature by means of a high-temperature flame and then quenching. In this process the gas flames impinge directly on the steel surface to be hardened. The rate of heating is very rapid, although not so fast as with induction heating. Plain carbon steels are usually quenched by a water spray, whereas the rate of cooling of alloy steels may be varied from a rapid water quench to a slow air cool depending on the composition.

Any type of hardenable steel can be flame hardened. For best results, the carbon content should be at least 0.35 percent, the usual range being 0.40 to 0.50 percent.

\subsection{Special Treatments}

\section{a. Austempering}

Austempering is a trade name for a patented heat-treating process. Essentially, it consists of heating steel to above the $\mathrm{Ac}_{3}$ transformation temperature and then quenching into a hot bath held at a temperature below that at which fine pearlite would form (the nose of the S-curve, fig. 8), but above the $\mathrm{M}_{\mathrm{s}}$ temperature (fig. 10). The product of isothermal decomposition of austenite in this temperature region is bainite. This constituent combines relatively high toughness and hardness. A typical microstructure of austempered steel is shown in figure $15, \mathrm{E}$.

The austempering process has certain limitations that make it impracticable for use with many steels. In order to assure a uniform structure (and hence uniform properties), it is essential that the entire cross section of the steel be cooled rapidly enough so that even the center escapes transformation at the nose of the S-curve. In carbon steels the time required to start transformation at the nose of the S-curve is extremely short, so that only relatively small sections (about 3/8-in. maximum thickness) can be successfully hot quenched in austempering baths. The time required for transformation of the austenite of alloy steels to fine pearlite is usually longer, and hence larger sections can be successfully austempered (about 1 in. maximum). However, the time required for transformation to bainite frequently becomes inordinately long with many alloy steels and the process of austempering, therefore, is generally impracticable for these steels.

\section{b. Martempering}

Martempering consists of heating a steel to above its $\mathrm{Ac}_{3}$ transformation and then quenching into a bath held at a temperature approximately equal to that of its $\mathrm{M}_{\mathrm{s}}$. The steel is maintained in the hot bath until its temperature is essentially uniform and then is cooled in air.

Severe internal stresses develop in steel during hardening. Steel contracts during cooling but undergoes a marked expansion when the austenite transforms to martensite. Since a quenched steel must cool from the surface inward, various portions transform at different times. The steel is thus subjected to a variety of differential expansions and contractions, resulting in considerable internal stress. By equalizing the temperature throughout the section before transformation takes place, and then cooling slowly through the martensite $\left(\mathrm{M}_{\mathrm{s}}-\mathrm{M}_{\mathrm{f}}\right)$ range, the internal stresses are considerably reduced. This is the prime objective of martempering.

\section{c. Gold Treatment}

The $\mathrm{M}_{\mathrm{f}}$ temperature of many alloy steels is so low that complete transformation of austenite to martensite does not occur on quenching to room 
temperature or on cooling after tempering. This retained austenite may be partially or completely transformed by cooling below atmospheric temperatures and such treatment is called "cold treatment." The beneficial effects of cold treatment have not been fully explored. It is known that the retained austenite of highly alloyed steels is frequently difficult to transform. Cooling these steels to low temperatures (to the temperature of solid $\mathrm{CO}_{2}$ or even lower) immediately after the quench is sometimes effective in transforming the retained austenite, but with the concomitant danger of cracking. When the cold treatment is applied after tempering, the retained austenite is considerably more resistant to transformation. If cold treatment is used, the steel should always be tempered afterwards.

Repeated alternate heating to a temperature slightly below that used in tempering and cooling to a subzero temperature in a refrigerated iced brine, carbon dioxide, liquid air, or liquid nitrogen is commonly used for transforming the retained austenite (dimensional stabilization) of steel gages, especially those of the ball-bearing type composition (AİSI 52100).

\section{Hardenability}

Hardenability is the property that determines the depth and distribution of hardness induced in steel by quenching. It is increased by increasing carbon and by the addition of all the common alloying elements (except cobalt), provided that these elements are completely dissolved in the austenite at quenching temperatures. The elements most frequently used for this purpose are manganese, chromium, and molybdenum. Hardenability is also enhanced by increased grain size ${ }^{2}$ and homogeneity of the austenite. However, a coarsegrained austenite increases the tendency of a steel to distort and crack during heat treatment. Coarse-grained steels also are less tough than finegrained steels.

A clear distinction must be drawn between the maximum hardness obtainable in a steel and its hardenability. In straight carbon and low-alloy steels, the maximum hardness is a function of carbon content only (fig. 13), whereas hardenability is concerned primarily with the depth of hardening.

Numerous methods have been proposed and used for determining the hardenability of steel.

\footnotetext{
2 The grain size that influences hardenability is that grain size of the
austenite that exists at the quenching temperature. It is usually measured under the microscope in terms of the number of grains per square inch at a magnification of $\times 100$. The common range of grain size numbers is as follows (note that the larger the number, the finer is the grain size; i.e., the more grains there are per square inch): Grain size no.

(American Society for $\quad$ Grains/in.2 Testing Materials)

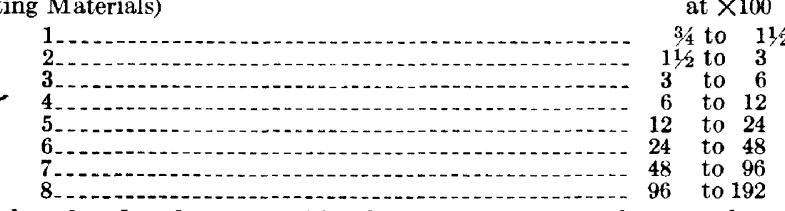

Numbers 3 and under are considered as coarse grain, numbers 4 and 5 as intermediate, and numbers 6 and higher as fine-grain steels.
}

The selection of a method depends largely upon the information desired and the range in hardenability of the steels.

For a fundamental study, hardenability is often measured in terms of the critical cooling rate (fig. $9, \mathrm{~B}$ ), but the standard end-quench (Jominy) test is widely used commercially. In the end-quench test a bar of steel 1 in. in diameter by 4 in. long, previously normalized and machined to remove the decarburized surface, is heated to the hardening temperature for $30 \mathrm{~min}$. It is then quickly transferred to a fixture that holds the bar in a vertical position and a jet of water under controlled conditions immediately is directed against the bottom end only. The end of the bar is thus cooled very quickly while cross sections remote from the end are cooled more slowly, the rate of cooling being dependent upon the distance from the quenched end. After cooling is completed, two diametrically opposite flats about $1 / 4$ in. wide are ground the length of the bar and Rockwell hardness measurements are made at intervals of 1/16 in. on the flat surfaces so prepared. The relationship of hardness to distance from the quenched end is an indication of the hardenability (fig. 21).

The conditions of the end-quench test have been standardized and the rates of cooling at various distances from the quenched end have been determined and are shown at the top of figure 21 . It is thus possible to correlate hardness with cooling rate, which is a function of the distance from the water-cooled end. The cooling rates at various positions in different size rounds when quenched in still oil and in still water also have been determined. Correlations can be made, therefore, between the hardness obtained at various positions on the end-quench bar and positions of equivalent hardness of round bars quenched in still oil or water (assuming that points of equal hardness

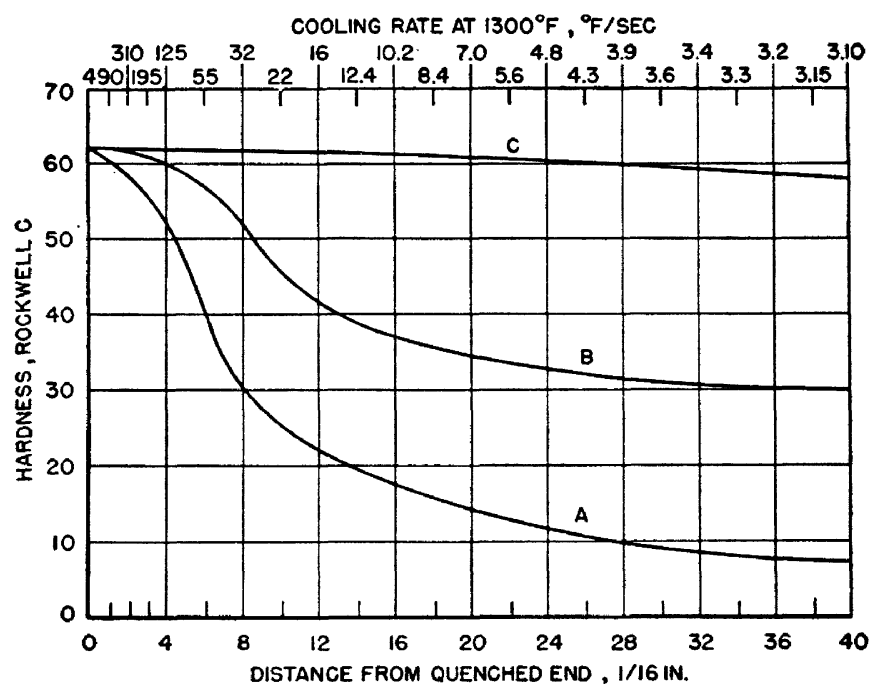

FIGCRE 21. Hardenability curves for different steels with the same carbon content.

A, Shallow hardening; $B$, intermediate hardening; $C$, deep hardening. The cooling rates shown in this figure are according to the results of Boege hold and Weinman, N.D.R.C. Report OSRD No. 3743, p. 42 (June 1, 1944). 
have the same cooling rate). Figure 22 shows this relationship between the distances on the endquenched bar and various locations for equivalent hardnesses in round bars quenched in still oil; figure $23^{-}$shows corresponding relations for bars quenched in still water.

If the hardenability (end-quench) curve of a steel is known, it is possible to ascertain from this curve and the curves given in figures 22 and 23 whether or not a selected size round made from the steel will have a desired hardness at its surface, $3 / 4$ radius, $1 / 2$ radius, or center, when quenched either in still oil or water, Conversely, the hardness values as determined at various positions in rounds after quenching in oil or water can be used to advantage in approximating the degree of hardenability of a steel suitable for replacement of similar parts.

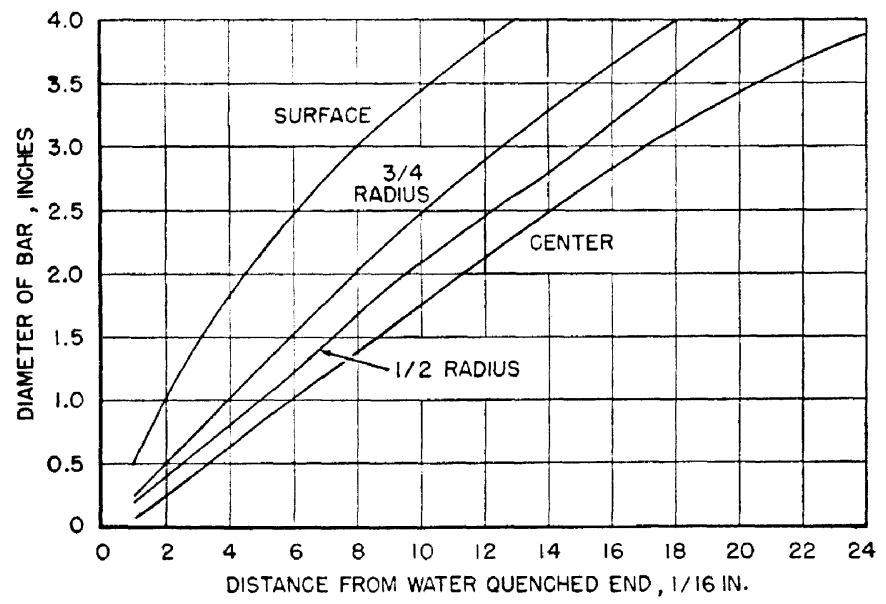

Figure 22. Relation between distances on the end-quench bar and various locations for equivalent hardnesses or cooling rates in round bars quenched in still oil.

(Metals Handbook, 1948 edition, p. 492.)

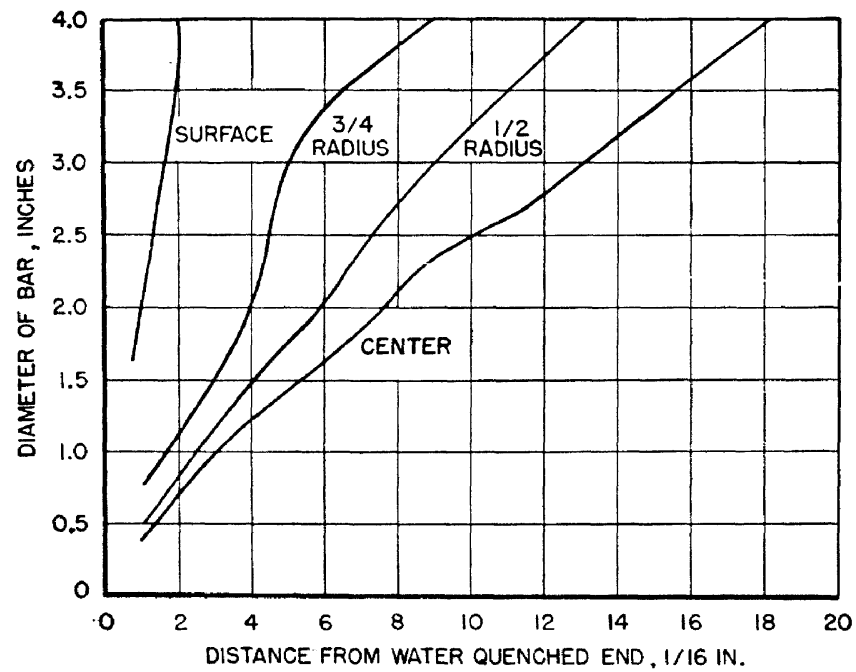

Figure 23. Relation between distances on the end-quench bar and various locations for equivalent hardnesses or cooling rates in round bars quenched in still water.

(Metals Handbook, 1948 edition, p. 492.)
The standard end-quench test is most useful for steels of moderate hardenability, that is, the low-alloy steels. For shallow hardening steels, such as plain carbon, a modification of this test (the L-type bar) is used.

\section{Heat Treatment of Cast Irons}

Cast irons are of three general types, gray, white, and nodular. The terms gray and white are descriptive of the characteristic appearances of the fractures and nodular is descriptive of the shape of the graphite particles.

In gray iron a large proportion of the carbon is present as graphitic or uncombined carbon in the form of flakes. The small proportion of carbon that is present as combined carbon or cementite is in the form of pearlite just as in a steel. Depending on the amount of combined carbon, the matrix of cast iron may be similar to a hypoeutectoid steel with varying amounts of free ferrite and graphite flakes dispersed throughout (fig. 24, A, $B$, and $C$ ). If the amount of combined carbon is about 0.8 percent, the matrix will be entirely pearlitic; if the amount is greater, the matrix will be similar to a hypereutectoid steel.

In white iron most, if not all, of the carbon is present as cementite (fig. 24, D). The dividing line between white and gray cast iron is not clearly defined and irons possessing characteristics of both are called mottled cast iron.

Whether a cast iron will be gray or white depends on two factors-composition and rate of cooling. Certain elements tend to promote the formation of graphitic carbon; the most important of these are silicon, nickel, and sulfur. Others tend to promote the formation of combined carbon; the most important of these are chromium, molybdenum, vanadium, and manganese. Rapid solidification and cooling, such as result from thin sections cast in sand or larger sections cast against chills, promote the formation of white iron. Iron so produced is frequently termed chilled iron. Because of variations in the rate of solidification and cooling, castings may be white at the surface layers, mottled immediately below, and gray in the interior.

In nodular cast iron, also known as "ductile iron," "nodular graphite iron," "spherulitic iron," and "spheroidal graphite iron," the graphite is present in the form of nodules or spheroids (fig. 24, $\mathrm{E}$ and $\mathrm{F}$ ). These nodules form during solidification due to the treatment of the molten iron, just prior to casting, with a few hundredths percent usually of either magnesium or cerium; the sulfur content must be below about 0.015 percent for the treatment to be effective with these elements. Nodular iron and gray iron have the same total carbon content. The mechanical properties of nodular iron can be varied by alloying.

Cast irons may be given a variety of heat treatments, depending on the compositions and 


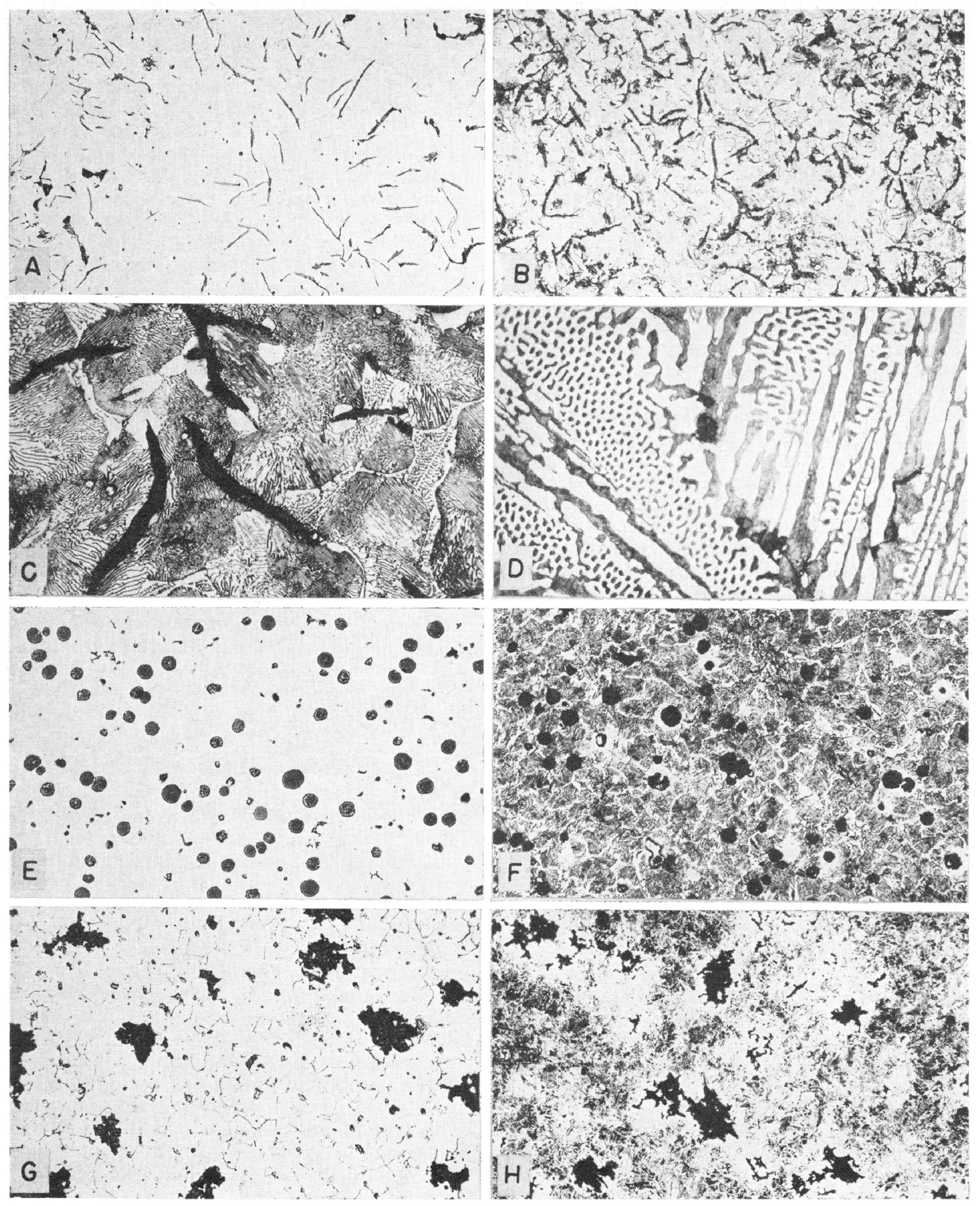

Figure 24. Microstructure of cast irons.

A, Gray iron. The dark flakes are graphite. Unetched. $\times 100$.

B, Same as (A). Etched with picral. $\times 100$.
C, Same as (B). The matrix consists of pearlite with a small amount of free ferrite (white) and is similar to a hypoeutectoid steel. The appearance of the graphite flakes is not affected by the etchant. $\times 500$.

$\times 500$, white iron. The white needles are cementite; the dark areas are pearlite; the dark spheroidal areas are the eutectic (Ledeburite). Etched with picral.

E, Nodular iron. The dark nodules are graphite; the white matrix is ferrite. Etched with picral. $\times 100$.

F, Pearlitic nodular iron. Nodular graphite (dark) in a pearlitic matrix. Etched with picral. $\times 100$.

H, Pearlitic malleable iron. Nodular graphite (dark) in a pearlitic matrix. Etched with picral. $\times 100$. 
desired properties. The principles of the heat treatments applied to cast iron are similar to those already discussed for steels.

\subsection{Relieving Residual Stresses (Aging)}

The heat treatment that reliev es residual stresses is commonly called "aging," "normalizing," or "mild annealing;" the term "stress relieving" is more accurately descriptive. This treatment can be accomplished by heating the cast iron to between $800^{\circ}$ and $1,100^{\circ} \mathrm{F}$, holding at temperature from $30 \mathrm{~min}$. to $5 \mathrm{hr}$, the time depending on the size and temperature, and cooling slowly in the furnace. Such treatment will cause only a slight decrease in hardness, very little decomposition of cementite, and only a slight change in the strength of the metal.

\subsection{Annealing}

Sometimes it is desirable to soften castings in order to facilitate machining. The temperature range most commonly used for this purpose is $1,400^{\circ}$ to $1,500^{\circ} \mathrm{F}$, although temperatures as low as $1,200^{\circ}$ to $1,250^{\circ} \mathrm{F}$ have been used satisfactorily. Highly alloyed irons are sometimes annealed at temperatures as high as $1,800^{\circ} \mathrm{F}$. In all annealing, care should be taken to prevent oxidation of the casting and cooling should be slow.

In general, softening for machinability is accompanied by a decrease in strength and in the amount of combined carbon, and by an increase in graphite content. Irons that contain carbideforming elements (such as chromium, molybdenum, vanadium, and manganese) are more resistant to softening than the ordinary gray iron and, therefore, must be annealed at considerably higher temperatures. Completely annealed ordinary gray cast iron has a Brinell hardness of 120 to 130 , and completely annealed alloy irons may have a Brinell hardness of 130 to 180 , depending on the composition.

The matrix of nodular iron can be made completely ferritic by heating at $1,300^{\circ} \mathrm{F}$ for 1 to $5 \mathrm{hr}$, depending on composition, size of casting, and amount of pearlite in the as-cast structure; cooling from the annealing temperature can be at any convenient rate. If massive or primary carbides are present in the as-cast structure, they may be converted to spheroidal graphite by heating at $1,600^{\circ}$ to $1,700^{\circ} \mathrm{F}$ for 1 to $5 \mathrm{hr}$. Slowly cooling from this temperature range to about $1,275^{\circ} \mathrm{F}$ and holding from 3 to $5 \mathrm{hr}$ will convert the matrix to ferrite. Nodular iron with a ferritic matrix has the desirable combination of maximum machinability, toughness, and ductility. The hardness of ferritic nodular iron varies with the alloy content from a low of about 130 Brinell to a high of about 210 Brinell.

\section{a. Malleabilizing}

Malleabilizing (also termed graphitizing) is a process of annealing white cast iron in such a way that the combined carbon is wholly or partly transformed to graphite in the nodular form (fig. 24, $\mathrm{G}$ and $\mathrm{H}$ ) instead of the flaky form that exists in gray cast iron. The nodular form of carbon is called temper or free carbon. In some instances, part of the carbon is lost in the malleabilizing process.

White iron that is to be malleabilized should contain all its carbon in the combined form. Any carbon present as graphitic carbon (and hence in the form of flakes) will not be affected by the graphitizing treatment and is undesirable in the final structure.

The temperatures used in malleabilizing usually range from about $1,500^{\circ}$ to $1,650^{\circ} \mathrm{F}$. Time at temperature is quite long, frequently being as much as two to three days. Holding at this temperature causes the decomposition of the cementite into austenite plus rather rounded forms of graphite. If the iron is then cooled very slowly through the critical range (less than $10^{\circ} \mathrm{F} / \mathrm{hr}$ ), the resultant structure will consist of ferrite plus temper carbon. Cooling less slowly through the transformation range, or using an iron containing an alloying element that retards graphitization, results in a final product containing various amounts of pearlite plus ferrite with, of course, temper carbon. Irons having a pearlitic structure plus temper carbon are known as pearlitic malleable irons (fig. 24, H). As might be expected, pearlitic malleable irons are susceptible to heat treatment in the same manner as steels.

\subsection{Normalizing, Quenching, and Tempering}

When heated to above the critical temperature (line $S K$, fig. 3), cast iron consists of austenite plus excess cementite or graphite and the austenite can be transformed in the same manner as in steel. Although irons that are almost completely graphitic (the common soft gray irons) can be hardened, this is not customary. Such irons must be held at temperatures well above the critical for long periods of time in order to assure the solution of carbon in the austenite.

For optimum results, the graphite flakes should be small and uniformly distributed and the matrix should be pearlitic with not too much free ferrite (combined carbon from about 0.50 to $0.80 \%$ ). Castings should be heated uniformly to the quenching temperature, which usually ranges from $1,500^{\circ}$ to $1,600^{\circ} \mathrm{F}$. The quenching medium commonly used is oil; water is used to a limited extent and some alloy castings may be quenched in air. The iron, as quenched, generally has a lower strength than as cast, but the strength is increased by tempering in the range of $350^{\circ}$ to $1,200^{\circ} \mathrm{F}$. Softening proceeds uniformly as the tempering temperature is increased above about $350^{\circ}$ to $1,200^{\circ} \mathrm{F}$.

A pearlitic matrix can be produced in nodular iron as cast or by normalizing. The normalizing treatment consists of heating to $1,600^{\circ}$ to $1,650^{\circ} \mathrm{F}$ 
holding at temperature for solution of carbon, followed by cooling in air. The mechanical properties of the normalized irons vary with the composition, fineness, and amounts of pearlite; heavy sections are lower in hardness and higher in ductility than light sections. The Brinell hardness numbers range from about 200 to 275 .

Martensitic or bainitic structures are produced in nodular iron by quenching from $1,600^{\circ}$ to $1,700^{\circ} \mathrm{F}$ in oil or water. The irons as quenched have high strengths but low ductility. However, the ductility of the as-quenched iron can be materially increased (strength and hardness decreased) by tempering at about $1,000^{\circ}$ to $1,300^{\circ} \mathrm{F}$.

\subsection{Special Heat Treatments}

Subject to the same limitations as steels, cast irons can be flame-hardened, induction-hardened, austempered, martempered, or nitrided.

\section{Practical Considerations}

Satisfactory heat treatment of steel (and iron) requires furnaces that have uniform controlled temperatures, means for accurate temperature measurement, and for protecting the surface of the material from scaling or decarburizing. Proper quenching equipment is needed also.

\subsection{Furnaces and Salt Baths}

There are many different types and sizes of furnaces used in heat treatment. As a general rule, furnaces are designed to operate in certain specific temperature ranges and attempted use in other ranges frequently results in work of inferior quality. In addition, using a furnace beyond its rated maximum temperature shortens its life and may necessitate costly and time-consuming repairs.

Fuel-fired furnaces (gas or oil) require air for proper combustion and an air compressor or blower is therefore a necessary adjunct. These furnaces are usually of the muffle type, that is, the combustion of the fuel takes place outside of and around the chamber in which the work is placed. If an open muffle is used, the furnace should be designed so as to prevent the direct impingement of flame on the work.

In furnaces heated by electricity the heating elements are generally in the form of wire or ribbon. Good design requires incorporation of additional heating elements at locations where maximum heat loss may be expected. Such furnaces commonly operate up to a maximum temperature of about $2,000^{\circ} \mathrm{F}$. Furnaces operating at temperatures up to about $2,500^{\circ} \mathrm{F}$ usually employ resistor bars of sintered carbides.

Furnaces intended primarily for tempering may be heated by gas or electricity and are frequently equipped with a fan for circulating the hot air.
Salt baths are available for operating at either tempering or hardening temperatures. Depending on the composition of the salt bath, heating can be conducted at temperatures as low as $325^{\circ} \mathrm{F}$ to as high as $2,450^{\circ} \mathrm{F}$. Lead baths can be used in the temperature range of $650^{\circ}$ to $1,700^{\circ} \mathrm{F}$. The rate of heating in lead or salt baths is much faster than in furnaces.

\section{a. Protective Atmospheres}

It is often necessary or desirable to protect steel or cast iron from surface oxidation (scaling) and loss of carbon from the surface layers (decarburization, fig. 15, F). Commercial furnaces, therefore, are generally equipped with some means of atmosphere control. This usually is in the form of a burner for burning controlled amounts of gas and air and directing the products of combustion into the furnace muffle. Water vapor, a product of this combustion, is detrimental and many furnaces are equipped with a means for eliminating it. For furnaces not equipped with atmosphere control, a variety of external atmosphere generators are available. The gas so generated is piped into the furnace and one generator may supply several furnaces. If no method of atmosphere control is available, some degree of protection may be secured by covering the work with cast iron borings or chips.

Since the work in salt or lead baths is surrounded by the liquid heating medium, the problem of preventing scaling or decarburization is simplified.

\section{b. Temperature Measurement and Control}

Accurate temperature noeasurement is essential to good heat treating. The usual method is by means of thermocouples; the most common basemetal couples are copper-Constantan (up to about $700^{\circ} \mathrm{F}$ ), iron-Constantan (up to about $1,400^{\circ} \mathrm{F}$ ), and Chromel-Alumel (up to about 2,200 $\mathrm{F}$ ). The most common noble-metal couples(which can be used up to about $2,800^{\circ} \mathrm{F}$ ) are platinum coupled with either the alloy 87 percent platinum13 percent rhodium or the alloy 90 percent platinum-10 percent rhodium. The temperatures quoted are for continuous operation.

The life of thermocouples is affected by the maximum temperature (which may frequently exceed those given above) and by the furnace atmosphere. Iron-Constantan is more suited for use in reducing and Chromel-Alumel in oxidizing atmospheres. Thermocouples are usually encased in metallic or ceramic tubes closed at the hot end to protect them from the furnace gases. A necessary adjunct is an instrument, such as a millivoltmeter or potentiometer, for measuring the electromotive force generated by the thermocouple. In the interest of accurate control, the hot junction of the thermocouple should be placed as close to the work as possible. The use of an automatic controller is valuable in controlling the temperature at the desired value. 
If temperature-measuring equipment is not available, it becomes necessary to estimate temperatures by some other means. An inexpensive, yet fairly accurate method involves the use of commercial crayons, pellets, or paints that melt at various temperatures within the range $125^{\circ}$ to $1,600^{\circ} \mathrm{F}$. The least accurate method of temperature estimation is by observation of the color of the hot hearth of the furnace or of the work. The heat colors observed are affected by many factors, such as the conditions of artificial or natural light, the character of the scale on the work, etc.

Steel begins to appear dull red at about $1,000^{\circ} \mathrm{F}$, and as the temperature increases the color changes gradually through various shades of red to orange, to yellow, and finally to white. A rough approximation of the correspondence between color and temperature is indicated in figure 25.

It is also possible to secure some idea of the temperature of the piece of steel in the range used for tempering from the color of the thin oxide film that forms on the cleaned surface of the steel when heated in this range. The approximate temperature-color relationship is indicated on the lower portion of the scale in figure 25 .

Since steel becomes nonmagnetic on heating through the $A_{2}$ temperature, the proper annealing and hardening temperature for medium and highcarbon steels can be estimated magnetically.

\subsection{Quenching Media and Accessories}

Quenching solutions act only through their ability to cool the steel. They have no beneficial chemical action on the quenched steel and in themselves impart no unusual properties. Most requirements for quenching media are met satisfactorily by water or aqueous solutions of inorganic salts such as table salt or caustic soda, or by some type of oil. The rate of cooling is relatively rapid during quenching in brine, somewhat less rapid in water, and slow in oil.

Brine usually is made of a 5- to 10-percent solution of salt (sodium chloride) in water. In addition to its greater cooling speed, brine has the ability to "throw" the scale from steel during quenching. The cooling ability of both water and brine, particularly water, is considerably affected by their temperature. Both should be kept coldwell below $60^{\circ} \mathrm{F}$. If the volume of steel being quenched tends to raise the temperature of the bath appreciably, the quenching bath should be cooled by adding ice or by some means of refrigeration.

There are many specially prepared quenching oils on the market; their cooling rates do not vary widely. A straight mineral oil with a Saybolt viscosity of about 100 at $100^{\circ} \mathrm{F}$ is generally used. Unlike brine and water, the oils have the greatest cooling velocity at a slightly elevated tempera-

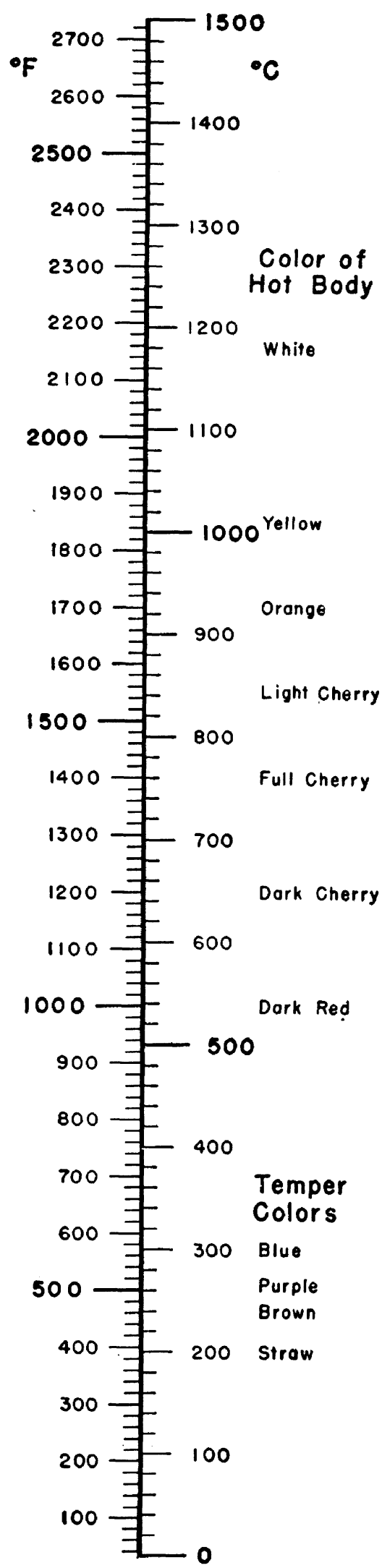

Figure 25. Temperature chart indicating conversion of Centrigrade to Fahrenheit or vice versa, color temperature scale for hardening-temperature range, and temperingtemperature range. 
ture-about $100^{\circ}$ to $140^{\circ} \mathrm{F}$-because of their decreased viscosity at these temperatures.

When steel is quenched, the liquid in immediate contact with the hot surface vaporizes; this vapor reduces the rate of heat abstraction markedly. Vigorous agitation of the steel or the use of a pressure spray quench is necessary to dislodge these vapor films and thus permit the desired rate of cooling.

Shallow hardening steels, such as plain carbon and certain varieties of alloy steels, have such a high critical cooling rate that they must be quenched in brine or water to effect hardening. In general, intricately shaped sections should not be made of shallow hardening steels because of the tendency of these steels to warp and crack during hardening. Such items should be made of deeper hardening steels capable of being hardened by quenching in oil or air.

A variety of different shapes and sizes of tongs for handling hot steels is necessary. It should be remembered that cooling of the area contacted by the tongs is retarded and that such areas may not harden, particularly if the steel being treated is very shallow hardening. Small parts may be wired together or quenched in baskets made of wire mesh.

Special quenching jigs and fixtures are frequently used to hold steels during quenching in a manner to restrain distortion.

When selective hardening is desired, portions of the steel may be protected by covering with alundum cement or some other insulating material. Selective hardening may be accomplished also by the use of water or oil jets designed to direct the quenching medium on the areas to be hardened. This also is accomplished by the induction and flame-hardening procedures previously described, particularly on large production jobs.

\subsection{Relation of Design to Heat Treatment}

Internal strains arise from many causes, but the most serious are those developed during quenching by reason of differential cooling and from the increase in volume that accompanies the martensitic transformation. These stresses are frequently sufficient to distort or crack the hardened steel. Since temperature gradients are largely a function of the size and shape of the piece being quenched, the basic principle of good design is to plan shapes that will keep the temperature gradient throughout a piece at a minimum during quenching.

Because of the abruptness in the change of section, some shapes are impractical to harden, without cracking or distortion, by quenching in water, but a certain latitude in design is permissible when using an oil-hardening or air-hardening steel

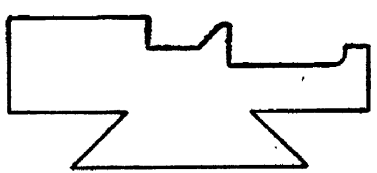

A
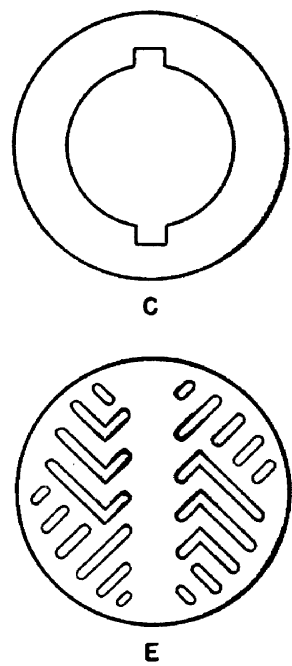

E

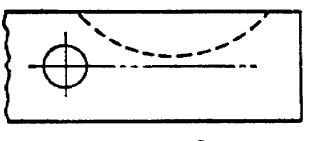

$\mathbf{G}$

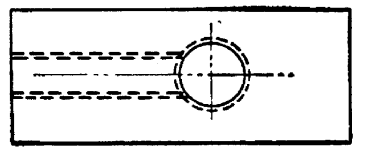

$\downarrow$

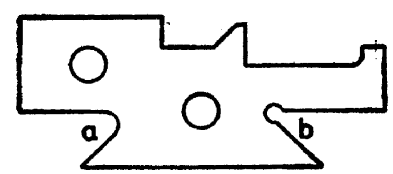

B
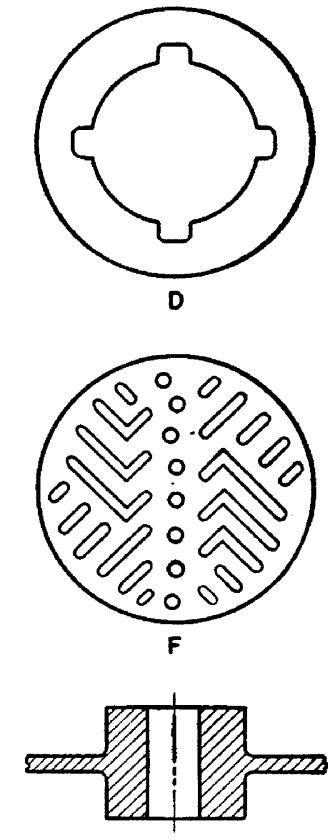

H
FigURE 26. Examples of good and bad designs from standpoint of hardening by heat treatment (Palmer and Luerssen, Tool steel simplified, p. 392, 1948).

A, End view of an undercutting form tool incorrectly designed.

$B$, The same tool better designed from the viewpoint of heat treatment. Heavy sections have been lightened by drilling holes, thus insuring more uniform cooling. The fillet at (a) minimizes danger of cracking at the sharp re-entrant angle. Where a fillet is not allowable, treatment as shown at (b) is helpful.

C, Cracking will tend to occur at the sharp roots of the keyways.

D, Fillets at the roots of the keyways will reduce the tendency toward cracking. The incorporation of the two additional keyways, even though cracking. The incorporation of the two additional keyways, even though E, A blanking die with the center rib heavier than the surrounding areas. This may cause warping on quenching.

$\mathrm{F}$, The same die with holes drilled in the center rib to equalize the amount of metal throughout the die, thus eliminating warpage difficulties.

$G$, A stem pinion with a keyway about one-half the diameter of the stem. The base of the keyway is extremely sharp, and the piece is further weakened by a hole drilled through the center of the stem near the keyway. The base of the keyway should be filleted and hole re-located. H, A dangerous design consisting of a thin collar adjoining a thick section. When hardening such pieces, the thin section often warps or cracks at the
junction with the hub. Extremely generous fillets and drilling holes through junction with the hub. Extremely generous

$\mathrm{J}$, When hardening, the concentration of strains at the junction of the two holes in the center are apt to cause failure. Such holes should be plugged before hardening.

K. A blanking die poorly designed. Crack will occur from point of fork prong to setscrew hole. The position of the setscrew hole should be changed to eliminate cracking. 
Other things being equal, temperature gradients are much lower in shapes quenched in oil than in water, and are still less in air. Thus a certain design may be perfectly safe for one type of steel, or one type of coolant, and unsafe for another.

Errors in design reach farther than merely affecting the internal strains during hardening. A sharp angle or notch serves to greatly concentrate the stresses applied during service, and the design of the part may be entirely responsible for concentruting the service stresses at a point already weakened by internal strains produced during hardening. Concentration of service stresses frequently parallels concentration of heattreating strains and is frequently caused and cured by the same combination of circumstances.

A purt is properly designed, from a standpoint of heat treatment, if the entire piece can be heated and cooled at approximately the same rate during the heat-treating operations. Perfection in this regard is unattainable because, even in a sphere, the surface cools more rapidly than the interior. The designer should, however, attempt to shape parts so that they will heat and cool as uniformly as possible. The greater the temperature difference between any two points in a given part during quenching, and the closer these two points are together, the greater will be the internal strain and, therefore, the poorer the design.

When large and small sections are unavoidable in the same piece, the thick part frequently can be lightened by drilling holes through it. Where changes in section are encountered, angles should be filletted generously. Some examples of poor and good design are shown in figure 26 .

\section{Nomenclature and Chemical Compositions of Steels}

\subsection{Structural Steels}

In order to facilitate the discussion of steels, some familiarity with their nomenclature is desirable.

A numerical index, sponsored by the Society of Automotive Engineers (SAE) and the American Iron and Steel Institute (AISI), is used to identify the chemical compositions of the structural steels. In this system, a four-numeral series is used to designate the plain carbon and alloy steels; five numerals are used to designate certain types of alloy steels. The first two digits indicate the type of steel, the second digit also generally (but not always) gives the approximate amount of the major alloying element and the last two (or three) digits are intended to indicate the approximate middle of the carbon range. However, a deviation from the rule of indicating the carbon range is sometimes necessary.
The series designation and types are summarized as follows:

\begin{tabular}{|c|c|}
\hline $\begin{array}{c}\text { Series } \\
\text { designation }\end{array}$ & Types \\
\hline $10 \mathrm{xx} \ldots \ldots$ & Nonsulphurized carbon steels \\
\hline $11 x_{\ldots} \ldots \ldots$ & Resulphurized carbon steels (free machining) \\
\hline $12 \mathrm{xx}_{\ldots} \ldots \ldots$ & $\begin{array}{l}\text { Rephosphorized and resulphurized carbon } \\
\text { steels (free machining) }\end{array}$ \\
\hline $13 \mathrm{xx} \ldots \ldots$ & Manganese $1.75 \%$ \\
\hline${ }^{*} 23 \times x \ldots \ldots$ & Nickel $3.50 \%$ \\
\hline$* 25 \mathrm{xx} \ldots \ldots$ & Nickel $5.00 \%$ \\
\hline $31 \mathrm{xx}_{\ldots} \ldots .$. & Nickel $1.25 \%$, chromium $0.65 \%$ \\
\hline $33 \mathrm{xx}_{\ldots} \ldots \ldots$ & Nickel $3.50 \%$, chromium $1.55 \%$ \\
\hline $40 \mathrm{xx}_{\ldots} \ldots .$. & Molybdenum 0.20 or $0.25 \%$ \\
\hline $41 \mathrm{xx}_{\ldots} \ldots . .$. & $\begin{array}{l}\text { Chromium } 0.50 \text { or } 0.95 \% \text {, molybdenum } 0.12 \\
\quad \text { or } 0.20 \%\end{array}$ \\
\hline $43 \times x$ & $\begin{array}{l}\text { Nickel } 1.80 \%, \text { chromium } 0.50 \text { or } 0.80 \% \text {, } \\
\text { molybdenum } 0.25 \%\end{array}$ \\
\hline $44 \mathrm{xx}_{\ldots} \ldots .$. & Molybdenum $0.40 \%$ \\
\hline $45 \mathrm{xx} \ldots \ldots$ & Molybdenum $0.52 \%$ \\
\hline $46 \times x_{\ldots} \ldots$. & Nickel $1.80 \%$, molybdenum $0.25 \%$ \\
\hline $47 \mathrm{xx}_{\ldots} \ldots .$. & $\begin{array}{l}\text { Nickel } 1.05 \% \text {, chromium } 0.45 \% \text {, molybde- } \\
\text { num } 0.20 \text { or } 0.35 \%\end{array}$ \\
\hline $48 \mathrm{xx}$ & Nickel $3.50 \%$, molybdenum $0.25 \%$ \\
\hline$\ldots$ & Chromium $0.25,0$. \\
\hline$\ldots$ & Carbon $1.00 \%$, chromium 0.50 \\
\hline $51 \times x$ & Chromium $0.80,0.90,0.95$, or $1.00 \%$ \\
\hline $1 \mathrm{rrx}$ & Carbon $1.00 \%$, chromium $1.05 \%$ \\
\hline . & Carbon $1.00 \%$, chromium $1.45 \%$ \\
\hline 6 & $\begin{array}{l}\text { Chromium } 0.60,0.80 \text { or } 0.95 \% \text {, vanadium } \\
0.12 \%, 0.10 \% \text { min., or } 0.15 \% \mathrm{~min} \text {. }\end{array}$ \\
\hline 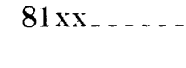 & $\begin{array}{l}\text { Nickel } 0.30 \% \text {, chromium } 0.40 \% \text {, molyb- } \\
\text { denum } 0.12 \%\end{array}$ \\
\hline $86 \times x$ & $\begin{array}{l}\text { Nickel } 0.55 \% \text {, chromium } 0.50 \% \text {, molyb- } \\
\text { denum } 0.20 \%\end{array}$ \\
\hline $87 \mathrm{xx}$ & $\begin{array}{l}\text { Nickel } 0.55 \% \text {, chromium } 0.50 \% \text {, molyb- } \\
\text { denum } 0.25 \%\end{array}$ \\
\hline $88 \times x_{-}$ & $\begin{array}{l}\text { Nickel } 0.55 \% \text {, chromium } 0.50 \% \text {, molyb- } \\
\text { denum } 0.35 \%\end{array}$ \\
\hline $92 \times x$ & $\begin{array}{l}\text { Manganese } 0.85 \% \text {, silicon } 2.00 \% \text {, chromium } \\
\quad 0 \text { or } 0.35 \%\end{array}$ \\
\hline $93 \times x$ & $\begin{array}{l}\text { Nickel } 3.25 \% \text {, chromium } 1.20 \% \text {, molyb- } \\
\text { denum } 0.12 \%\end{array}$ \\
\hline $94 \times x_{-}$ & $\begin{array}{l}\text { Nickel } 0.45 \% \text {, chromium } 0.40 \% \text {, molyb- } \\
\text { denum } 0.12 \%\end{array}$ \\
\hline $8 \mathrm{xx}$ & $\begin{array}{l}\text { Nickel } 1.00 \% \text {, chromium } 0.80 \% \text {, molyb- } \\
\text { denum } 0.25 \%\end{array}$ \\
\hline
\end{tabular}

Listings of the SAE-AISI type numbers and chemical composition limits of the standard and tentative standard structural steels (complete as of February 1960) are given in table 1. The SAE numbers are the same as the AISI numbers, except that the latter may be given a letter prefix to indicate the method of manufacture. These prefixes and their meanings are as follows: $\mathrm{B}$ denotes acid bessemer carbon steel, $\mathrm{C}$ denotes basic open hearth or basic electric furnace carbon steels, E denotes electric furnace alloy steels.

Small quantities of certain elements are present in alloy steels that are not specified as required. These elements are considered as incidental and may be present to the maximum amounts as follows: copper, 0.35 percent; nickel, 0.25 percent; chromium, 0.20 percent; molybdenum, 0.06 percent. 
The list of standard steels is altered from time to time to accommodate steels of proven merit and to provide for changes in the metallurgical and engineering requirements of industry.

Many of the alloy structural steels are manufactured to meet certain specified limits in hardenability as determined by the standard end-quecnh test. Such steels, table 2, are designated by the letter " $\mathrm{H}$ " following the SAE-AISI number. The chemical composition limits of these steels have been modified somewhat from the ranges or limits applicable to the same grades when specified by chemical composition only. The hardenability of an "H" steel is guaranteed by the manufacturer to fall within a hardenability band having maximum and minimum limits as shown by two limiting hardenability curves for that particular steel.

TABLE 1. Composition limits of standard steels

NONRESULPHURIZED CARBON STEELS A

\begin{tabular}{|c|c|c|c|c|c|c|c|c|c|c|c|}
\hline \multicolumn{2}{|c|}{ Designation number } & \multicolumn{4}{|c|}{ Chemical composition limits, percent } & \multicolumn{2}{|c|}{ Designation number } & \multicolumn{4}{|c|}{ Chemical composition limits, percent } \\
\hline AISI & $\mathrm{SAE}$ & $\mathrm{C}$ & $\mathrm{Mn}$ & $P(\max )$ & $\mathrm{S}(\max )$ & AISI & $\mathrm{SAE}$ & $\mathrm{C}$ & $\mathrm{Mn}$ & $P(\max )$ & $S(\max )$ \\
\hline C 1008 & 1008 & $0.10 \max$ & $0.25 / 0.50$ & 0.040 & 0.050 & C 1039 & 1039 & $0.37 / 0.44$ & $0.70 / 1.00$ & 0.040 & 0.050 \\
\hline C 1010 & 1010 & $.08 / 0.13$ & $.30 / 0.60$ & .040 & .050 & C 1040 & 1040 & $.37 / 0.44$ & $.60 / 0.90$ & .040 & .050 \\
\hline C 1011 & & $.08 / 0.13$ & $.60 / 0.90$ & .040 & .050 & C 1041 & 1041 & $.36 / 0.44$ & 1. $35 / 1.65$ & .040 & .050 \\
\hline C 1012 & 1012 & $.10 / 0.15$ & $.30 / 0.60$ & .040 & .050 & C 1042 & 1042 & $.40 / 0.47$ & $0.60 / 0.90$ & .040 & .050 \\
\hline C 1015 & 1015 & $.13 / 0.18$ & $.30 / 0.60$ & .040 & .050 & C 1043 & 1043 & $.40 / 0.47$ & $.70 / 1.00$ & .040 & .050 \\
\hline C 1016 & 1016 & $.13 / 0.18$ & $.60 / 0.90$ & .040 & .050 & C 1045 & 1045 & $.43 / 0.50$ & $.60 / 0.90$ & .040 & .050 \\
\hline C 1017 & 1017 & $.15 / 0.20$ & $.30 / 0.60$ & .040 & .050 & C 1046 & 1046 & $.43 / 0.50$ & $.70 / 1.00$ & .040 & .050 \\
\hline C 1018 & 1018 & $.15 / 0.20$ & $.60 / 0.90$ & .040 & .050 & C 1048 & 1048 & $.44 / 0.52$ & $1.10 / 1.40$ & .040 & .050 \\
\hline C 1019 & 1019 & $.15 / 0.20$ & $.70 / 1.00$ & .040 & .050 & C 1049 & 1049 & $.46 / 0.53$ & $.60 / 0.90$ & .040 & .050 \\
\hline C 1020 & 1020 & $.18 / 0.23$ & $.30 / 0.60$ & .040 & .050 & C 1050 & 1050 & $.48 / 0.55$ & $.60 / 0.90$ & .040 & .050 \\
\hline C 1021 & 1021 & $.18 / 0.23$ & $.60 / 0.90$ & .040 & .050 & C 1051 & & $.45 / 0.56$ & $.85 / 1.15$ & .040 & .056 \\
\hline C 1022 & 1022 & $.18 / 0.23$ & $.70 / 1.00$ & .040 & .050 & C 1052 & 1052 & $.47 / 0.55$ & 1. $20 / 1.50$ & .040 & .050 \\
\hline C 1023 & 1023 & $.20 / 0.25$ & $.30 / 0.60$ & .040 & .050 & C 1053 & & $.48 / 0.55$ & $0.70 / 1.00$ & .040 & .050 \\
\hline C 1024 & 1024 & $.19 / 0.25$ & $1.35 / 1.65$ & .040 & .050 & C 1055 & 1055 & $.50 / 0.60$ & $.60 / 0.90$ & .040 & .050 \\
\hline C 1025 & 1025 & $.22 / 0.28$ & $0.30 / 0.60$ & .040 & .050 & C 1060 & 3060 & $.55 / 0.65$ & $.60 / 0.90$ & .040 & .050 \\
\hline C 1026 & 1026 & $.22 / 0.28$ & $.60 / 0.90$ & .040 & .050 & C 1070 & 1070 & $.65 / 0.75$ & $.60 / 0.90$ & .040 & .050 \\
\hline C 1027 & 1027 & $.22 / 0.29$ & $1.20 / 1.50$ & .040 & $.05 t)$ & C 1078 & 1078 & $.72 / 0.85$ & $.30 / 0.60$ & .040 & .050 \\
\hline C 1029 & & $.25 / 0.31$ & $0.60 / 0.90$ & .040 & .050 & C 1080 & 1080 & $.75 / 0.88$ & $.60 / 0.90$ & .040 & .050 \\
\hline C 1030 & 1030 & $.28 / 0.34$ & $.60 / 0.90$ & .040 & .050 & C 1084 & 1084 & $.80 / 0.93$ & $.60 / 0.90$ & .040 & .050 \\
\hline C 1031 & & $.28 / 0.34$ & $.30 / 0.60$ & .040 & .050 & C 1085 & 1085 & $.80 / 0.93$ & $.70 / 1.00$ & .040 & .050 \\
\hline C 1033 & 1033 & $.30 / 0.36$ & $.70 / 1.00$ & .040 & .050 & C 1086 & 1086 & $.80 / 0.93$ & $.30 / 0.50$ & .040 & .050 \\
\hline C 1035 & 1035 & $.32 / 0.38$ & $.60 / 0.90$ & .040 & .050 & C 1090 & 1090 & $.85 / 0.98$ & $.60 / 0.90$ & .040 & .050 \\
\hline C 1036 & 1036 & $.30 / 0.37$ & $1.20 / 1.50$ & .040 & .050 & C 1095 & 1095 & $.90 / 1.03$ & $.30 / 0.50$ & .040 & .050 \\
\hline C 1037 & 1037 & $.32 / 0.38$ & $0.70 / 1.00$ & .040 & .050 & & & & & & \\
\hline C 1038 & 1038 & $.35 / 0.42$ & $.60 / 0.90$ & .040 & .050 & & & & & & \\
\hline
\end{tabular}

RESULPHURIZED CARBON STEELS b

\begin{tabular}{|c|c|c|c|c|c|c|c|c|c|c|c|}
\hline \multicolumn{2}{|c|}{ Designation number } & \multicolumn{4}{|c|}{ Chemical composition limits, percent } & \multicolumn{2}{|c|}{ Designation number } & \multicolumn{4}{|c|}{ Chemical composition limits, percent } \\
\hline AISI & $\mathrm{SAE}$ & $\mathrm{C}$ & Mn & $P(\max )$ & $\mathrm{S}$ & AISI & $\mathrm{SAE}$ & $\mathrm{C}$ & $\mathrm{Mn}$ & $P(\max )$ & $\mathrm{S}$ \\
\hline $\begin{array}{ll}\text { C } & 1108 \\
\text { C } & 1109 \\
\text { C } & 1110 \\
\text { C } & 1113 \\
\text { C } & 1115\end{array}$ & $\begin{array}{r}1108 \\
1109 \\
1115\end{array}$ & $\begin{array}{l}0.08 / 0.13 \\
.08 / 0.13 \\
.08 / 0.13 \\
.10 / 0.16 \\
.13 / 0.18\end{array}$ & $\begin{array}{r}0.50 / 0.80 \\
.60 / 0.90 \\
.30 / 0.60 \\
1.00 / 1.30 \\
0.60 / 0.90\end{array}$ & $\begin{array}{r}0.040 \\
.040 \\
.040 \\
.040 \\
.040\end{array}$ & $\begin{array}{l}0.08 / 0.13 \\
.08 / 0.13 \\
.08 / 0.13 \\
.24 / 0.33 \\
.08 / 0.13\end{array}$ & $\begin{array}{l}\text { C } 1126 \\
\text { C } 1132 \\
\text { C } 1137 \\
\text { C } 1138 \\
\text { C } 1139\end{array}$ & $\begin{array}{l}1126 \\
1132 \\
1137 \\
1138 \\
1139\end{array}$ & $\begin{array}{l}0.23 / 0.29 \\
.27 / 0.34 \\
.32 / 0.39 \\
.34 / 0.40 \\
.35 / 0.43\end{array}$ & $\begin{array}{l}0.70 / 1.00 \\
1.35 / 1.65 \\
1.35 / 1.65 \\
0.70 / 1.00 \\
1.35 / 1.65\end{array}$ & $\begin{array}{r}0.040 \\
.040 \\
.040 \\
.040 \\
.040\end{array}$ & $\begin{array}{r}0.08 / 0.13 \\
.08 / 0.13 \\
.08 / 0.13 \\
.08 / 0.13 \\
.12 / 0.20\end{array}$ \\
\hline $\begin{array}{ll}\text { C } & 1116 \\
\text { C } & 1117 \\
\text { C } & 1118 \\
\text { C } & 1119 \\
\text { C } & 1120 \\
\text { C } & 1125\end{array}$ & $\begin{array}{l}1116 \\
1117 \\
1118 \\
1119 \\
1120\end{array}$ & $\begin{array}{l}.14 / 0.20 \\
.14 / 0.20 \\
.14 / 0.20 \\
.14 / 0.20 \\
.18 / 0.23 \\
.22 / 0.28\end{array}$ & $\begin{array}{r}1.10 / 1.40 \\
1.00 / 1.30 \\
1.30 / 1.60 \\
1.00 / 1.30 \\
0.70 / 1.00 \\
.60 / 0.90\end{array}$ & $\begin{array}{l}.040 \\
.040 \\
.040 \\
.040 \\
.040 \\
.040\end{array}$ & $\begin{array}{l}.16 / 0.23 \\
.08 / 0.13 \\
.08 / 0.13 \\
.24 / 0.33 \\
.08 / 0.13 \\
.08 / 0.13\end{array}$ & $\begin{array}{ll}\text { C } & 1140 \\
\text { C } & 1141 \\
\text { C } & 1144 \\
\text { C } & 1145 \\
\text { C } & 1146 \\
\text { C } & 1151\end{array}$ & $\begin{array}{l}1140 \\
1141 \\
1144 \\
1145 \\
1146 \\
1151\end{array}$ & $\begin{array}{l}.37 / 0.44 \\
.37 / 0.45 \\
.40 / 0.48 \\
.42 / 0.49 \\
.42 / 0.49 \\
.48 / 0.55\end{array}$ & $\begin{array}{r}0.70 / 1.00 \\
1.35 / 1.65 \\
1.35 / 1.65 \\
0.70 / 1.00 \\
.70 / 1.00 \\
.70 / 1.00\end{array}$ & $\begin{array}{l}.040 \\
.040 \\
.040 \\
.040 \\
.040 \\
.040\end{array}$ & $\begin{array}{l}.08 / 0.13 \\
.08 / 0.13 \\
.24 / 0.33 \\
.04 / 0.07 \\
.08 / 0.13 \\
.08 / 0.13\end{array}$ \\
\hline
\end{tabular}

ACID BESSEMER RESULPHURIZED CARBON STEEL c

\begin{tabular}{|c|c|c|c|c|c|}
\hline \multicolumn{2}{|c|}{ Designation number } & \multicolumn{4}{|c|}{ Chemical composition limits, percent } \\
\hline AISI & SAE & $\mathrm{C}$ & Mn & $\mathbf{P}$ & $\mathrm{s}$ \\
\hline $\begin{array}{ll}\text { B } & 1111 \\
\text { B } & 1112 \\
\text { B } & 1113\end{array}$ & $\begin{array}{l}1111 \\
1112 \\
1113\end{array}$ & $\begin{array}{r}0.13 \max \\
.13 \max \\
.13 \max \end{array}$ & $\begin{array}{r}0.60 / 0.90 \\
.70 / 1.00 \\
.70 / 1.00\end{array}$ & $\begin{array}{r}0.07 / 0.12 \\
.07 / 0.12 \\
.07 / 0.12\end{array}$ & $\begin{array}{r}0.08 / 0.15 \\
.16 / 0.23 \\
.24 / 0.33\end{array}$ \\
\hline
\end{tabular}

REPHOSPHORIZED AND RESULPHURIZED CARBON STEELS d

\begin{tabular}{|c|c|c|c|c|c|}
\hline \multicolumn{2}{|c|}{ Designation number } & \multicolumn{4}{|c|}{ Chemical composition limits, percent } \\
\hline AISI & SAE & $\mathrm{C}$ & Mn & $\mathrm{P}$ & $\mathrm{S}$ \\
\hline C 1211 & 1111 & $0.13 \max$ & $0.60 / 0.90$ & $0.07 / 0.12$ & $0.08 / 0.15$ \\
\hline C 1212 & 1112 & $.13 \max$ & $.70 / 1.00$ & $.07 / 0.12$ & .160 .23 \\
\hline C 1213 & 1113 & $.13 \max$ & $.70 / 1.00$ & $.07 / 0.12$ & $.24 / 0.33$ \\
\hline${ }^{*} \mathrm{C} 12 \mathrm{~L} 14$ & $12 \mathrm{~L} 14$ & $.15 \max$ & $.80 / 1.20$ & $.04 / 0.09$ & $.25 / 0.35$ \\
\hline
\end{tabular}

${ }^{*}$ Lead $=0.15 / 0.35$ percent

See footnotes at end of table. 
TABLE 1. Composition limits of standard steels-Continued

OPEN HEARTH AND ELECTRIC FURNACE ALLOY STEELS -

\begin{tabular}{|c|c|c|c|c|c|c|c|c|c|c|}
\hline \multicolumn{2}{|c|}{ Designation number } & \multicolumn{9}{|c|}{ Chemical composition limits, percent } \\
\hline AISI & SAE & $\mathrm{C}$ & $\mathrm{Mn}$ & $P(\max )$ & $\mathrm{S}(\max )$ & $\mathrm{Si}$ & $\mathrm{Ni}$ & $\mathrm{Cr}$ & Mo & $\mathrm{V}$ \\
\hline $\begin{array}{l}1330 \\
1335 \\
1340 \\
1345\end{array}$ & $\begin{array}{l}1330 \\
1335 \\
1340 \\
1345\end{array}$ & $\begin{array}{r}0.28 / 0.33 \\
.33 / 0.38 \\
.38 / 0.43 \\
.43 / 0.48\end{array}$ & 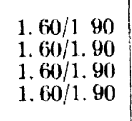 & $\begin{array}{r}0.040 \\
.040 \\
.040 \\
.040\end{array}$ & $\begin{array}{r}0.040 \\
.040 \\
.040 \\
.040\end{array}$ & $\begin{array}{r}0.20 / 0.35 \\
.20 / 0.35 \\
.20 / 0.35 \\
.20 / 0.35\end{array}$ & & - & & \\
\hline 3140 & 3140 & $.38 / 0.43$ & $0.70 / 0.90$ & .040 & .040 & $.20 / 0.35$ & 1. $10 / 1.40$ & $0.55 / 0.75$ & & \\
\hline E 3310 & 3310 & $.08 / 0.13$ & $.45 / 0.60$ & .025 & .025 & $.20 / 0.35$ & 3. $25 / 3.75$ & $1.40 / 1.75$ & & \\
\hline 4012 & 4012 & $.09 / 0.14$ & $.75 / 1.00$ & .040 & .040 & $.20 / 0.35$ & & & $0.15 / 0.25$ & \\
\hline 4023 & 4023 & $.20 / 0.25$ & $.70 / 0.90$ & .040 & .040 & $.20 / 0.35$ & & - & $.20 / 0.30$ & 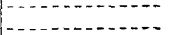 \\
\hline 4024 & 4024 & $.20 / 0.25$ & $.70 / 0.90$ & .040 & $* .035 / .050$ & $.20 / 0.35$ & & & $.20 / 0.30$ & \\
\hline 4027 & 4027 & $.25 / 0.30$ & $.70 /(0.90$ & .040 & 040 & $.20 / 0.35$ & & & $.20 / 0.30$ & \\
\hline $\begin{array}{l}4028 \\
40137\end{array}$ & 4028 & $.25 / 0.30$ & $.70 / 0.90$ & .040 & $* .035 / .050$ & $.20 / 0.35$ & & & $.20 / 0.30$ & \\
\hline $\begin{array}{l}4037 \\
4042\end{array}$ & 4037 & $\begin{array}{l}.35 / 0.40 \\
40 / 0.45\end{array}$ & $\begin{array}{l}.70 / 0.90 \\
70 / 0.90\end{array}$ & .040 & $\begin{array}{r}.040 \\
040\end{array}$ & $\begin{array}{r}20 / 0.35 \\
20 / 0.35\end{array}$ & & & $\begin{array}{r}.20 / 0.30 \\
20 / 0.30\end{array}$ & - \\
\hline $\begin{array}{l}4042 \\
4047\end{array}$ & $\begin{array}{l}4042 \\
4047\end{array}$ & $\begin{array}{l}.40 / 0.45 \\
.45 / 0.50\end{array}$ & $\begin{array}{l}.70 / 0.90 \\
.70 / 0.90\end{array}$ & $\begin{array}{l}.040 \\
.040\end{array}$ & $\begin{array}{l}.040 \\
.040\end{array}$ & $\begin{array}{l}.20 / 0.35 \\
.20 / 0.35\end{array}$ & & & $\begin{array}{l}.20 / 0.30 \\
.20 / 0.30\end{array}$ & \\
\hline 4063 & 4063 & $.60 / 0.67$ & $.75 / 1.00$ & .040 & .040 & $.20 / 0.35$ & & & $.20 / 0.30$ & \\
\hline 4118 & 4118 & $.18 / 0.23$ & $.70 / 0.90$ & .040 & .040 & $.20 / 0.35$ & & $0.40 / 0.60$ & $.08 / 0.15$ & \\
\hline 4130 & 4130 & $.28 / 0.33$ & $.40 / 0.60$ & .040 & .040 & $.20 / 0.35$ & & $.80 / 1.10$ & $.15 / 0.25$ & \\
\hline 4135 & 4135 & $.33 / 0.38$ & $.70 / 0.90$ & .040 & .040 & $.20 / 0.35$ & & $.80 / 1.10$ & $.15 / 0.25$ & \\
\hline 4137 & 4137 & $.35 / 0.40$ & $.70 / 0.90$ & .040 & .040 & $.20 / 0.35$ & & $.80 / 1.10$ & $.15 / 0.25$ & \\
\hline $\begin{array}{l}4140 \\
4142\end{array}$ & 4140 & $.38 / 0.43$ & $.75 / 1.00$ & .040 & .040 & $.20 / 0.35$ & & $.80 / 1.00$ & $.15 / 0.25$ & $\cdots$ \\
\hline $\begin{array}{l}4142 \\
4145\end{array}$ & $\begin{array}{l}4142 \\
4145\end{array}$ & & $\begin{array}{r}.75 / 1.00 \\
75 / 1.00\end{array}$ & $\begin{array}{l}.040 \\
.040\end{array}$ & $\begin{array}{l}.040 \\
.040\end{array}$ & $\begin{array}{l}.20 / 0.35 \\
20 / 0.35\end{array}$ & & $\begin{array}{l}.80 / 1.10 \\
.80 / 1.10\end{array}$ & $\begin{array}{l}.15 / 0.25 \\
.15 / 0.25\end{array}$ & \\
\hline $\begin{array}{l}4140 \\
4147\end{array}$ & $\begin{array}{l}4146 \\
4147\end{array}$ & $\begin{array}{l}.43 / 0.48 \\
.45 / 0.50\end{array}$ & $.75 / 1.00$ & $\begin{array}{l}.040 \\
.040\end{array}$ & $\begin{array}{l}.040 \\
.040\end{array}$ & $\begin{array}{l}.20 / 0.05 \\
.20 / 0.35\end{array}$ & & $\begin{array}{l}.80 / 1.10 \\
.80 / 1.10\end{array}$ & $\begin{array}{l}.15 / 0.25 \\
.15 / 0.25\end{array}$ & \\
\hline 4150 & 4150 & $.48 / 0.53$ & $.75 / 1.00$ & .040 & .040 & $.20 / 0.35$ & & $.80 / 1.10$ & $.15 / 0.25$ & \\
\hline 4320 & 4320 & $.17 / 0.22$ & $.45 / 0.65$ & .040 & .040 & $.20 / 0.35$ & $1.65 / 2.00$ & $.40 / 0.60$ & $.20 / 0.30$ & \\
\hline $\begin{array}{r}4337 \\
\mathrm{E} 4337\end{array}$ & 4337 & $.35 / 0.40$ & $.60 / 0.80$ & .040 & .040 & $.20 / 0.35$ & $1.65 / 2.00$ & $.70 / 0.90$ & $.20 / 0.30$ & \\
\hline & 4340 & $\begin{array}{r}35 / 0.40 \\
38 / 0.43\end{array}$ & $\begin{array}{l}.65 / 0.85 \\
.60 / 0.80\end{array}$ & $\begin{array}{r}.025 \\
040\end{array}$ & $\begin{array}{l}.025 \\
.040\end{array}$ & $\begin{array}{r}20 / 0.35 \\
20 / 0.35\end{array}$ & $\begin{array}{l}\text { 1. } 65 / 2.00 \\
1.65 / 2.00\end{array}$ & $\begin{array}{r}70 / 0.90 \\
70 / 0.90\end{array}$ & $\begin{array}{r}20 / 0.30 \\
20 / 0.30\end{array}$ & \\
\hline E 4340 & F 4340 & $.38 / 0.43$ & $.65 / 0.85$ & .025 & .025 & $.20 / 0.35$ & 1. $65 / 2.00$ & $.70 / 0.90$ & $.20 / 0.30$ & \\
\hline $\begin{array}{l}4422 \\
4427\end{array}$ & $\begin{array}{l}4422 \\
4427\end{array}$ & $\begin{array}{l}.20 / 0.25 \\
.24 / 0.29\end{array}$ & $\begin{array}{l}.70 / 0.90 \\
.70 / 0.90\end{array}$ & $\begin{array}{l}.040 \\
.040\end{array}$ & $\begin{array}{l}.040 \\
.040\end{array}$ & $\begin{array}{l}.20 / 0.35 \\
.20 / 0.35\end{array}$ & & & $\begin{array}{l}.35 / 0.45 \\
.35 / 0.45\end{array}$ & \\
\hline 4520 & 4520 & $.18 / 0.23$ & $.45 / 0.65$ & .040 & .040 & $.20 / 0.35$ & & & $.45 / 0.60$ & \\
\hline 4615 & 4615 & $.13 / 0.18$ & $.45 / 0.65$ & .040 & .040 & $.20 / 0.35$ & 1. $65 / 2.00$ & & $.20 / 0.30$ & \\
\hline 4617 & 4617 & $.15 / 0.20$ & $.45 / 0.65$ & .040 & .040 & $.20 / 6.35$ & 1. $65 / 2.00$ & & $.20 / 0.30$ & \\
\hline 4620 & 4620 & $.17 / 0.22$ & $.45 / 0.65$ & .040 & .040 & $.20 / 0.35$ & $1.65 / 2.00$ & . & $.20 / 0.30$ & \\
\hline 4621 & 4621 & $.18 / 0.23$ & $.70 / 0.90$ & .040 & .040 & $.20 / 0.35$ & $1.65 / 2.00$ & . & $.20 / 0.30$ & \\
\hline 4718 & 4718 & $.16 / 0.21$ & $.70 / 0.90$ & .040 & .040 & $.20 / 0.35$ & $0.90 / 1.20$ & $.35 / 0.55$ & $.30 / 0.40$ & \\
\hline 4721 & 4720 & $.17 / 0.22$ & $.50 / 0.70$ & .040 & .040 & $.20 / 0.35$ & $.90 / 1.20$ & $.35 / 0.55$ & $.15 / 0.25$ & \\
\hline 4815 & 4815 & $.13 / 0.18$ & $.40 / 0.60$ & .040 & .040 & $.20 / 0.35$ & 3. 25/3.75 & & $.20 / 0.30$ & \\
\hline 4817 & 4817 & $.15 / 0.20$ & $.40 / 0.60$ & .040 & .040 & $.20 / 0.35$ & $3.25 / 3.75$ & & $.20 / 0.30$ & \\
\hline & $4821)$ & $.18 / 0.23$ & $.50 / 0.70$ & .040 & .040 & $.20 / 0.35$ & $3.25 / 3.75$ & & $.20 / 0.30$ & \\
\hline 5015 & 5015 & $.12 / 0.17$ & $.30 / 0.50$ & .040 & .040 & $.20 / 0.35$ & & $.30 / 0.50$ & & \\
\hline 5046 & 5046 & $.43 / 0.50)$ & $.75 / 1.00$ & .040 & .040 & $.20 / 0.35$ & & $.20 / 0.35$ & & \\
\hline 5115 & 5115 & $.13 / 0.18$ & $.70 / 0.90$ & .040 & .040 & $.20 / 0.35$ & & $.70 / 0.90$ & & \\
\hline $\begin{array}{l}5120 \\
5130\end{array}$ & 5120 & $.17 / 0.22$ & $.70 / 0.90$ & .040 & .040 & $.20 / 0.35$ & & $.70 / 0.90$ & & \\
\hline $\begin{array}{l}5130 \\
5132\end{array}$ & 5130 & $.28 / 0.33$ & $.70 / 0.90$ & .040 & .040 & $.20 / 0.35$ & & $.80 / 1.10$ & $\ldots$ & \\
\hline $\begin{array}{l}5132 \\
5135\end{array}$ & $\begin{array}{l}5132 \\
5135\end{array}$ & $\begin{array}{r}.30) / 0.35 \\
.33 / 0.38\end{array}$ & $\begin{array}{r}60 / 0.80 \\
.60 / 0.80\end{array}$ & $\begin{array}{l}.040 \\
.040\end{array}$ & $\begin{array}{l}.040 \\
.040\end{array}$ & $\begin{array}{l}.20 / 0.35 \\
.20 / 0.35\end{array}$ & & $\begin{array}{l}.75 / 1.00 \\
.80 / 1.05\end{array}$ & $\ldots$ & -- \\
\hline 5140 & 5140 & $.38 / 0.43$ & $.70 / 0.90$ & .040 & .040 & $.20 / 0.35$ & & $.70 / 0.90$ & -- & -- \\
\hline 5145 & 5145 & $.43 / 0.48$ & $.70 / 0.90$ & .040 & .040 & $.20 / 0.35$ & 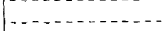 & $.70 / 0.90$ & - & - \\
\hline 5147 & 5147 & $.45 / 0.52$ & $.70 / 0.95$ & .040 & .040 & $.20 / 0.35$ & . & $.85 / 1.15$ & & \\
\hline 5150 & 5150 & $.48 / 0.53$ & $.70 / 0.90$ & .040 & .040 & $.20 / 0.35$ & & $.70 / 0.90$ & $\ldots$ & - \\
\hline 5155 & 5155 & $.50 / 0.60$ & $.70 / 0.90$ & .040 & .040 & $.20 / 0.35$ & 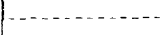 & $.70 / 0.90$ & -. & $\ldots$ \\
\hline 5160 & 5160 & $.55 / 0.65$ & $.75 / 1.00$ & .040 & .040 & $.20 / 0.35$ & & $.70 / 0.90$ & $\ldots$ & \\
\hline E 50100 & 50100 & $.95 / 1.10$ & $.25 / 0.45$ & .025 & .025 & $.20 / 0.35$ & & $.40 / 0.60$ & & \\
\hline $\begin{array}{l}\text { E } 51100 \\
\text { E } 52100\end{array}$ & $\begin{array}{l}51100 \\
52100\end{array}$ & $\begin{array}{r}95 / 1.10 \\
95 / 1.10\end{array}$ & $\begin{array}{l}.25 / 0.45 \\
.25 / 0.45\end{array}$ & .025 & .025 & $.20 / 0.35$ & - & $\begin{array}{r}.90 / 1.15 \\
30 / 1.60\end{array}$ & $\ldots$ & \\
\hline L 02100 & 52100 & $.95 / 1.10$ & $.20 / 0.40$ & & .025 & $.20 / 0.35$ & - & $1.30 / 1.60)$ & $\cdots$ & - \\
\hline 6118 & 6118 & $.16 / 0.21$ & $.50 / 0.70$ & .040 & .040 & $.20 / 0.35$ & & $.50 / 0.70$ & & $0.10 / 0.15$ \\
\hline 6120 & 6120 & $.17 / 0.22$ & $.70 / 0.90$ & .040 & .040 & $.20 / 0.35$ & & $.70 / 0.90$ & & $10 \mathrm{~min}$ \\
\hline 6150 & 6150 & $.48 / 0.53$ & $.70 / 0.90$ & .040 & .040 & $.20 / 0.35$ & & $.80 / 1.10$ & & $.15 \mathrm{~min}$ \\
\hline 8115 & 8115 & $.13 / 0.18$ & $.70 / 0.90$ & .040 & .040 & $.20 / 0.35$ & $0.20 / 0.40$ & $.30 / 0.50$ & $.08 / 0.15$ & \\
\hline 8615 & 8615 & $.13 / 0.18$ & $.70 / 0.90$ & .040 & .040 & $.20 / 0.35$ & $.40 / 0.70$ & $.40 / 0.60$ & $.15 / 0.25$ & \\
\hline 8617 & 8617 & $.15 / 0.20$ & $.70 / 0.90$ & .040 & .040 & $.20 / 0.35$ & $.40 / 0.70$ & $.40 / 0.60$ & $.15 / 0.25$ & \\
\hline 8621$)$ & 8620 & $.18 / 0.23$ & $.70 / 0.90$ & .040 & .040 & $.20 / 0.35$ & $.40 / 0.70$ & $.40 / 0.60$ & $.15 / 0.25$ & \\
\hline 8622 & 8622 & $.20 / 0.25$ & $.70 / 0.90$ & .040 & .040 & $.20 / 0.35$ & $.40 / 0.70$ & $.40 / 0.60$ & $.15 / 0.25$ & \\
\hline 8625 & 8625 & $.23 / 0.28$ & $.70 / 0.90$ & .040 & .040 & $.20 / 0.35$ & $.40 / 0.70$ & $.40 / 0.60$ & $.15 / 0.25$ & 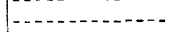 \\
\hline 8627 & 8627 & $.25 / 0.30$ & $.70 / 0.90$ & .040 & .040 & $.20 / 0.35$ & $.40 / 0.70$ & $.40 / 0.60$ & $.15 / 0.25$ & \\
\hline 8630 & 8630 & $.28 / 0.33$ & $.70 / 0.90$ & .040 & .040 & $.20 / 0.35$ & $.40 / 0.70$ & $.40 / 0.60$ & $.15 / 0.25$ & $\ldots$ \\
\hline 8637 & 8637 & $.35 / 0.40$ & $.75 / 1.00$ & .040 & .040 & $.20 / 0.35$ & $.40 / 0.70$ & $.40 / 0.60$ & $.15 / 0.25$ & $\ldots$ \\
\hline 8640 & 8640 & $.38 / 0.43$ & $.75 / 1.00$ & .040 & .040 & $.20 / 0.35$ & $.40 / 0.70$ & $.40 / 0.60$ & $.15 / 0.25$ & \\
\hline 8642 & 8642 & $.40 \% 0.45$ & $.75 / 1.00$ & .040 & .040 & $.20 / 0.35$ & $.40 / 0.70$ & $.40 / 0.60$ & $.15 / 0.25$ & - \\
\hline 8645 & 8645 & $.43 / 0.48$ & $.75 / 1.00$ & .040 & .040 & $.20 / 0.35$ & $.40 / 0.70$ & $.40 / 0.60$ & $.15 / 0.25$ & \\
\hline 8650 & 8650 & $.48 / 0.53$ & $.75 / 1.00$ & .040 & .040 & $.20 / 0.35$ & $.40 / 0.70$ & $.40 / 0.60$ & $.15 / 0.25$ & 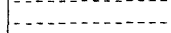 \\
\hline 8655 & 8655 & $.50 / 0.60$ & $.75 / 1.00$ & .040 & .040 & $.20 / 0.35$ & $.40 / 0.70$ & $.40 / 0.60$ & $.15 / 0.25$ & $\ldots$ \\
\hline 8660 & 8660 & $.55 / 0.65$ & $.75 / 1.00$ & .040 & .040 & $.20 / 0.35$ & $.40 / 0.70$ & $.40 / 0.60$ & $.15 / 0.25$ & \\
\hline
\end{tabular}

* Range.

See footuotes at end of table. 
TABLE 1. Composition limits of standard steels-Continued

OPEN HEARTH AND ELECTRIC FURNACE ALLOY STEELS --Continued

\begin{tabular}{|c|c|c|c|c|c|c|c|c|c|c|}
\hline \multicolumn{2}{|c|}{ Designation number } & \multicolumn{9}{|c|}{ Chemical composition limits, percent } \\
\hline AISI & SAE & $\mathbf{C}$ & Mn & $P(\max )$ & $S(\max )$ & $\mathrm{Si}$ & $\mathrm{Ni}$ & $\mathrm{Cr}$ & Mo & v \\
\hline $\begin{array}{l}8720 \\
8735 \\
8740 \\
8742\end{array}$ & $\begin{array}{l}8720 \\
8740 \\
8742\end{array}$ & $\begin{array}{r}0.18 / 0.23 \\
.33 / 0.38 \\
.38 / 0.43 \\
.40 / 0.45\end{array}$ & $\begin{array}{r}0.70 / 0.90 \\
.75 / 1.00 \\
.75 / 1.00 \\
.75 / 1.00\end{array}$ & $\begin{array}{r}0.040 \\
.040 \\
.040 \\
.040\end{array}$ & $\begin{array}{r}0.040 \\
.040 \\
.040 \\
.040\end{array}$ & $\begin{array}{r}0.20 / 0.35 \\
.20 / 0.35 \\
.20 / 0.35 \\
.20 / 0.35\end{array}$ & $\begin{array}{r}0.40 / 0.70 \\
.40 / 0.70 \\
.40 / 0.70 \\
.40 / 0.70\end{array}$ & $\begin{array}{r}0.40 / 0.60 \\
.40 / 0.60 \\
.40 / 0.60 \\
.40 / 0.60\end{array}$ & $\begin{array}{r}0.20 / 0.30 \\
.20 / 0.30 \\
.20 / 0.30 \\
.20 / 0.30\end{array}$ & - \\
\hline 8822 & 8822 & $.20 / 0.25$ & $.75 / 1.00$ & .040 & .040 & $.20 / 0.35$ & $.40 / 0.70$ & $.40 / 0.60$ & $.30 / 0.40$ & \\
\hline $\begin{array}{l}9255 \\
9260 \\
9262\end{array}$ & $\begin{array}{l}9255 \\
9260 \\
9262\end{array}$ & $\begin{array}{l}.50 / 0.60 \\
.55 / 0.65 \\
.55 / 0.65\end{array}$ & $\begin{array}{r}.70 / 0.95 \\
.70 / 1.00 \\
.75 / 1.00\end{array}$ & $\begin{array}{l}.040 \\
.040 \\
.040\end{array}$ & $\begin{array}{l}.040 \\
.040 \\
.040\end{array}$ & $\begin{array}{l}1.80 / 2.20 \\
1.80 / 2.20 \\
1.80 / 2.20\end{array}$ & 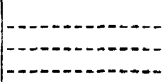 & $.25 / 0.40$ & (n) & \\
\hline E 9310 & 9310 & $.08 / 0.13$ & $.45 / 0.65$ & .025 & .025 & $0.20 / 0.35$ & $3.00 / 3.50$ & $1.00 / 1.40$ & $.08 / 0.15$ & \\
\hline $\begin{array}{l}9840 \\
9850\end{array}$ & $\begin{array}{l}9840 \\
9850\end{array}$ & $\begin{array}{l}.38 / 0.43 \\
.48 / 0.53\end{array}$ & $\begin{array}{l}.70 / 0.90 \\
.70 / 0.90\end{array}$ & $\begin{array}{l}.040 \\
.040\end{array}$ & $\begin{array}{l}.040 \\
.040\end{array}$ & $\begin{array}{l}.20 / 0.35 \\
.20 / 0.35\end{array}$ & $\begin{array}{r}0.85 / 1.15 \\
.85 / 1.15\end{array}$ & $\begin{array}{r}0.70 / 0.90 \\
.70 / 0.90\end{array}$ & $\begin{array}{l}.20 / 0.30 \\
.20 / 0.30\end{array}$ & \\
\hline
\end{tabular}

BORON STEELS •

These steels can be expected to have 0.0005 percent minimum boron content.

\begin{tabular}{|c|c|c|c|c|c|c|c|c|c|c|}
\hline \multicolumn{2}{|c|}{ Designation number } & \multicolumn{9}{|c|}{ Chemical composition limits, percent } \\
\hline AISI & SAE & $\mathbf{C}$ & Mn & $P(\max )$ & $S(\max )$ & Si & $\mathrm{Ni}$ & $\mathrm{Cr}$ & Mo & $\mathrm{V}$ \\
\hline $\begin{array}{l}50 \mathrm{~B} 40 \\
50 \mathrm{~B} 44 \\
50 \mathrm{~B} 46 \\
50 \mathrm{~B} 50 \\
50 \mathrm{~B} 60\end{array}$ & $\begin{array}{l}50 \mathrm{~B} 40 \\
50 \mathrm{~B} 44 \\
50 \mathrm{~B} 46 \\
50 \mathrm{~B} 50 \\
50 \mathrm{~B} 60\end{array}$ & $\begin{array}{r}0.38 / 0.43 \\
.43 / 0.48 \\
.43 / 0.50 \\
.48 / 0.53 \\
.55 / 0.65\end{array}$ & $\begin{array}{r}0.75 / 1.00 \\
.75 / 1.00 \\
.75 / 1.00 \\
.75 / 1.00 \\
.75 / 1.00\end{array}$ & $\begin{array}{r}0.040 \\
.040 \\
.040 \\
.040 \\
.040\end{array}$ & $\begin{array}{r}0.040 \\
.040 \\
.040 \\
.040 \\
.040\end{array}$ & $\begin{array}{r}0.20 / 0.35 \\
.20 / 0.35 \\
.20 / 0.35 \\
.20 / 0.35 \\
.20 / 0.35\end{array}$ & 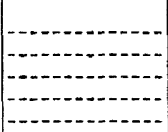 & $\begin{array}{r}0.40 / 0.60 \\
.40 / 0.60 \\
.20 / 0.35 \\
.40 / 0.60 \\
.40 / 0.60\end{array}$ & \begin{tabular}{l}
$-\cdots$ \\
\hdashline- \\
$-\cdots$
\end{tabular} & 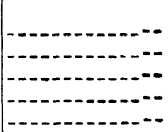 \\
\hline $51 \mathrm{~B} 60$ & $51 \mathrm{~B} 60$ & $.55 / 0.65$ & $.75 / 1.00$ & .040 & .040 & $.20 / 0.35$ & & $.70 / 0.90$ & & \\
\hline $81 \mathrm{~B} 45$ & $81 \mathrm{~B} 45$ & $.43 / 0.48$ & $.75 / 1.00$ & .040 & .040 & $.20 / 0.35$ & $0.20 / 0.40$ & $.35 / 0.55$ & $0.08 / 0.15$ & \\
\hline $86 \mathrm{~B} 45$ & $86 \mathrm{~B} 45$ & $.43 / 0.48$ & $.75 / 1.00$ & .040 & .040 & $.20 / 0.35$ & $.40 / 0.70$ & $.40 / 0.60$ & $.15 / 0.25$ & \\
\hline $\begin{array}{l}94 \mathrm{~B} 15 \\
94 \mathrm{~B} 17 \\
94 \mathrm{~B} 30 \\
94 \mathrm{~B} 40\end{array}$ & $\begin{array}{l}\text { 94B15 } \\
94 \mathrm{~B} 17 \\
\mathbf{9 4 B 3 0} \\
\mathbf{9 4 B 4 0}\end{array}$ & $\begin{array}{l}.13 / 0.18 \\
.15 / 0.20 \\
.28 / 0.33 \\
.38 / 0.43\end{array}$ & $\begin{array}{l}.75 / 1.00 \\
.75 / 1.00 \\
.75 / 1.00 \\
.75 / 1.00\end{array}$ & $\begin{array}{l}.040 \\
.040 \\
.040 \\
.040\end{array}$ & $\begin{array}{l}.040 \\
.040 \\
.040 \\
.040\end{array}$ & $\begin{array}{l}.20 / 0.35 \\
.20 / 0.35 \\
.20 / 0.35 \\
.20 / 0.35\end{array}$ & $\begin{array}{l}.30 / 0.60 \\
.30 / 0.60 \\
.30 / 0.60 \\
.30 / 0.60\end{array}$ & $\begin{array}{l}.30 / 0.50 \\
.30 / 0.50 \\
.30 / 0.50 \\
.30 / 0.50\end{array}$ & $\begin{array}{l}.08 / 0.15 \\
.08 / 0.15 \\
.08 / 0.15 \\
.08 / 0.15\end{array}$ & - \\
\hline
\end{tabular}

NITRIDING STEEL・

\begin{tabular}{|c|c|c|c|c|c|c|c|c|c|c|}
\hline \multicolumn{2}{|c|}{ Designation number } & \multicolumn{9}{|c|}{ Chemical composition ranges and limits, percent } \\
\hline AISI & SAE & $\mathbf{C}$ & Mn & $\mathbf{P}(\max )$ & $S(\max )$ & $\mathrm{Si}$ & Al & $\mathrm{Cr}$ & Mo & $\mathbf{v}$ \\
\hline - n & $\ldots$ & $0.38 / 0.43$ & $0.50 / 0.70$ & 0.040 & 0.040 & $0.20 / 0.40$ & $0.95 / 1.30$ & 1. $40 / 1.80$ & $0.30 / 0.40$ & \\
\hline
\end{tabular}

a Silicon: When silicon is required, the following ranges and limits are commonly used: Standard steel designations Silicon ranges or limits Up to $\mathrm{C} 1015$ excl .............. $0.10 \%$ max.

C 1015 to $C 1025$ incl Over C $1025 \ldots . . . . . .10 / 0.20 \%$ or $0.15 / 0.30 \%$

Copper: When required, copper is specified as an added element to a stand-

Lead: When required, lead is specified as an added element to a standard steel.

b Silicon: When silicon is required, the following ranges and limits are commonly used:

Standard steel designations Silicon ranges or limits

Up to $\mathrm{C} 1113$ excl.

C1113 and over.

Lead: When required, lead is specified as an added element to a standard steel.

- Silicon: Because of the technological nature of the process, acid bessemer steels are not produced with specified silicon content.

Lead: When required, lead is specified as an added element to a standard steel. d Silicon: It is not common practice to produce these steels to specified Lead: When required, lead is specified as an added element to a stand-
ard steel.

e Grades shown in the above list with prefix letter $\mathbf{E}$ generally are manufactured by the basic electric furnace process. All others are normally by the basic electric furnace process with adjustments in phosphorus and sulphur.

The phosphorus and sulphur limitations for each process are as follows: Basic electric furnace Acid electric furnace Minimum silicon limit for acid open hearth or acid electric furnace alloy steel is 0.15 percent.

Small quantities of certain elements are present in alloy steels which are not specified or required. These elements are considered as incidental and may, be present to the following maximum amounts: Copper, 0.35 percent; nickel 0.25 percent; chromium, 0.20 percent, and molybdenum, 0.06 percent.

Where minimum and maximum sulphur content is shown it is indicative of resulphurized steels. 
TABLE 2. Standard H-steels

OPEN MEARTH AND ELECTRIC FURNACE STEELS

\begin{tabular}{|c|c|c|c|c|c|c|c|c|}
\hline \multicolumn{2}{|c|}{ Designation number } & \multicolumn{7}{|c|}{ Chemical composition limits, percent } \\
\hline AISI & $S A E$ & $\mathrm{C}$ & $\mathbf{M n}_{n}$ & $\mathrm{Si}$ & $\mathrm{Ni}$ & $\mathrm{Cr}$ & Mo & $\boldsymbol{V}$ \\
\hline $\begin{array}{ll}1330 & \mathrm{H} \\
1335 & \mathrm{HI} \\
1340 & \mathrm{H}\end{array}$ & $\begin{array}{lll}1330 & \mathrm{IL} \\
1335 & \mathrm{H} \\
1340 & \mathrm{HI}\end{array}$ & $\begin{array}{r}0.27 / 0.33 \\
.32 / 0.38 \\
.37 / 0.44\end{array}$ & $\begin{array}{l}1.45 / 2.05 \\
1.45 / 2.05 \\
1.45 / 2.05\end{array}$ & $\begin{array}{r}0.20 / 0.35 \\
.20 / 0.35 \\
.20 / 0.35\end{array}$ & 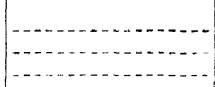 & - & & 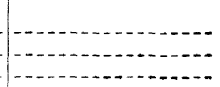 \\
\hline $3140 \mathrm{H}$ & $3140 \mathrm{H}$ & $.37 / 0.44$ & $0.60 / 1.00$ & $.20 / 0.35$ & $1.00 / 1.45$ & $0.45 / 0.85$ & & \\
\hline $3310 \mathrm{II}$ & $3310 \mathrm{II}$ & $.07 / 0.13$ & $.30 / 0.70$ & $.20 / 0.35$ & $3.20 / 3.80$ & $1.30 / 1.80$ & & \\
\hline $\begin{array}{rr}4027 & \mathrm{H} \\
4028 & \mathrm{H} \\
4037 & \mathrm{H} \\
4042 & \mathrm{H} \\
4047 & \mathrm{H} \\
4063 & \mathrm{HI}\end{array}$ & $\begin{array}{rr}4027 & \mathrm{HI} \\
40028 & \mathrm{II} \\
4037 & \mathrm{H} \\
4042 & \mathrm{H} \\
4047 & \mathrm{H} \\
4063 & \mathrm{HI}\end{array}$ & $\begin{array}{l}.24 / 0.30 \\
.24 / 0.30 \\
.34 / 0.41 \\
.39 / 0.46 \\
.44 / 0.51 \\
.59 / 0.69\end{array}$ & $\begin{array}{l}.60 / 1.00 \\
.60 / 1.00 \\
.60 / 1.00 \\
.60 / 1.00 \\
.60 / 1.00 \\
.65 / 1.10\end{array}$ & $\begin{array}{l}.20 / 0.35 \\
.20 / 0.35 \\
.20 / 0.35 \\
.20 / 0.35 \\
.20 / 0.35 \\
.20 / 0.35\end{array}$ & $\mid \begin{array}{c}\cdots \\
\cdots \\
\cdots \\
\cdots \\
\cdots\end{array}$ & $\begin{array}{c}\cdots- \\
\cdots- \\
\cdots\end{array}$ & $\begin{array}{r}0.20 / 0.30 \\
.20 / 0.30 \\
.20 / 0.30 \\
.20 / 0.30 \\
.20 / 0.30 \\
.20 / 0.30\end{array}$ & $\begin{array}{l}\ldots- \\
\cdots \\
\cdots \\
\cdots\end{array}$ \\
\hline $\begin{array}{ll}4118 & H \\
4130 & H \\
4135 & H \\
4137 & H \\
4140 & H \\
4142 & H \\
4145 & \text { II } \\
4147 & \text { II } \\
4150 & H\end{array}$ & $\begin{array}{ll}4118 & \mathrm{H} \\
4130 & \mathrm{HI} \\
4135 & \mathrm{II} \\
4137 & \mathrm{II} \\
4140 & \mathrm{H} \\
4142 & \mathrm{H} \\
4145 & \mathrm{II} \\
4147 & \mathrm{H} \\
4150 & \mathrm{HI}\end{array}$ & $\begin{array}{l}.17 / 0.23 \\
.270 .33 \\
.32 / 0.38 \\
.34 / 0.41 \\
.37 / 0.44 \\
.39 / 0.46 \\
.42 / 0.49 \\
.44 / 0.51 \\
.47 / 0.54\end{array}$ & $\begin{array}{l}.60 / 1.00 \\
.30 / 0.70 \\
.60 / 1.00 \\
.60 / 1.00 \\
.65 / 1.10 \\
.65 / 1.10 \\
.65 / 1.10 \\
.65 / 1.10 \\
.65 / 1.10\end{array}$ & $\begin{array}{l}.20 / 0.35 \\
.20 / 0.35 \\
.20 / 0.35 \\
.20 / 0.35 \\
.20 / 0.35 \\
.20 / 0.35 \\
.20 / 0.35 \\
.20 / 0.35 \\
.20 / 0.35\end{array}$ & $\begin{array}{l} \\
-1\end{array}$ & $\begin{array}{r}0.30 / 0.70 \\
.75 / 1.20 \\
.75 / 1.20 \\
.75 / 1.20 \\
.75 / 1.20 \\
.75 / 1.20 \\
.75 / 1.20 \\
.75 / 1.20 \\
.75 / 1.20\end{array}$ & $\begin{array}{l}.08 / 0.15 \\
.15 / 0.25 \\
.15 / 0.25 \\
.15 / 0.25 \\
.15 / 0.25 \\
.15 / 0.25 \\
.15 / 0.25 \\
.15 / 0.25 \\
.15 / 0.25\end{array}$ & 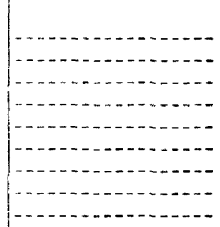 \\
\hline $\begin{array}{rr}4320 & \mathrm{H} \\
4337 & \mathrm{H} \\
4340 & \mathrm{H} \\
\mathrm{E} 4340 & \mathrm{II}\end{array}$ & $\begin{array}{rrr}4320 & \text { II } \\
4337 & \text { II } \\
4340 & \text { II } \\
\mathrm{E} 4340 & \text { II }\end{array}$ & $\begin{array}{l}.17 / 0.23 \\
.34 / 0.41 \\
.37 / 0.44 \\
.37 / 0.44\end{array}$ & $\begin{array}{l}.40 / 0.70 \\
.55 / 0.90 \\
.55 / 0.90 \\
.60 / 0.95\end{array}$ & $\begin{array}{l}.20 / 0.35 \\
.20 / 0.35 \\
.20 / 0.35 \\
.20 / 0.35\end{array}$ & $\begin{array}{l}1.55 / 2.00 \\
1.55 / 2.00 \\
1.55 / 2.00 \\
1.55 / 2.00\end{array}$ & $\begin{array}{l}.35 / 0.65 \\
.65 / 0.95 \\
.65 / 0.95 \\
.65 / 0.95\end{array}$ & $\begin{array}{l}.20 / 0.30 \\
.20 / 0.30 \\
.20 / 0.30 \\
.20 / 0.30\end{array}$ & $\begin{array}{l}-- \\
-- \\
--\end{array}$ \\
\hline $4520 \mathrm{HI}$ & $4520 \mathrm{HI}$ & $.17 / 0.23$ & $.35 / 0.75$ & $.20 / 0.35$ & & & $.45 / 0.60$ & \\
\hline $\begin{array}{ll}4620 & \text { HI } \\
4621 & \text { II }\end{array}$ & $\begin{array}{ll}4620 & \mathrm{II} \\
4621 & \mathrm{II}\end{array}$ & $\begin{array}{l}.17 / 0.23 \\
.17 / 0.23\end{array}$ & $\begin{array}{l}.35 / 0.75 \\
.60 / 1.00\end{array}$ & $\begin{array}{l}.20 / 0.35 \\
.20 / 0.35\end{array}$ & $\begin{array}{l}\text { 1. } 55 / 2.00 \\
1.55 / 2.00\end{array}$ & $\ldots$ & $\begin{array}{l}.20 / 0.30 \\
.20 / 0.30\end{array}$ & \\
\hline $\begin{array}{ll}4718 \mathrm{H} \\
4720 \mathrm{HI}\end{array}$ & $\begin{array}{ll}4718 & \mathrm{H} \\
4720 & \mathrm{HI}\end{array}$ & $\begin{array}{l}.15 / 0.21 \\
.17 / 0.23\end{array}$ & $\begin{array}{l}.60 / 0.95 \\
.45 / 0.75\end{array}$ & $\begin{array}{l}.20 / 0.35 \\
.20 / 0.35\end{array}$ & $\begin{array}{l}0.85 / 1.25 \\
0.85 / 1.25\end{array}$ & $\begin{array}{l}.30 / 0.60 \\
.30 / 0.60\end{array}$ & $\begin{array}{l}.30 / 0.40 \\
.15 / 0.25\end{array}$ & $\cdots$ \\
\hline $\begin{array}{ll}4815 & \mathrm{HI} \\
4817 & \mathrm{H} \\
4820 & \mathrm{II}\end{array}$ & $\begin{array}{ll}4815 & \mathrm{H} \\
4817 & \mathrm{HI} \\
4820 & \mathrm{HI}\end{array}$ & $\begin{array}{l}.12 / 0.18 \\
.14 / 0.20 \\
.17 / 0.23\end{array}$ & $\begin{array}{l}.30 / 0.70 \\
.30 / 0.70 \\
.40 / 0.80\end{array}$ & $\begin{array}{l}.20 / 0.35 \\
.20 / 0.35 \\
.20 / 0.35\end{array}$ & \begin{tabular}{l|} 
3. $20 / 3.80$ \\
3. $20 / 3.80$ \\
$3.20 / 3.80$
\end{tabular} & 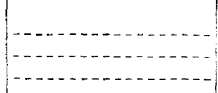 & $\begin{array}{l}.20 / 0.30 \\
.20 / 0.30 \\
.20 / 0.30\end{array}$ & $\begin{array}{l}-- \\
--\end{array}$ \\
\hline $5046 \mathrm{H}$ & $5046 \mathrm{H}$ & $.43 / 0.50$ & $.65 / 1.10$ & $.20 / 0.35$ & & $.13 / 0.43$ & & \\
\hline $\begin{array}{ll}5120 & \mathrm{H} \\
5130 & \mathrm{H} \\
5132 & \mathrm{H} \\
5135 & \mathrm{H} \\
5140 & \mathrm{H} \\
5145 & \mathrm{H} \\
5147 & \mathrm{H} \\
5150 & \mathrm{H} \\
5155 & \mathrm{H} \\
5160 & \mathrm{H}\end{array}$ & $\begin{array}{ll}5120 & \mathrm{H} \\
5130 & \mathrm{H} \\
5132 & \mathrm{H} \\
5135 & \mathrm{H} \\
5140 & \mathrm{H} \\
5145 & \mathrm{H} \\
5147 & \mathrm{H} \\
5150 & \mathrm{H} \\
5155 & \mathrm{H} \\
5160 & \mathrm{H}\end{array}$ & $\begin{array}{l}.17 / 0.23 \\
.27 / 0.33 \\
.29 / 0.35 \\
.32 / 0.38 \\
.37 / 0.44 \\
.42 / 0.49 \\
.45 / 0.52 \\
.47 / 0.54 \\
.50 / 0.60 \\
.55 / 0.65\end{array}$ & $\begin{array}{l}.60 / 1.00 \\
.60 / 1.00 \\
.50 / 0.90 \\
.50 / 0.90 \\
.60 / 1.00 \\
.60 / 1.00 \\
.60 / 1.05 \\
.60 / 1.00 \\
.60 / 1.00 \\
.65 / 1.10\end{array}$ & $\begin{array}{l}.20 / 0.35 \\
.20 / 0.35 \\
.20 / 0.35 \\
.20 / 0.35 \\
.20 / 0.35 \\
.20 / 0.35 \\
.20 / 0.35 \\
.20 / 0.35 \\
.20 / 0.35 \\
.20 / 0.35\end{array}$ & \begin{tabular}{|l|} 
\\
\hdashline-1
\end{tabular} \mid & $\begin{array}{l}.60 / 1.00 \\
.75 / 1.20 \\
.65 / 1.10 \\
.70 / 1.15 \\
.60 / 1.00 \\
.60 / 1.00 \\
.80 / 1.25 \\
.60 / 1.00 \\
.60 / 1.00 \\
.60 / 1.00\end{array}$ & 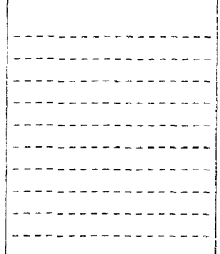 & $\begin{array}{l}-- \\
-- \\
- \\
- \\
- \\
\cdots \\
- \\
- \\
-\end{array}$ \\
\hline $\begin{array}{ll}6118 & \mathrm{H} \\
6120 & \mathrm{H} \\
6150 & \mathrm{H}\end{array}$ & $\begin{array}{ll}6118 & \mathrm{H} \\
6120 & \mathrm{H} \\
6150 & \mathrm{H}\end{array}$ & $\begin{array}{l}.15 / 0.21 \\
.17 / 0.23 \\
.47 / 0.54\end{array}$ & $\begin{array}{l}.40 / 0.80 \\
.60 / 1.00 \\
.60 / 1.00\end{array}$ & $\begin{array}{l}.20 / 0.35 \\
.20 / 0.35 \\
.20 / 0.35\end{array}$ & $\left|\begin{array}{l}\mid \\
\hdashline\end{array}\right|$ & $\begin{array}{l}.40 / 0.80 \\
.60 / 1.00 \\
.75 / 1.20\end{array}$ & & $\begin{array}{l}0.10 / 0.15 \\
.10 \mathrm{~min} . \\
.15 \mathrm{~min} .\end{array}$ \\
\hline $\begin{array}{ll}8617 & \mathrm{H} \\
8620 & \mathrm{H} \\
8622 & \mathrm{H} \\
8625 & \mathrm{H} \\
8627 & \mathrm{H} \\
8630 & \mathrm{H} \\
8637 & \mathrm{H} \\
8640 & \mathrm{H} \\
8642 & \mathrm{H} \\
8645 & \mathrm{H} \\
8650 & \mathrm{H} \\
8655 & \mathrm{H} \\
8660 & \mathrm{H}\end{array}$ & $\begin{array}{ll}8617 & \mathrm{H} \\
8620 & \mathrm{H} \\
8622 & \mathrm{H} \\
8625 & \mathrm{H} \\
8627 & \mathrm{H} \\
8630 & \mathrm{H} \\
8637 & \mathrm{H} \\
8640 & \mathrm{H} \\
8642 & \mathrm{H} \\
8645 & \mathrm{H} \\
8650 & \mathrm{H} \\
8655 & \mathrm{H} \\
8660 & \mathrm{H}\end{array}$ & $\begin{array}{l}.14 / 0.20 \\
.17 / 0.23 \\
.19 / 0.25 \\
.22 / 0.28 \\
.24 / 0.30 \\
.27 / 0.33 \\
.34 / 0.41 \\
.37 / 0.44 \\
.39 / 0.46 \\
.42 / 0.49 \\
.47 / 0.54 \\
.50 / 0.60 \\
.55 / 0.65\end{array}$ & $\begin{array}{l}.60 / 0.95 \\
.60 / 0.95 \\
.60 / 0.95 \\
.60 / 0.95 \\
.60 / 0.95 \\
.60 / 0.95 \\
.70 / 1.05 \\
.70 / 1.05 \\
.70 / 1.05 \\
.70 / 1.05 \\
.70 / 1.05 \\
.70 / 1.05 \\
.70 / 1.05\end{array}$ & $\begin{array}{l}.20 / 0.35 \\
.20 / 0.35 \\
.20 / 0.35 \\
.20 / 0.35 \\
.20 / 0.35 \\
.20 / 0.35 \\
.20 / 0.35 \\
.20 / 0.35 \\
.20 / 0.35 \\
.20 / 0.35 \\
.20 / 0.35 \\
.20 / 0.35 \\
.20 / 0.35\end{array}$ & $\begin{array}{l}0.35 / 0.75 \\
.35 / 0.75 \\
.35 / 0.75 \\
.35 / 0.75 \\
.35 / 0.65 \\
.35 / 0.75 \\
.35 / 0.75 \\
.35 / 0.75 \\
.35 / 0.75 \\
.35 / 0.75 \\
.35 / 0.75 \\
.35 / 0.75 \\
.35 / 0.75\end{array}$ & $\begin{array}{l}.35 / 0.65 \\
.35 / 0.65 \\
.35 / 0.65 \\
.35 / 0.65 \\
.35 / 0.65 \\
.35 / 0.65 \\
.35 / 0.65 \\
.35 / 0.65 \\
.35 / 0.65 \\
.35 / 0.65 \\
.35 / 0.65 \\
.35 / 0.65 \\
.35 / 0.65\end{array}$ & $\begin{array}{l}.15 / 0.25 \\
.15 / 0.25 \\
.15 / 0.25 \\
.15 / 0.25 \\
.15 / 0.25 \\
.15 / 0.25 \\
.15 / 0.25 \\
.15 / 0.25 \\
.15 / 0.25 \\
.15 / 0.25 \\
.15 / 0.25 \\
.15 / 0.25 \\
.15 / 0.25\end{array}$ & \begin{tabular}{l}
${ }^{\prime}$ \\
- \\
\hdashline
\end{tabular} \\
\hline $\begin{array}{l}8720 \mathrm{H} \\
8740 \mathrm{H} \\
8742 \mathrm{H}\end{array}$ & $\begin{array}{l}8720 \mathrm{H} \\
8740 \mathrm{H} \\
8742 \mathrm{H}\end{array}$ & $\begin{array}{l}.17 / 0.23 \\
.37 / 0.44 \\
.39 / 0.46\end{array}$ & $\begin{array}{l}.60 / 0.95 \\
.70 / 1.05 \\
.70 / 1.05\end{array}$ & $\begin{array}{l}.20 / 0.35 \\
.20 / 0.35 \\
.20 / 0.35\end{array}$ & $\begin{array}{l}.35 / 0.75 \\
.35 / 0.75 \\
.35 / 0.75\end{array}$ & $\begin{array}{l}.35 / 0.65 \\
.35 / 0.65 \\
.35 / 0.65\end{array}$ & $\begin{array}{l}.20 / 0.30 \\
.20 / 0.30 \\
.20 / 0.30\end{array}$ & $-\cdots$ \\
\hline $8822 \mathrm{H}$ & $8822 \mathrm{H}$ & $.19 / 0.25$ & $.70 / 1.05$ & $.20 / 0.35$ & $.35 / 0.75$ & $.35 / 0.65$ & $.30 / 0.40$ & \\
\hline $\begin{array}{ll}9260 & \mathrm{H} \\
9262 & \mathrm{H}\end{array}$ & $\begin{array}{ll}9260 & \mathrm{H} \\
9262 & \mathrm{H}\end{array}$ & $\begin{array}{l}.55 / 0.65 \\
.55 / 0.65\end{array}$ & $\begin{array}{l}.65 / 1.10 \\
.65 / 1.10\end{array}$ & $\begin{array}{l}1.70 / 2.20 \\
\text { 1. } 70 / 2.20\end{array}$ & & $.20 / 0.50$ & & \\
\hline $9310 \mathrm{H}$ & $9310 \mathrm{H}$ & $.07 / 0.13$ & $.40 / 0.70$ & $0.20 / 0.35$ & $2.95 / 3.55$ & $1.00 / 1.45$ & $.08 / 0.15$ & \\
\hline $\begin{array}{l}9840 \mathrm{H} \\
9850 \mathrm{H}\end{array}$ & $\begin{array}{l}9840 \mathrm{H} \\
9850 \mathrm{H}\end{array}$ & $\begin{array}{l}.37 / 0.44 \\
.47 / 0.54\end{array}$ & $\begin{array}{l}.60 / 0.95 \\
.60 / 0.95\end{array}$ & $\begin{array}{l}.20 / 0.35 \\
.20 / 0.35\end{array}$ & $\begin{array}{r}0.80 / 1.20 \\
.80 / 1.20\end{array}$ & $\begin{array}{r}0.65 / 0.95 \\
.65 / 0.95\end{array}$ & $\begin{array}{l}.20 / 0.30 \\
.20 / 0.30\end{array}$ & \\
\hline
\end{tabular}

See footnote at end of table. 
TABLE 2. Standard H-steels-Continued

BORON H-STEELS

These steels can be expected to have 0.0005 percent minimum boron content

\begin{tabular}{|c|c|c|c|c|c|c|c|c|}
\hline \multicolumn{2}{|c|}{ Designation number } & \multicolumn{7}{|c|}{ Chemical composition limits, percent } \\
\hline AISI & $\mathrm{SAE}$ & $\mathrm{C}$ & $\mathrm{Mn}$ & Si & $\mathrm{Ni}$ & $\mathrm{Cr}$ & Mo & $V$ \\
\hline $\begin{array}{l}51 \mathrm{~B} 40 \mathrm{H} \\
50 \mathrm{~B} 44 \mathrm{H} \\
50 \mathrm{~B} 46 \mathrm{H} \\
50 \mathrm{~B} 50 \mathrm{H} \\
50 \mathrm{~B} 60 \mathrm{H}\end{array}$ & $\begin{array}{l}50 \mathrm{~B} 40 \mathrm{H} \\
50 \mathrm{~B} 44 \mathrm{H} \\
50 \mathrm{~B} 46 \mathrm{H} \\
50 \mathrm{~B} 50 \mathrm{H} \\
50 \mathrm{~B} 60 \mathrm{H}\end{array}$ & $\begin{array}{l}0.37 / 0.44 \\
.42 / 0.49 \\
.43 / 0.50 \\
.47 / 0.54 \\
.55 / 0.65\end{array}$ & $\begin{array}{l}0.65 / 1.10 \\
.65 / 1.10 \\
.65 / 1.10 \\
.65 / 1.10 \\
.65 / 1.10\end{array}$ & $\begin{array}{l}0.20 / 0.35 \\
.20 / 0.35 \\
.20 / 0.35 \\
.200 .35 \\
.20 / 0.35\end{array}$ & (1) & $\begin{array}{l}0.30 / 0.70 \\
.30 / 0.70 \\
.13 / 0.43 \\
.30 / 0.70 \\
.30 / 0.70\end{array}$ & $\mid \begin{array}{l}\cdots \\
\cdots \\
\cdots \\
\cdots\end{array}$ & -1 \\
\hline $51 \mathrm{~B} 60 \mathrm{H}$ & $51 \mathrm{~B} 60 \mathrm{H}$ & $.55 / 0.65$ & $.65 / 1.10$ & $.20 / 0.35$ & & $.60 / 1.00$ & & \\
\hline $81 \mathrm{~B} 45 \mathrm{HI}$ & $81 \mathrm{~B} 45 \mathrm{H}$ & $.42 / 0.49$ & $.70 / 1.05$ & $.20 / 0.35$ & $0.15 / 0.45$ & $.30 / 0.60$ & $0.08 / 0.15$ & \\
\hline $86 \mathrm{~B} 45 \mathrm{II}$ & $86 \mathrm{~B} 45 \mathrm{II}$ & $.42 / 0.49$ & $.70 / 1.05$ & $.20 / 0.35$ & $.35 / 0.75$ & $.35 / 0.65$ & $.15 / 0.25$ & \\
\hline $94 \mathrm{~B} 15 \mathrm{H}$ & $94 \mathrm{B15} \mathrm{H}$ & $.12 / 0.18$ & $.70 / 1.05$ & $.20 / 0.35$ & $.25 / 0.65$ & $.25 / 0.55$ & $.08 / 0.15$ & \\
\hline $94 \mathrm{~B} 17 \mathrm{HI}$ & $94 \mathrm{~B} 17 \mathrm{II}$ & $.14 / 0.20$ & $.70 / 1.05$ & $.20 / 0.35$ & $.25 / 0.65$ & $.25 / 0.55$ & $.08 / 0.15$ & \\
\hline $94 \mathrm{~B} 30 \mathrm{H}$ & $94 \mathrm{B3} 0 \mathrm{II}$ & $.27 / 0.33$ & $.70 / 1.05$ & $.20 / 0.35$ & $.25 / 0.65$ & $.25 / 0.55$ & $.08 / 0.15$ & \\
\hline $94 \mathrm{~B} 40 \mathrm{H}$ & $94 \mathrm{~B} 40 \mathrm{H}$ & $.37 / 0.44$ & $.70 / 1.05$ & $.20 / 0.35$ & $.25 / 0.65$ & $.25 / 0.55$ & $.08 / 0.15$ & \\
\hline
\end{tabular}

*Sulphur content $0.035 / 0.050$ percent

The phosphorus and sulphur limitations for each steelmaking process are as follows:

Basic electric furnace ............... 0.025 percent maximum

Basic open hearth..................... 040 percent maximum

Acid electric furnace............. 0.050 percent maximum

Acid open hearth .................

\subsection{Tool Steels}

Technically, any steel used as a tool may be termed a tool steel. Practically, however, the term is restricted to steels of special composition that are usually melted in electric furnaces and manufactured expressly for certain types of services.

The current commonly used tool steels have been classified by the American Iron and Steel Institute into six major groups and each commonly accepted group or subgroup has been assigned an alphabetical letter. Methods of quenching, applications, special characteristics, and steels for particular industries were considered in this type classification of tool steels which is as follows:

\section{Group}

Water hardening W

Symbol and type

Shock resisting ... $\mathrm{S}$

Cold work $\ldots \ldots-\left\{\begin{array}{l}\text { O-Oil hardening } \\ \text { A-Medium alloy } \\ \text { D-High carbon-high chromium }\end{array}\right.$

Hot work........ $\mathrm{H}-(\mathrm{H} 1$ to $\mathrm{H} 19$ incl. chromium base, $\mathrm{H} 20$ to $\mathrm{H} 39$ incl. tungsten base, $\mathrm{H} 40$ to $\mathrm{H} \quad 59$ incl. molybdenum base)

High speed..... $\left\{\begin{array}{l}\mathrm{T}-\text { Tungsten base } \\ \mathrm{M}-\text { Molybdenum base }\end{array}\right.$

Special purpose $--\left\{\begin{array}{l}\text { L-Low alloy } \\ \text { F-Carbon tungsten } \\ \text { P-Mold steels }\left(P_{1} 1 \text { to } P 19 \text { incl. }\right.\end{array}\right.$ low carbon, $\mathrm{P} 20$ to $\mathrm{P} 39$ incl. other types)

The AISI identification and type classification of tool steels is given in table 3. Each major group, identified by a letter symbol, may contain
Minimum silicon limit for acid open hearth or acid electric furnace alloy steel is 0.15 percent

Small quantities of certain elements are present in alloy steels which are not specified or required. These elements are considered as incidental and may be present to the following maximum amounts: Copper, 0.35 percent nickel, 0.25 percent; chromium, 0.20 percent; and molybdenum, 0.06 percent.
$\mathrm{T}_{\mathrm{ABLE}}$ 3.-Identification and type classification of tool steels

\begin{tabular}{l|c|c|c|c|c|c|c|c|c}
\hline \hline $\begin{array}{c}\text { Desig- } \\
\text { nation } \\
\text { IISI }\end{array}$ & $\mathrm{C}$ & $\mathrm{Mn}$ & $\mathrm{Si}$ & $\mathrm{Cr}$ & $\mathrm{Ni}_{\mathrm{i}}$ & $\mathrm{V}$ & $\mathrm{w}$ & $\mathrm{Mo}$ & $\mathrm{Co}$ \\
\hline
\end{tabular}

WATER HARDENING

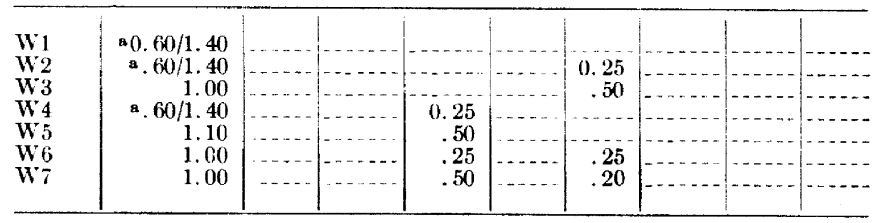

SHOCK RESISTING

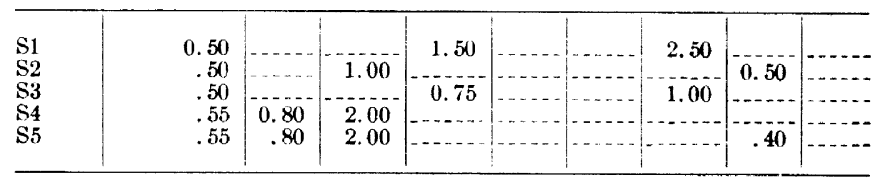

COLD WORK; OIL HARDENING

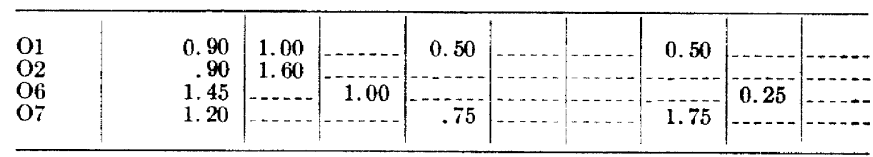

COLD WORK; MEDICM ALLOY AIR HARDENING

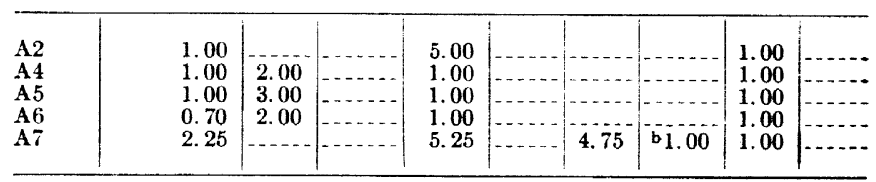

See footnotes at end of table. 
TABLE 3. Identification and type classification of tool steels-Continued

\begin{tabular}{|c|c|c|c|c|c|c|c|c|c|}
\hline \multirow{2}{*}{$\begin{array}{c}\text { Desig- } \\
\text { nation } \\
\text { AISI }\end{array}$} & \multicolumn{9}{|c|}{ Identifying elements, percent } \\
\hline & $\mathbf{C}$ & $\mathrm{Mn}$ & $\mathrm{Si}$ & $\mathrm{Cr}$ & $\mathrm{Ni}$ & $\mathbf{v}$ & w & Mo & Co \\
\hline \multicolumn{10}{|c|}{ COLD WORK; HIGH CARBON-HIGH CHROMIUM } \\
\hline $\begin{array}{l}\text { D1 } \\
\text { D2 } \\
\text { D3 } \\
\text { D4 } \\
\text { D5 } \\
\text { D6 } \\
\text { D7 }\end{array}$ & $\begin{array}{l}1.0 \\
1.5 \\
2.2 \\
2.25 \\
1.50 \\
2.22 \\
2.35\end{array}$ & $\ldots$ & 1.00 & $\begin{array}{l}12.00 \\
12.00 \\
12.00 \\
12.00 \\
12.00 \\
12.00 \\
12.00\end{array}$ & & 4.00 & 1.00 & \begin{tabular}{c}
1.00 \\
1.00 \\
\hdashline 1.00 \\
1.00 \\
1.00
\end{tabular} & 3.00 \\
\hline \multicolumn{10}{|c|}{ HOT WORK; CHROMIUM BASE } \\
\hline $\begin{array}{l}\mathrm{H} 11 \\
\mathrm{H} 12 \\
\mathrm{H} 13 \\
\mathrm{H} 14 \\
\mathrm{H} 15 \\
\mathrm{H} 16\end{array}$ & $\begin{array}{r}0.35 \\
.35 \\
.35 \\
.40 \\
.40 \\
.55\end{array}$ & & [ & $\begin{array}{l}5.00 \\
5.00 \\
5.00 \\
5.00 \\
5.00 \\
7.00\end{array}$ & $\ldots$ & $\begin{array}{r}0.40 \\
.40 \\
1.00\end{array}$ & $\begin{array}{r}1.50 \\
5.00 \\
7.00\end{array}$ & \begin{tabular}{|l|}
1.50 \\
1.50 \\
1.50 \\
5.00 \\
\end{tabular} & \\
\hline \multicolumn{10}{|c|}{ HOT WORK; TUNGSTEN BASE } \\
\hline $\begin{array}{l}\mathrm{H} 23 \\
\mathrm{H} 24 \\
\mathrm{H} 25 \\
\mathrm{H} 26\end{array}$ & $\begin{array}{r}0.35 \\
.35 \\
.35 \\
.30 \\
.45 \\
.25 \\
.50\end{array}$ & & ר. & $\begin{array}{r}2.00 \\
3.50 \\
2.00 \\
12.00 \\
3.00 \\
4.00 \\
4.00\end{array}$ & & 1.00 & $\begin{array}{r}9.00 \\
9.00 \\
11.00 \\
12.00 \\
15.00 \\
15.00 \\
18.00\end{array}$ & &.- \\
\hline
\end{tabular}

HOT WORK; MOLYBDENUM BASE

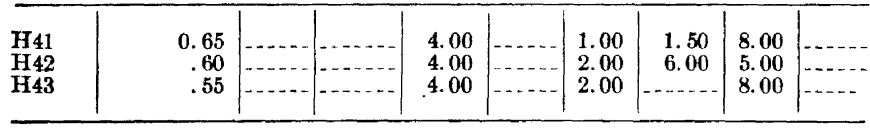

HIGH SPEED; TUNGSTEN BASE

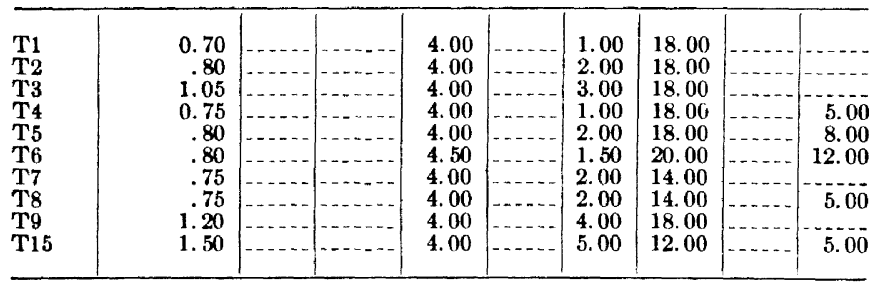

a number of individual types that are identified by a suffix number following the letter symbol. The percentages of the elements shown in the table for each type are not to be considered as the mean of the composition ranges of the elements. Steels of the same type, manufactured by various producers, may differ in analysis from the values listed and may contain elements not listed in the type identification.

\subsection{Stainless and Heat Resisting Steels}

The stainless and heat resisting steels possess relatively high resistance to oxidation and to attack by corrosive media at room and elevated temperatures and they are produced to cover wide ranges in mechanical and physical properties. They are melted exclusively by the electric furnace process.

A three-numeral system is used to identify stainless and heat resisting steels by type and according to four general classes. The first digit indicates the class and last two digits indicate

\begin{tabular}{|c|c|c|c|c|c|c|c|c|c|}
\hline \multirow{2}{*}{$\begin{array}{c}\text { Desig- } \\
\text { nation } \\
\text { AISI }\end{array}$} & \multicolumn{9}{|c|}{ ldentifying elements, percent } \\
\hline & $\mathrm{C}$ & Mn & $\mathrm{Si}$ & $\mathrm{Cr}$ & $\mathrm{Ni}$ & $\mathbf{v}$ & $\mathbf{w}$ & Mo & Co \\
\hline \multicolumn{10}{|c|}{ HIGH SPEED; MOLYBDENUM BASE } \\
\hline $\begin{array}{l}\text { M1 } \\
\text { M2 } \\
\text { M3 } \\
\text { M4 } \\
\text { M6 } \\
\text { M7 } \\
\text { M8 } \\
\text { M10 } \\
\text { M15 } \\
\text { M30 } \\
\text { M33 } \\
\text { M34 } \\
\text { M35 } \\
\text { M36 }\end{array}$ & $\begin{array}{r}0.80 \\
.80 \\
1.00 \\
1.30 \\
0.80 \\
1.00 \\
0.80 \\
.85 \\
1.50 \\
0.80 \\
.90 \\
.90 \\
.80 \\
.80\end{array}$ & \begin{tabular}{|c|}
$-\ldots$. \\
\hdashline \\
\hdashline
\end{tabular} & \begin{tabular}{|c} 
\\
\\
\end{tabular} & $\begin{array}{l}4.00 \\
4.00 \\
4.00 \\
4.00 \\
4.00 \\
4.00 \\
4.00 \\
4.00 \\
4.00 \\
4.00 \\
3.75 \\
4.00 \\
4.00 \\
4.00\end{array}$ & \begin{tabular}{|c}
{$[-\cdots$} \\
\\
\hdashline
\end{tabular} & $\begin{array}{l}1.00 \\
2.00 \\
2.70 \\
4.00 \\
1.50 \\
2.00 \\
1.50 \\
2.00 \\
5.00 \\
1.25 \\
1.15 \\
2.00 \\
2.00 \\
2.00\end{array}$ & $\begin{array}{l}1.50 \\
6.00 \\
6.00 \\
5.50 \\
4.00 \\
1.75 \\
5.00 \\
6.50 \\
2.00 \\
1.50 \\
2.00 \\
6.00 \\
6.00\end{array}$ & $\begin{array}{l}8.00 \\
5.00 \\
5.00 \\
4.50 \\
5.00 \\
8.75 \\
5.00 \\
8.00 \\
3.50 \\
8.00 \\
9.50 \\
8.00 \\
5.00 \\
5.00\end{array}$ & $\begin{array}{l}12.00 \\
5.00 \\
5.00 \\
8.00 \\
5.00 \\
8.00\end{array}$ \\
\hline \multicolumn{10}{|c|}{ SPECIAL PURPOSE; LOW ALLOY } \\
\hline $\begin{array}{l}\text { L1 } \\
\text { L2 } \\
\text { L3 } \\
\text { L4 } \\
\text { L5 } \\
\text { L6 } \\
\text { L7 }\end{array}$ & $\begin{array}{r}1.00 \\
80.50 / 1.10 \\
1.00 \\
1.00 \\
1.00 \\
0.70 \\
1.00\end{array}$ & $\begin{array}{l}0.60 \\
1.00 \\
0.35\end{array}$ & & $\begin{array}{l}1.25 \\
1.00 \\
1.50 \\
1.50 \\
1.00 \\
0.75 \\
1.40\end{array}$ & 1.50 & $\begin{array}{r}0.20 \\
.20 \\
.25 \\
\hdashline \\
\hdashline\end{array}$ & & $\begin{array}{r}0.25 \\
\text { b. } 25 \\
.40\end{array}$ & \\
\hline \multicolumn{10}{|c|}{ SPECIAL PURPOSE; CARBON TUNGSTEN } \\
\hline $\begin{array}{l}\text { F1 } \\
\text { F2 } \\
\text { F3 }\end{array}$ & $\begin{array}{l}1.00 \\
1.25 \\
1.25\end{array}$ & & & 0.75 & & & $\begin{array}{l}1.25 \\
3.50 \\
3.50\end{array}$ & & \\
\hline \multicolumn{10}{|c|}{ SPECIAL PURPOSE: MOLD } \\
\hline $\begin{array}{l}\text { P1 } \\
\text { P2 } \\
\text { P3 } \\
\text { P4 } \\
\text { P5 } \\
\text { P6 }\end{array}$ & $\begin{array}{r}0.10 \\
.07 \\
.10 \\
.07 \\
.10 \\
.10\end{array}$ & $\cdots$ & & $\begin{array}{l}2.00 \\
0.60 \\
5.00 \\
2.25 \\
1.50\end{array}$ & \begin{tabular}{|c|}
0.50 \\
1.25 \\
3.50 \\
\end{tabular} & & & 0.20 & \\
\hline \multicolumn{10}{|c|}{ SPECIAL PURPOSE; } \\
\hline P20 & 0.30 & & & 0.75 & & & & 0.25 & \\
\hline
\end{tabular}

s Varying carbon contents may be available.

b. Cb, $1.25 \%$.

type. Modification of types are indicated by suffix letters. The meaning of this AISI system is as follows:

Series

2xx....... Chromium-nickel-manganese steels; nonhardenable, austenitic and nonmagnetic

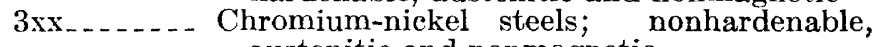
austenitic and nonmagnetic

$4 \mathrm{xx} . . . . .$. Chromium steels; hardenable, martensitic and magnetic

$4 \mathrm{xx}$....... Chromium steels; nonhardenable, ferritic and magnetic

$5 \mathrm{xx} \ldots . . . .$. Chromium steels; low chromium heat resisting.

The chemical composition ranges and limits of the standard stainless and heat resisting steels are given in table 4 .

\section{Recommended Heat Treatments}

\subsection{Structural Steels}

A listing of recommended heat treatments for many of the steels listed in tables 1 and 2 are given in tables 5 and 6 . Treatments for the standard 


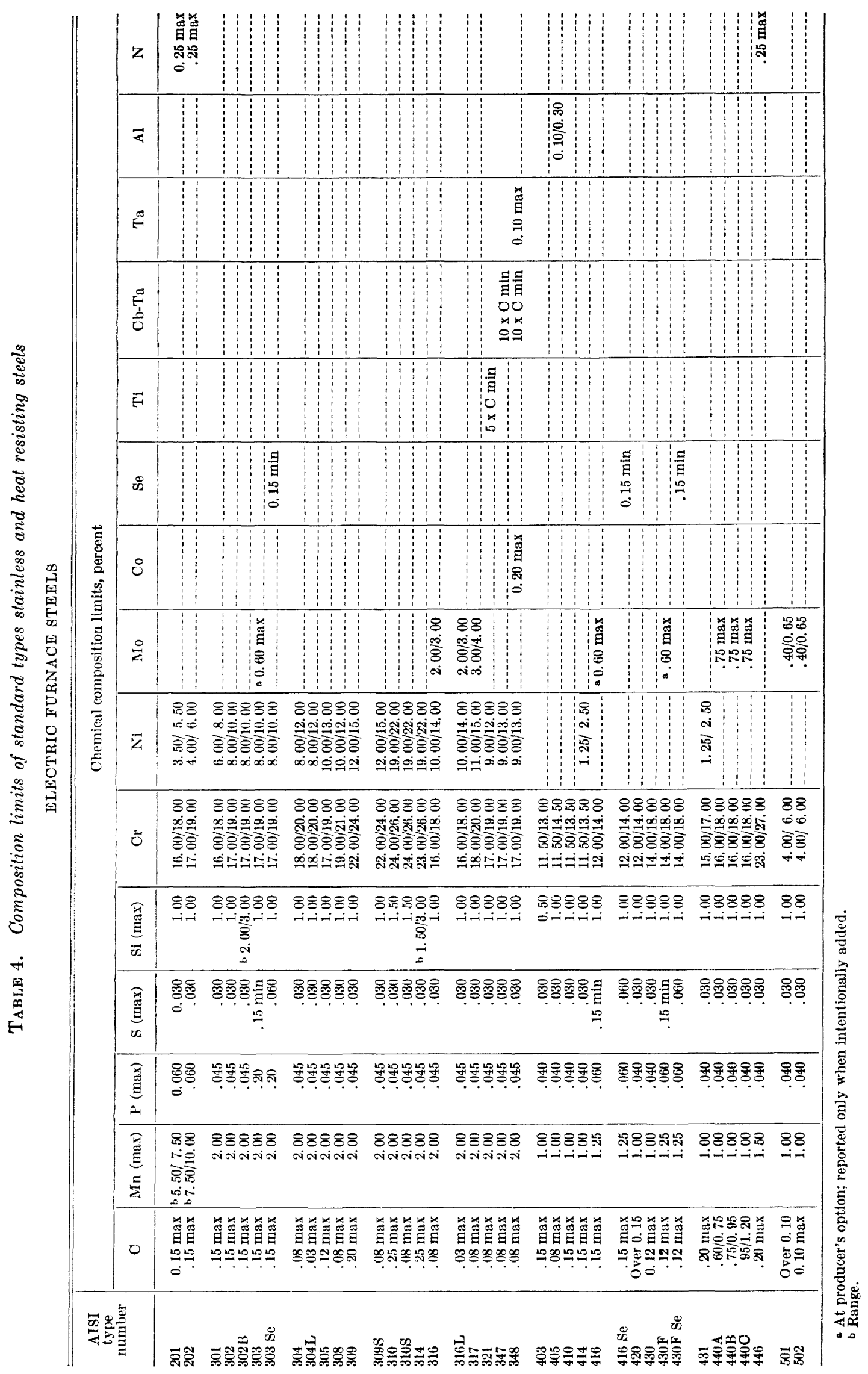


TABLE 5. Recommended heat treatments for carburizing grade steels

\begin{tabular}{|c|c|c|c|c|c|c|c|}
\hline AISI or SAE number & $\begin{array}{l}\text { Carburizing } \\
\text { temperature }\end{array}$ & Cooling method & Reheat & Cooling medium & $2 d$ reheat & Cooling medium & $\begin{array}{l}\text { Tempering } \\
\text { temperature }\end{array}$ \\
\hline \multirow{3}{*}{1008 to $1024 ; 1108$ to $1120 ; 1211$ to 1214 . } & ${ }^{\circ} F$ & & ${ }^{\circ} F$ & & $\circ F$ & & ${ }^{\circ} F$ \\
\hline & \multirow[t]{2}{*}{$1,650 / 1,700$} & \multirow{2}{*}{$\begin{array}{l}\text { Brine or water } \\
\text { Water or oil } \\
\text { Cool slowly } \\
\ldots \text { do }\end{array}$} & $\begin{array}{l}1,400 / 1,450 \\
1,400 / 1,450\end{array}$ & Brine or water & & & \multirow[t]{2}{*}{$250 / 300$} \\
\hline & & & $1,650 / 1,700$ & Water or oil. & $1,400 / 1,450$ & Brine or w & \\
\hline $3310 \ldots$ & $1,650 / 1,700$ & $\left\{\begin{array}{l}\text { Oil } \\
\text { Cool slowly } \\
\ldots . . . \text { do }\end{array}\right.$ & $\begin{array}{l}1,375 / 1,425 \\
1,375 / 1,425 \\
1,525 / 1,575\end{array}$ & Oil do. & $1,375 / 1,425$ & Oil & $250 / 300$ \\
\hline 4012 to $4024 ; 4118$ & $1,650 / 1,700$ & $\left\{\begin{array}{l}\text { Oil } \\
\text { Cool slowly }\end{array}\right.$ & $\begin{array}{l}1,425 / 1,475 \\
1,425 / 1,475\end{array}$ & & & & $250 / 300$ \\
\hline \multirow[b]{2}{*}{4422 and $4427 ; 8822$} & & Oil & $1,600 / 1,650$ & do..... & $1,425 / 1,475$ & Oil_ & \\
\hline & $1,650 / 1,700$ & $\left\{\begin{array}{l}\text { Cool slowly } \\
\text { do do }\end{array}\right.$ & $\begin{array}{l}1,450 / 1,500 \\
1,450 / 1,500 \\
1,625 / 1,675\end{array}$ & Oil do & $1,450 / 1,500$ & Oil & $250 / 300$ \\
\hline $4520 \ldots \ldots+n$ & $1,650 / 1,700$ & $\left\{\begin{array}{l}\text { Oil } \\
\text { Cool slowly }\end{array}\right.$ & $\begin{array}{l}1,475 / 1,525 \\
1,475 / 1,525 \\
1,650 / 1,700\end{array}$ & Oil $\mathrm{do}^{-}$ & -47511525 & & $250 / 300$ \\
\hline \multirow[t]{2}{*}{$4320 ; 4615$ to $4621 ; 4718$ and 4720} & \multirow[t]{2}{*}{$1,650 / 1,700$} & $\left\{\begin{array}{l}\mathrm{Oil} \\
\mathrm{Cool} \text { slowly }\end{array}\right.$ & $\begin{array}{l}1,425 / 1,475 \\
1,375 / 1,425\end{array}$ & Oil do. & & & \multirow[t]{2}{*}{$250 / 300$} \\
\hline & & 1.... do ...... & $1,525 / 1,575$ & $\ldots d o_{-}$ & $1,375 / 1,425$ & Oil.- & \\
\hline \multirow[t]{2}{*}{4815 to 4820} & \multirow[t]{2}{*}{$1,650 / 1,700$} & $\left\{\begin{array}{l}\text { Oil } \\
\text { Cool slowly }\end{array}\right.$ & $\begin{array}{l}1,350 / 1,400 \\
1,350 / 1,400\end{array}$ & Oil $\mathrm{do}$ & & & \multirow[t]{2}{*}{$250 / 300$} \\
\hline & & L.... do & $1,550 / 1,600$ & $\ldots$ do & $1,350 / 1,400$ & Oil & \\
\hline $5015 ; 5115$ and $5120 \ldots$ & $1,650 / 1,700$ & $\left\{\begin{array}{l}\text { Oil } \\
\text { Cool slow } \mathrm{dy}\end{array}\right.$ & $1,425 / 1,475$ & Oil do & -- & & $250 / 300$ \\
\hline \multirow{3}{*}{6118 and $6120 \ldots$} & \multirow{3}{*}{$1,650 / 1,700$} & (Oil & $1,600 / 1,650$ & ...... do & $1,425 / 1,475$ & Oil. & \\
\hline & & 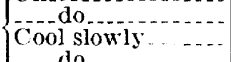 & $1,450 / 1,500$ & Oil or water. & & & \multirow[t]{2}{*}{$300 / 400$} \\
\hline & & (Oil & $1,600 / 1,650$ & Oil $\ldots . . .$. & $1,450 / 1,500$ & Oil or water & \\
\hline \multirow[t]{2}{*}{$\begin{array}{l}8115 ; 8615 \text { to } 8622 ; 8720 ; 8822 ; 9310 ; 94 \mathrm{~B} 15 \\
\text { and } 94 \mathrm{~B} 17 \text {. }\end{array}$} & $1,650 / 1,700$ & $\left\{\begin{array}{c}\text { Cool slowly } \\
\ldots\end{array}\right.$ & $1,450 / 1,500$ & Oil do & (1) & & \multirow[t]{2}{*}{$250 / 300$} \\
\hline & & & $1,550 / 1,600$ & $-\cdots$ & $1,450 / 1,500$ & & \\
\hline
\end{tabular}

TABLE 6. Recommended heat treatments for heat treating grade steels

(No tempering treatments are given, as these temperatures depend upon the desired hardness)

\begin{tabular}{|c|c|c|c|c|c|c|c|c|c|}
\hline $\begin{array}{l}\text { AISI or } \\
\text { SAE } \\
\text { number }\end{array}$ & $\begin{array}{l}\text { Normalizing } \\
\text { temperature }\end{array}$ & $\begin{array}{l}\text { Annealing } \\
\text { temperature }\end{array}$ & $\begin{array}{l}\text { Hardening } \\
\text { temperature }\end{array}$ & $\begin{array}{l}\text { Quenching } \\
\text { medium }\end{array}$ & $\begin{array}{c}\text { AISI or } \\
\text { SAE } \\
\text { number }\end{array}$ & $\begin{array}{l}\text { Normalizing } \\
\text { temperature }\end{array}$ & $\begin{array}{c}\text { Annealing } \\
\text { temperature }\end{array}$ & $\begin{array}{l}\text { Hardening } \\
\text { temperature }\end{array}$ & $\begin{array}{l}\text { Quenching } \\
\text { medium }\end{array}$ \\
\hline $\begin{array}{l}1030 \\
1040 \\
1050 \\
1060 \\
1070\end{array}$ & $\begin{array}{c}{ }^{\circ} F \\
1,625 / 1,725 \\
1,600 / 1,700 \\
1,550 / 1,650 \\
1,500 / 1,600 \\
1,500 / 1600\end{array}$ & $\begin{array}{c}{ }^{\circ} F \\
1,525 / 1,575 \\
1,475 / 1,525 \\
1,450 / 1,500 \\
1,425 / 1,475 \\
1,425 / 1,475\end{array}$ & $\begin{array}{c}{ }^{\circ} F \\
1,550 / 1,600 \\
1,500 / 1,550 \\
1,475 / 1,525 \\
1,450 / 1,500 \\
1,450 / 1,500\end{array}$ & $\begin{array}{l}\text { Water or brine. } \\
\text { Do. } \\
\text { Do. } \\
\text { Do. } \\
\text { Do. }\end{array}$ & $\begin{array}{r}5046 \\
5130 \\
5145 \\
5160 \\
50100\end{array}$ & $\begin{array}{c}{ }^{\circ} F \\
1,600 / 1,700 \\
1,600 / 1,7 C 0 \\
1,600 / 1,700 \\
1,600 / 1,700 \\
1,600 / 1,700\end{array}$ & $\begin{array}{c}{ }^{\circ} F \\
1,475 / 1,525 \\
1,500 / 1,550 \\
1,475 / 1,525 \\
1,450 / 1,500 \\
1,400 / 1,450\end{array}$ & $\begin{array}{c}{ }^{\circ} F \\
1,500 / 1,550 \\
1,550 / 1,600 \\
1,525 / 1,575 \\
1,500 / 1,550 \\
1,450 / 1,500\end{array}$ & $\begin{array}{l}\text { Oil. } \\
\text { Oil or water. } \\
\text { Oil. } \\
\text { Do. } \\
\text { Do. }\end{array}$ \\
\hline $\begin{array}{l}1080 \\
1090 \\
1132 \\
1140 \\
1151\end{array}$ & $\begin{array}{l}1,475 / 1,575 \\
1,475 / 1,575 \\
1,625 / 1,725 \\
1,600 / 1,700 \\
1,550 / 1,650\end{array}$ & $\begin{array}{l}1,375 / 1,425 \\
1,375 / 1,425 \\
1,525 / 1,575 \\
1,475 / 1,525 \\
1,450 / 1,500\end{array}$ & $\begin{array}{l}1,400 / 1,450 \\
1,400 / 1,450 \\
1,550 / 1,600 \\
1,500 / 1,550 \\
1,475 / 1,525\end{array}$ & $\begin{array}{l}\text { Do. } \\
\text { Do. } \\
\text { Do. } \\
\text { Do. } \\
\text { Do. }\end{array}$ & $\begin{array}{r}51100 \\
52100 \\
6150 \\
8630 \\
8645\end{array}$ & $\begin{array}{l}1,600 / 1,700 \\
1,600 / 1,700 \\
1,600 / 1,700 \\
1,600 / 1,700 \\
1,600 / 1,700\end{array}$ & $\begin{array}{l}1,400 / 1,450 \\
1,400 / 1,450 \\
1,500 / 1,550 \\
1,500 / 1,550 \\
1,475 / 1,525\end{array}$ & $\begin{array}{l}1,475 / 1,525 \\
1,500 / 1,550 \\
1,550 / 1,600 \\
1,525 / 1,575 \\
1,500 / 1,550\end{array}$ & $\begin{array}{l}\text { Do. } \\
\text { Do. } \\
\text { Do. } \\
\text { Do. } \\
\text { Do. }\end{array}$ \\
\hline $\begin{array}{l}1330 \\
1340 \\
3140 \\
4028 \\
4042\end{array}$ & $\begin{array}{l}1,600 / 1,700 \\
1,550 / 1,650 \\
1,550 / 1,650 \\
1,600 / 1,700 \\
1,550 / 1,650\end{array}$ & $\begin{array}{l}1,500 / 1,550 \\
1,475 / 1,525 \\
1,475 / 1,525 \\
1,525 / 1,575 \\
1,475 / 1,525\end{array}$ & $\begin{array}{l}1,525 / 1,575 \\
1,500 / 1,550 \\
1,475 / 1,525 \\
1,550 / 1,600 \\
1,500 / 1,550\end{array}$ & $\begin{array}{l}\text { Oil or water. } \\
\text { Do. } \\
\text { Oil. } \\
\text { Oil or water. } \\
\text { Oil. }\end{array}$ & $\begin{array}{l}8660 \\
8735 \\
8742 \\
9260 \\
9840\end{array}$ & $\begin{array}{l}1,600 / 1,700 \\
1,600 / 1,700 \\
1,600 / 1,700 \\
1,600 / 1,760 \\
1,600 / 1,700\end{array}$ & $\begin{array}{l}1,450 / 1,500 \\
1,500 / 1,550 \\
1,500 / 1,550 \\
1,500 / 1,550 \\
1,475 / 1,525\end{array}$ & $\begin{array}{l}1,475 / 1,525 \\
1,525 / 1,575 \\
1,525 / 1,575 \\
1,550 / 1,600 \\
1,500 / 1,550\end{array}$ & $\begin{array}{l}\text { Do. } \\
\text { Do. } \\
\text { Do. } \\
\text { Do. } \\
\text { Do. }\end{array}$ \\
\hline $\begin{array}{l}4063 \\
4130 \\
4140 \\
4150 \\
4340\end{array}$ & $\begin{array}{l}1,550 / 1,650 \\
1,600 / 1,700 \\
1,600 / 1,700 \\
1,600 / 1,700 \\
1,600 / 1,700\end{array}$ & $\begin{array}{l}1,450 / 1,500 \\
1,525 / 1,555 \\
1,500 / 1,550 \\
1,475 / 1,525 \\
1,500 / 1,550\end{array}$ & $\begin{array}{l}1,475 / 1,525 \\
1,550 / 1,600 \\
1,525 / 1,575 \\
1,500 / 1,550 \\
1,500 / 1,550\end{array}$ & $\begin{array}{l}\text { Do. } \\
\text { Oil or water. } \\
\text { Oil. } \\
\text { Do. } \\
\text { Do. }\end{array}$ & 9850 & & & & \\
\hline
\end{tabular}

steels that are omitted can be estimated by interpolation (also see fig. 11). Where different quenching media are suggested, the smaller sec- tions may harden satisfactorily in the slower quenching medium. The upper end of the heat treating ranges should always be used for large 
size sections. The inclusion of normalizing and annealing temperatures does not imply that these treatments are necessarily a prelude to hardening.

For hardening, the general rule is to place the cold steel in a furnace containing a slightly oxidizing atmosphere or neutral salt bath at the hardening temperature and let it heat naturally, hold $1 / 2$ $\mathrm{hr}$ /in of thickness, and then quench; it is sometimes advisable to warm intricate sections or complex shapes before putting them into the high temperature unit and to remove from the quenching medium while still warm. Usually, the quenched piece should be allowed to cool until it can be comfortably held in the bare hand and then immediately tempered. To minimize cracking, it is sometimes desirable to temper the quenched piece before it reaches room temperature; a double temper (i.e., repeating the treatment) is recommended for this condition.

For carburizing, most of the steels may be given either (1) a single, (2) double, or (3) triple treatment as is indicated in table 5. The time at the carburizing temperature will vary depending upon the temperature used and the desired thickness of the case. The relation between time, temperature and case depth is illustrated in figure 19.

\subsection{Tool Steels}

Recommended heat treatments for the different types of tool steels are summarized in table 7 .

The time the steel is at the normalizing temperature, after being heated uniformly through, varies from about $15 \mathrm{~min}$ for a small section to about 1 $\mathrm{hr}$ for large sizes; cooling from the normalizing temperature is in still air. For annealing, the upper range in temperature is recommended for large and the lower limit for small sections. The time the steel is at the annealing temperature, after being heated uniformly through, ranges from about $1 \mathrm{hr}$ for thin sections of carbon or low alloy to about $4 \mathrm{hr}$ for heavy sections of high alloy steel. Cooling from the annealing temperature through the transformation range should not exceed about $75^{\circ} \mathrm{F} / \mathrm{hr}$ for the carbon and low alloy and $50^{\circ} \mathrm{F} / \mathrm{hr}$ for the high alloy steels.

For hardening, the protective atmosphere, rate of heating, hardening temperature, time at temperature, and rate of cooling vary with the composition of the steels. A general rule is to heat the plain carbon and low alloy steels rapidly in a furnace having a slightly oxidizing atmosphere or in a neutral salt bath at the hardening temperature, hold $1 / 2 \mathrm{hr} /$ in of thickness, and then quench. The high alloy steels, such as the $\mathrm{T}$ and $\mathrm{M}$ types, are usually preheated to minimize distortion and cracking and then heated rapidly in a furnace containing a highly carburizing atmosphere or in a molten bath at the hardening temperature, held at temperature for time as indicated in the table, and then quenched. Tools should be tempered immediately after quenching; a double temper is recommended for the high alloy steels.
The carburizing steels (type P) may be (1) quenched directly from the carburizing temperature; (2) quenched directly from the carburizing temperature followed by quenching from the recommended hardening temperature; (3) slowly cooled from the carburizing temperature followed by quenching from the recommended hardening temperature; or (4) slowly cooled from the carburizing temperature, reheated to the carburizing temperature and quenched, followed by reheating to and quenching from the recommended hardening temperature. For most purposes, method (3) is generally suitable. Tempering should follow in all cases.

\subsection{Stainless and Heat Resisting Steels}

The response of stainless and heat resisting steels to heat treatment depends upon their composition. The general methods employed are similar to those used with other steels and no special equipment is needed. Heat treatment may be performed in any conventional electric, gas fired, oil fired, salt bath, or induction furnace in which the required temperatures can be obtained. Precautions should be taken to avoid exposure of the steel to the direct flame of the burners. Conditions that will result in carburization of the surface of the steel should be avoided. In general, oxidizing furnace atmospheres are preferred. Bright, scale-free heat treatment is possible by the use of specially prepared and controlled atmospheres.

The stainless steels may be divided into three general groups as follows:

\section{a. Group I-Hardenable Chromium Steels (Martensitic and Magnetic)}

These steels respond to heat treatment in a manner similar to most lower alloy steels and will, by suitable thermal treatment, develop a wide range of mechanical properties. The tempering range of $700^{\circ}$ to $1000^{\circ} \mathrm{F}$. should be avoided because it is conducive to increased brittleness.

\section{b. Group II-Nonhardenable Chromium Steels (Fer- ritic and Magnetic)}

These steels are essentially nonhardenable by heat treatment. They develop their maximum softness, ductility and corrosion resistance in the annealed condition.

\section{c. Group III-Nonhardenable Chromium-Nickel and Chromium-Nickel-Manganese Steels (Austenitic and Nonmagnetic)}

These steels are essentially nonmagnetic and cannot be hardened by heat treatment. Cold working develops a wide range of mechanical properties and some of these steels, in the severely cold worked condition, may become slightly magnetic. They are annealed by rapidly cooling (air or water) from high temperatures to develop maximum softness and ductility as well as corrosion resistance.

Recommended heat treatments for the steels listed in table 4 are given in table 8 . 
TABLE 7. Recommended heat treatments for tool steels

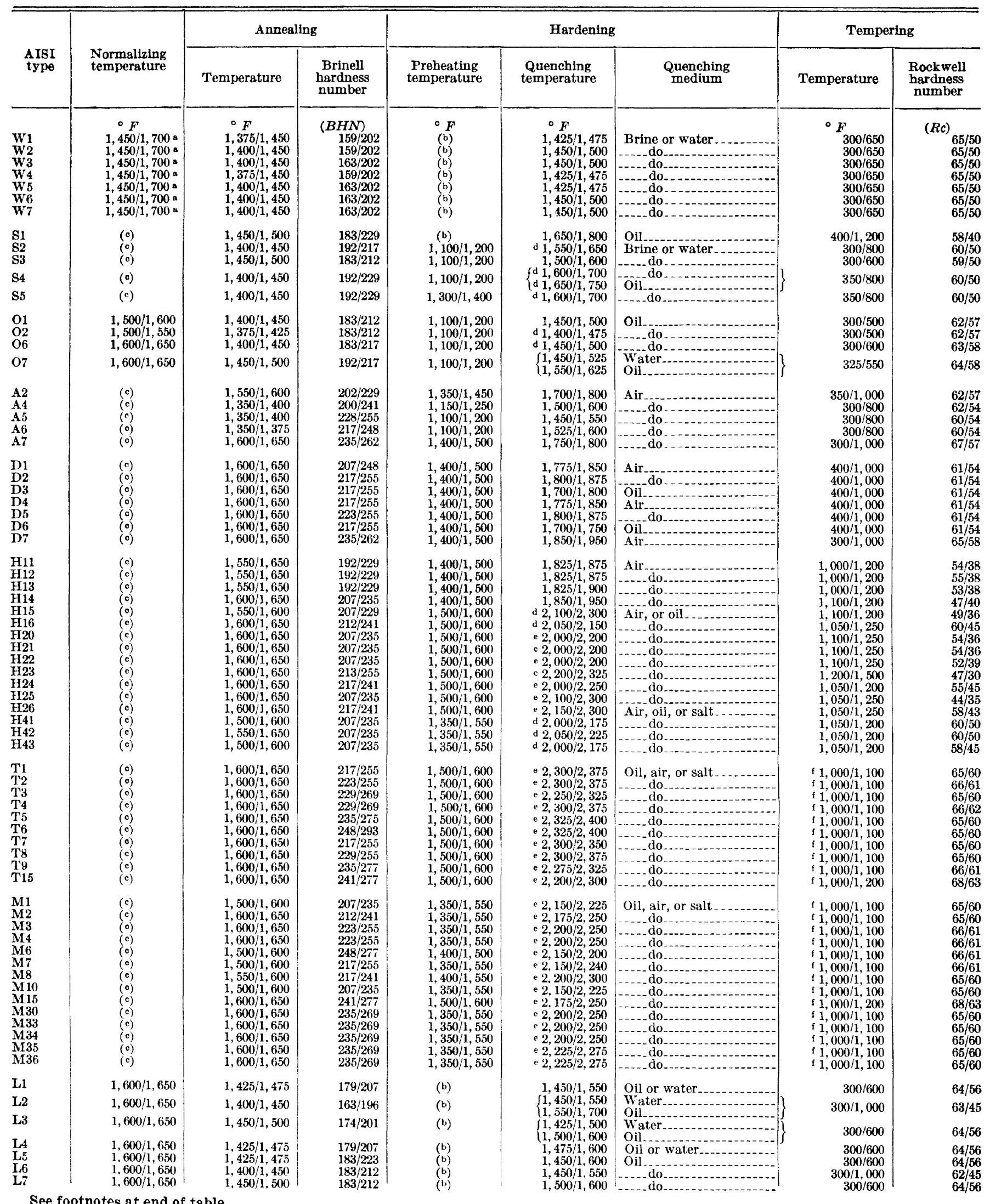


TABLE 7. Recommended heat treatments for tool steels-Continued

\begin{tabular}{|c|c|c|c|c|c|c|c|c|}
\hline \multirow[b]{2}{*}{$\begin{array}{l}\text { AISI } \\
\text { type }\end{array}$} & \multirow[b]{2}{*}{$\begin{array}{l}\text { Normalizing } \\
\text { temperature }\end{array}$} & \multicolumn{2}{|c|}{ Annealing } & \multicolumn{3}{|c|}{ Hardening } & \multicolumn{2}{|c|}{ Tempering } \\
\hline & & Temperature & $\begin{array}{c}\text { Brinell } \\
\text { hardness } \\
\text { number }\end{array}$ & $\begin{array}{c}\text { Preheating } \\
\text { temperature }\end{array}$ & $\begin{array}{l}\text { Quenching } \\
\text { temperature }\end{array}$ & $\begin{array}{c}\text { Quenching } \\
\text { medium }\end{array}$ & Temperature & $\begin{array}{l}\text { Rockwell } \\
\text { hardness } \\
\text { number }\end{array}$ \\
\hline $\begin{array}{l}\text { F1 } \\
\text { F2 } \\
\text { F3 }\end{array}$ & $\begin{array}{l}{ }^{\circ} F \\
1,600 / 1,650 \\
1,600 / 1,650 \\
1,600 / 1,650\end{array}$ & $\begin{array}{l}{ }^{\circ} F \\
1,400 / 1,475 \\
1,450 / 1,500 \\
1,450 / 1,500\end{array}$ & $\begin{array}{l}(B H N) \\
183 / 207 \\
207 / 235 \\
212 / 248\end{array}$ & $\begin{array}{l}{ }^{\circ} F \\
1,100 / 1,200 \\
1,100 / 1,200 \\
1,100 / 1,200\end{array}$ & $\begin{array}{l}\stackrel{\circ}{F} \\
1,500 / 1,600 \\
1,500 / 1,600 \\
1,500 / 1,600\end{array}$ & $\begin{array}{l}\text { Water or brine } \\
\text { Water, brine, or oil.... }\end{array}$ & $\begin{aligned} &{ }^{\circ} F \\
& 300 / 500 \\
& 300 / 500 \\
& 300 / 500\end{aligned}$ & 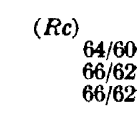 \\
\hline
\end{tabular}

CARBURIZING GRADES

\begin{tabular}{|c|c|c|c|c|c|c|c|c|}
\hline \multirow{2}{*}{$\begin{array}{c}\text { AISI } \\
\text { type }\end{array}$} & \multirow{2}{*}{$\begin{array}{l}\text { Normalizing } \\
\text { temperature }\end{array}$} & \multicolumn{2}{|c|}{ Annealing } & \multirow{2}{*}{$\begin{array}{l}\text { Carburizing } \\
\text { temperature }\end{array}$} & \multicolumn{2}{|c|}{ Hardening } & \multicolumn{2}{|c|}{ Tempering } \\
\hline & & Temperature & Hardness & & Temperature & Quenching medium & Temperature & Rc of case \\
\hline $\begin{array}{l}\text { P1 } \\
\text { P2 } \\
\text { P3 } \\
\text { P4 } \\
\text { P5 } \\
\text { P6 } \\
\text { P20 }\end{array}$ & $\begin{array}{l}\circ F \\
(\mathrm{~g}) \\
(\mathrm{g}) \\
(\mathrm{g}) \\
(\mathrm{c}) \\
(\mathrm{g}) \\
(\mathrm{g}) \\
1625 \text { to } 1675\end{array}$ & $\begin{array}{l}{ }^{\circ} F \\
1,350 / 1,650 \\
1,350 / 1,500 \\
1,350 / 1,500 \\
1,600 / 1,650 \\
1,550 / 1,600 \\
1,550 / 1,600 \\
1,400 / 1,450\end{array}$ & $\begin{array}{c}(B H N) \\
81 / 100 \\
103 / 123 \\
109 / 137 \\
116 / 128 \\
105 / 110 \\
190 / 210 \\
150 / 180\end{array}$ & $\begin{array}{l}{ }^{\circ} F \\
1,650 / 1,700 \\
1,650 / 1,700 \\
1,650 / 1,700 \\
1,775 / 1,825 \\
1,650 / 1,700 \\
1,650 / 1,700 \\
1,600 / 1,650\end{array}$ & $\begin{array}{c}{ }^{\circ} F \\
1,450 / 1,475 \\
1,525 / 1,550 \\
1,475 / 1,525 \\
1,755 / 1,825 \\
1,550 / 1,600 \\
1,450 / 1,500 \\
1,500 / 1,600\end{array}$ & $\begin{array}{l}\text { Water or brine } \\
\text { Oil } \\
\text { Air or water } \\
\text { Oil }\end{array}$ & $\begin{array}{l}{ }^{\circ} F \\
300 / 500 \\
300 / 500 \\
300 / 500 \\
300 / 500 \\
300 / 500 \\
300 / 450 \\
300 / 500\end{array}$ & $\begin{array}{l}64 / 58 \\
64 / 58 \\
64 / 58 \\
64 / 58 \\
64 / 58 \\
61 / 58 \\
64 / 58\end{array}$ \\
\hline
\end{tabular}

a Normalizing:

0.60 to $0.75 \% \mathrm{C}, 1500^{\circ} \mathrm{F}$;

.75 to $.90 \% \mathrm{C}, 1450^{\circ} \mathrm{F}$

1.10 to $1.40 \% \mathrm{C}, 1600^{\circ}$ to $1700^{\circ} \mathrm{F}$

b Preheating not necessary.

c Do not normalize.

Time at hardening temperature, 2 to $5 \mathrm{~min}$.

Double' tempering recommended.

Normalizing not required.

TABLE 8. Recommended heat treatments for stainless and heat resisting steels

GROUP I. HARDENABLE CIROMIUM STEELS (MARTENSITIC AND MAGNETIC)

\begin{tabular}{|c|c|c|c|c|c|c|c|c|}
\hline \multirow{2}{*}{$\begin{array}{l}\text { AISI } \\
\text { type }\end{array}$} & \multicolumn{2}{|c|}{ Annealing a } & \multicolumn{2}{|c|}{ Hardening b } & \multicolumn{2}{|c|}{ Stress relicving } & \multicolumn{2}{|c|}{ Tempering } \\
\hline & Temperature & Hardness & Temperature & Hardness & Temperature & Hardness & Temperature & Mardness \\
\hline $\begin{array}{l}403 \\
410 \\
414 \\
416 \\
416 \mathrm{Se} \\
420 \\
431 \\
440 \mathrm{~A} \\
440 \mathrm{~B} \\
440 \mathrm{C} \\
501 \\
502\end{array}$ & $\begin{array}{c}\circ \bar{F} \\
1,550 / 1,650 \\
1,550 / 1,650 \\
\mathrm{1}, 200 / 1,300 \\
1,550 / 1,650 \\
1,550 / 1,650 \\
1,600 / 1,650 \\
\mathrm{1}, 150 / 1.225 \\
1,625 / 1,675 \\
1,625 / 1,675 \\
1,625 / 1,675 \\
1,525 / 1,600 \\
1,525 / 1,600\end{array}$ & $\begin{array}{r}75 / 83 \mathrm{R}_{\mathrm{B}} \\
75 / 85 \mathrm{R}_{\mathrm{B}} \\
98 \mathrm{R}_{\mathrm{B}} / 24 \mathrm{R}_{\mathrm{c}} \\
78 / 83 \mathrm{R}_{\mathrm{B}} \\
80 / 90 \mathrm{R}_{\mathrm{B}} \\
81 / 89 \mathrm{R}_{\mathrm{B}} \\
97 \mathrm{R}_{\mathrm{B}} / 24 \mathrm{R}_{\mathrm{c}} \\
91 / 95 \mathrm{R}_{\mathrm{B}} \\
94 / 98 \mathrm{R}_{\mathrm{B}} \\
95 / 99 \mathrm{R}_{\mathrm{B}} \\
80 / 90 \mathrm{R}_{\mathrm{B}} \\
72 / 80 \mathrm{R}_{\mathrm{B}}\end{array}$ & $\begin{array}{l}{ }^{\circ} F \\
1,700 / 1,850 \\
1,700 / 1,850 \\
1,800 / 1,950 \\
1,700 / 1,850 \\
1,700 / 1,850 \\
1,800 / 1,900 \\
1,800 / 1,950 \\
1,850 / 1.950 \\
1,850 / 1,950 \\
1,850 / 1,950 \\
1,600 / 1,700 \\
\text { (d) }\end{array}$ & $\begin{array}{l}39 / 43 \mathrm{R}_{\mathrm{c}} \\
39 / 43 \mathrm{R}_{\mathrm{c}} \\
42 / 47 \mathrm{R}_{\mathrm{c}} \\
40 / 44 \mathrm{R}_{\mathrm{c}} \\
39 / 43 \mathrm{R}_{\mathrm{c}} \\
53 / 56 \mathrm{R}_{\mathrm{c}} \\
42 / 46 \mathrm{R}_{\mathrm{c}} \\
55 / 58 \mathrm{R}_{\mathrm{c}} \\
57 / 59 \mathrm{R}_{\mathrm{c}} \\
60 / 62 \mathrm{R}_{\mathrm{c}} \\
35 / 45 \mathrm{R}_{\mathrm{c}}\end{array}$ & $\begin{array}{l}0 \% \\
450 / 700 \\
450 / 700 \\
450 / 700 \\
450 / 700 \\
450 / 700 \\
300 / 700 \\
450 / 700 \\
300 / 700 \\
300 / 700 \\
300 / 700\end{array}$ & $\begin{array}{l}40 / 37 \mathrm{R}_{\mathrm{c}} \\
40 / 37 \mathrm{R}_{\mathrm{c}} \\
44 / 40 \mathrm{R}_{\mathrm{c}} \\
40 / 37 \mathrm{R}_{\mathrm{c}} \\
40 / 37 \mathrm{R}_{\mathrm{c}} \\
53 / 48 \mathrm{R}_{\mathrm{c}} \\
42 / 36 \mathrm{R}_{\mathrm{c}} \\
56 / 51 \mathrm{R}_{\mathrm{c}} \\
58 / 53 \mathrm{R}_{\mathrm{c}} \\
60 / 55 \mathrm{R}_{\mathrm{c}}\end{array}$ & $\begin{array}{l}{ }^{\circ} F \\
1,000 / 1,400 \\
1,000 / 1,400 \\
1.100 / 1,300 \\
1,000 / 1,400 \\
1,000 / 1,400 \\
1.000 / 1,200\end{array}$ & $\begin{array}{r}34 \mathrm{R}_{\mathrm{c}} / 86 \mathrm{R}_{\mathrm{I}} \\
34 \mathrm{R}_{\mathrm{c}} / 86 \mathrm{R}_{\mathrm{I}} \\
29 \mathrm{R}_{\mathrm{c}} / 99 \mathrm{R}_{\mathrm{I}} \\
34 \mathrm{R}_{\mathrm{c}} / 86 \mathrm{R}_{\mathrm{F}} \\
34 \mathrm{R}_{\mathrm{c}} / 86 \mathrm{R}_{\mathrm{I}} \\
35 \mathrm{R}_{\mathrm{c}} / 90 \mathrm{R}_{\mathrm{I}} \\
45 / 25 \mathrm{P}\end{array}$ \\
\hline
\end{tabular}

GROUP II. NONHARDENABLE CHROMIUM STEELS (FERRITIC AND MAGNETIC)

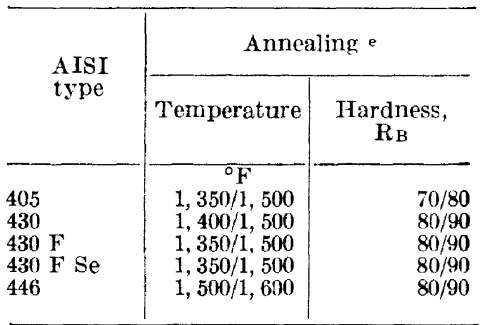

GROUP III. NONHARDENABLE CHROMIYM-NICKEI AND CHROMICM-NICKEL-MAYGANESE STEELS (ACSTEXITIC AND NONMAGNETIC)

\begin{tabular}{l|l||l|l}
\hline $\begin{array}{c}\text { AISI } \\
\text { type }\end{array}$ & $\begin{array}{c}\text { Annealing } \\
\text { temperature f }\end{array}$ & $\begin{array}{c}\text { A ISI } \\
\text { type }\end{array}$ & $\begin{array}{c}\text { Annealing } \\
\text { temperature }\end{array}$ \\
\hline 201 & $1,850 / 2,050$ & 309 & $1,909 / 2,050$ \\
202 & $1,850 / 2,050$ & $309 \mathrm{~S}$ & $1,900 / 2,050$ \\
301 & $1,850 / 2,050$ & 310 & $1,900 / 2,150$ \\
302 & $1,850 / 2,050$ & $310 \mathrm{~S}$ & $1,900 / 2,050$ \\
$302 \mathrm{~B}$ & $1,850 / 2,050$ & 314 & $2,000 / 2,100$ \\
303 & $1,850 / 2,050$ & 316 & $1,859 / 2,050$ \\
$303 \mathrm{Se}$ & $1,850 / 2,050$ & $316 \mathrm{~L}$ & $1,850 / 2,050$ \\
304 & $1,850 / 2,050$ & 317 & $1,850 / 2,050$ \\
$304 \mathrm{~L}$ & $1,850 / 2,050$ & 321 & $1,750 / 1,950$ \\
305 & $1,850 / 2,050$ & 347 & $1,850 / 1,950$ \\
308 & $1,850 / 2,050$ & 348 & $1,850 / 1,950$ \\
\hline
\end{tabular}

- Cool slowly to $1,100^{\circ} \mathrm{F}$

b Although these steels harden appreciably on air cooling, quenching in oil is preferable.

- Full annealing impractical; may be air cooled from indicated temperature.

d Generally used in annealed condition only.

- Air cool.

Cooling may be in air or by quenching in water. The resultant hardness of all of these steels will be in the range of approximately Rockell B 80 to 90 . 


\section{Properties and Uses of Steels}

\subsection{Structural Steels}

The strength properties of heat treated (quenched and tempered) structural carbon and alloy steels are closely related to their hardness and are surprisingly similar for a selected hardness provided that the steels originally were hardened throughout their cross sections. The relation of tensile strength, yield strength, elongation, and reduction of area to hardness is shown in figure 27. The tempering temperatures necessary to secure certain hardness levels in steels are affected by alloying elements, and two different steels may have to be tempered at two different temperatures to secure the same hardness. When this has been accomplished, however, the strength and ductility of the two steels will be quite similar. It must be emphasized that these relationships are valid only if the heat treated structures are tempered martensite. A steel that has been incompletely hardened (that is, quenched at too slow a rate to prevent the formation of some fine pearlite) may have, after tempering, a hardness and tensile strength equal to that of a completely hardened and tempered steel, but its yield strength and ductility will be inferior.
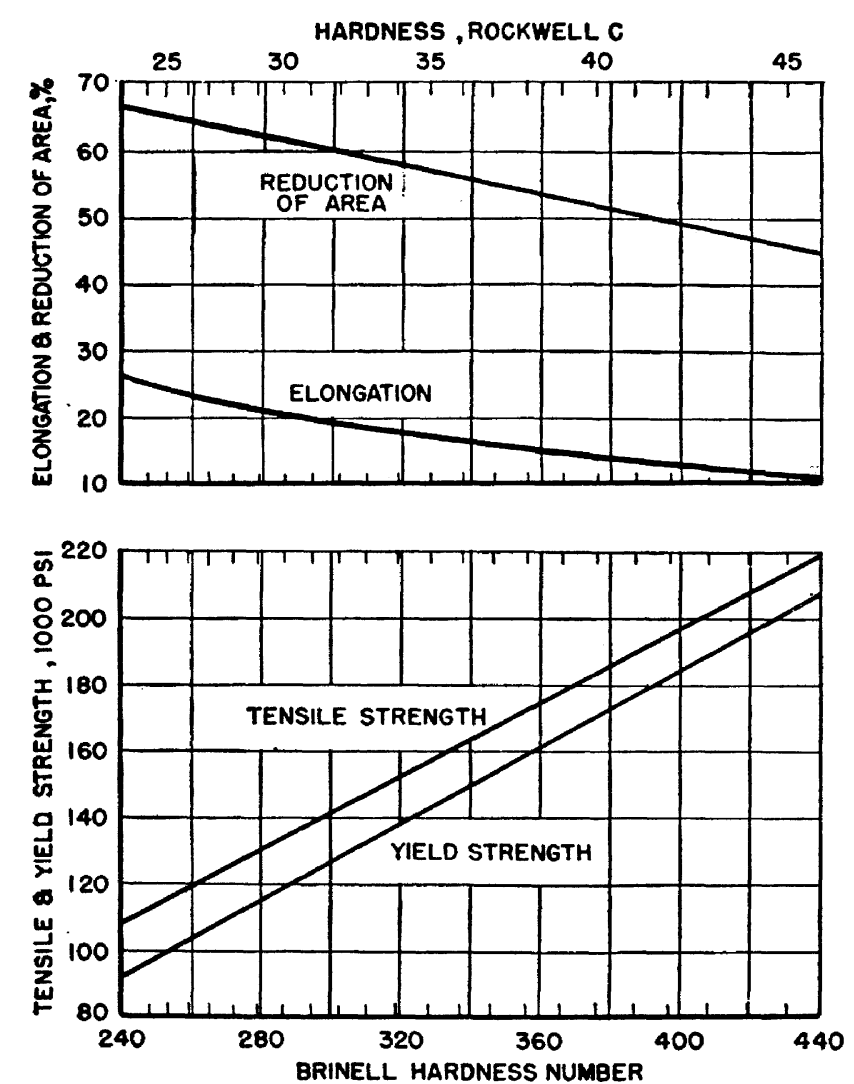

FIGURE 27. Tensile strength, yield strength, elongation, and reduction of area as a function of hardness in structural steels.

Valid only for steels originally hardened throughout and then tempered. Although drawn as lines. the relationship between these properties is not exact, and some deviations may be expected.
The modulus of elasticity of steel is the same as that of iron (about $29,000,000 \mathrm{lb} / \mathrm{in}^{2}$ ). It is not affected by heat treatment or by the addition of alloying elements. Since stiffness, or the resistance to deformation under load, is a function of the modulus of elasticity, it follows that the stiffness of steel cannot be changed by heat treatment or by alloying elements, provided that the total stress is below the elastic limit of the steel in question. Either heat treatment or alloying elements can raise the elastic limit and thus apparently improve the stiffness in that higher allowable unit stresses may be imposed on the steel.

\section{a. Plain Carbon Structural Steels}

The plain carbon steels are the least costly and may be used for a variety of purposes. The lower carbon grades (up to about $0.25 \%$ of carbon), frequently termed machinery steels, are used in the hot- and cold-worked conditions and for carburizing. Except when carburized, they are not very responsive to hardening by heat treatment because of the low carbon content. The medium carbon steels (about 0.30 to $0.60 \%$ ) are the forging grades and are commonly used in the heat-treated condition. The higher carbon grades are the spring and tool steels.

Carbon steels are essentially shallow-hardening, usually requiring a water or brine quench, although very small sections may be successfully hardened in oil. Even with the most drastic quench, they cannot be hardened throughout even in moderate (about $3 / 4$-in.) cross sections. Large cross sections (about 4 in.) cannot be fully hardened even on the surface except by induction or flame hardening.

\section{b. Alloy Structural Steels}

From the viewpoint of heat treatment, the advantages accruing from the use of alloy steels are threefold: (a) Increased hardenability, (b) retention of fine-grained austenite, and (c) retardation of softening during tempering.

All of the alloying elements commonly used in structural alloy steels are effective to varying degrees in displacing the $\mathbf{S}$-curve to the right as compared with plain carbon steels of similar carbon contents. Consequently, they can be hardened throughout in larger sections and, generally, by means of a milder quenching medium, such as oil. Because of the slower rates of quenching that can be employed in hardening these steels, they are less likely to distort or crack during hardening than the plain carbon steels.

The hardenability of alloy steels varies widely, depending on the composition. Certain elements and combinations of elements are very effective in increasing hardenability. Of the five alloying elements most generally used, and within the amounts normally present in the structural steels, nickel enhances hardenability but mildly, vanadium, chromium, manganese, and molybdenum moderately to strongly, depending upon the amount of alloy dissolved in the austenite at the 
hardening temperature. Combinations of chromium, nickel, and molybdenum, such as are present in the 4300 series (table 1), result in very deep hardening steels.

The alloying elements that form stable carbides, principally vanadium and molybdenum (and chromium to a lesser degree), are very effective in inhibiting grain growth in austenite. These steels may be overheated to a considerable degree during heating for hardening without suffering grain grow th. This is desirable since martensite formed from fine-grained austenite is tougher than that formed from coarse-grained austenite.

Alloying elements, particularly those that form the more stable carbides, tend to retard the softening effects of tempering so that alloy steels must frequently be tempered at higher temperatures than carbon steels in order to secure the same hardness. This is beneficial in conferring increased toughness, i.e., resistance to shock.

It is pertinent to note that manganese and nickel lower the annealing and hardening temperatures, and that chromium, molybdenum, and vanadium raise these temperatures. Combinations of these alloys may therefore, raise, lower, or have no effect on the heat-treating temperatures, depending on the combinations of elements and their amounts.

The low carbon (up to about $0.25 \%$ of carbon) alloy steels are used mainly as carburizing steels. The medium carbon (about 0.30 to $0.60 \%$ of carbon) alloy steels find wide use as stressed members in an almost infinite variety of structural parts. Although some of these alloy steels containing high carbon are used for certain special applications, the maximum amount of carbon present in the alloy structural steels is generally about 0.5 percent.

\subsection{Tool Steels}

Practical experience has shown that in a majority of instances the choice of a tool steel is not limited to a single type or even to a particular family for a working solution to an individual tooling problem. It is desirable to select the steel that will give the most economical overall performance; the tool life obtained with each steel under consideration should be judged by weighing such factors as expected productivity, ease of fabrication, and cost.

Hardness, strength, toughness, wear resistance, and resistance to softening by heat are prime factors that must be considered in selecting tool steel for general applications. Many other factors must be considered in individual applications; they include permissible distortion in hardening, permissible decarburization, hardenability, resistance to heat checking, machinability, grindability, and heat treating requirements.

The straight carbon tool steels can be used for a variety of purposes, depending upon the carbon content and heat treatment. The lower carbon ranges are used for tools where toughness and resistance to shock are of primary importance; these steels are usually tempered at temperatures of $500^{\circ}$ to $700^{\circ} \mathrm{F}$ or even higher. The higher carbon ranges are used where the main requirements are hardness, resistance to abrasion, or ability to hold a keen edge; these steels are usually tempered at temperatures of $300^{\circ}$ to $500^{\circ} \mathrm{F}$.

An addition of 0.20 to 0.50 percent of chromium or of vanadium is frequently made to the carbon tool steels. The chromium-bearing carbon steels have a greater depth of hardnening and are slightly more wear-resistant than the chromiumfree steels of the same carbon content. Vanadium decreases slightly the depth of hardening but increases toughness. (This may appear contradictory to previous statements that alloying elements increase hardenability. In the case of the carbon-vanadium tool steels, the normal hardening temperatures are too low to allow the solution of vanadium carbide in the austenite. The presence of undissolved carbides decreases hardenability).

The cutting ability, or the ability to hold an edge, is closely related to the hardness. For most purposes, therefore, cutting tools are used in a highly hardened condition. Excessive heat, whether caused by heavy cutting or careless grinding, will "draw the temper" (that is, decrease the hardness) and ruin the tool, necessitating rehardening and retempering. Since hardened carbon steels soften rapidly under the influence of heat, the carbon steels cannot be used as cutting tools under conditions where an appreciable amount of heat is generated at the cutting edge. Their uses are limited to conditions entailing light cuts on relatively soft materials, such as brass, aluminum, and unhardened low carbon steels:

The ranges for the carbon content and some typical applications of carbon tool steels are as follows:

0.60 to 0.75 percent of carbon-Hot forming or heading dies for short runs, machinery parts, hammers (sledges and pinch bars), concrete breakers, and rivet sets.

0.75 to 0.90 percent of carbon-Hot and cold sets, chisels, dies, shear blades, mining drill steel, smiths' tools, set hammers, swages, and flatteners.

0.90 to 1.10 percent of carbon-Hand chisels, small shear blades, large taps, granite drills, trimming dies, drills, cutters, slotting and milling tools, mill picks, circular cutters, threading dies, cold header dies, jewelers' cold striking dies, blanking, forming and drawing dies, and punches.

1.10 to 1.40 percent of carbon-Small cutters, small taps, drills, reamers, slotting and planing tools, wood-cutting tools, turning tools, and razors.

Suitable tempering temperatures for carbon tool steels are as follows:

$300^{\circ}$ to $375^{\circ} \mathrm{F}$-Lathe tools and milling cutters, scrapers, drawing mandrels, dies, bone-cutting tools, engraving tools, gages, and threading dies.

$375^{\circ}$ to $500^{\circ} \mathrm{F}$-Hand taps and dies, hand reamers, drills, bits, cutting dies, pen knives, milling cutters, chasers, press dies for blanking and forming, rock drills, dental and surgical instru- 
ments, hammer faces, wood-carving tools, shear blades, and hack saws.

$500^{\circ}$ to $700^{\circ} \mathrm{F}$-Bending dies, shear blades, chuck jaws, forging dies, tools for wood cutting, hammers and drop dies, axes, cold chisels, coppersmith tools, screwdrivers, molding and planing tools, hack saws, butcher knives, and saws.

The high-speed steels are intended for use under heavy cutting conditions where considerable heat is generated. These steels are very complex, containing large amounts of alloying elements. The high-speed steels, which harden from a very high temperature $\left(2,150^{\circ}\right.$ to $\left.2,400^{\circ} \mathrm{F}\right)$, develop what is termed "secondary hardness" after tempering at about $1,050^{\circ}$ to $1,100^{\circ} \mathrm{F}$ and maintain their cutting edge at considerably higher temperature than do carbon tool steels.

Dies, depending on their use, can be made of a variety or steels. When intended for use at low temperatures, even carbon steel may be satisfac. tory sometimes. For use at elevated temperatures, certain minimum amounts of alloying elements are necessary and for the higher ranges of hot-working temperatures, steels of the high-speed steel type are frequently used.

The manufacture of dies usually involves such considerable expense in machining that cost of material and heat treatment form but a relatively small proportion of the total. It is imperative, therefore, that die steels be selected carefully and properly heat treated. The so-called "nondeforming" tool steels (type $O$ ) are favorites for dies that are not required to operate at elevated temperatures. These steels usually contain about 0.9 percent of carbon and 1.2 percent to 1.6 percent of manganese. With the lower manganese content they also contain about 0.5 percent each of chromium and tungsten. The expansion of these steels during hardening is much less than is experienced with carbon steels, and the shrinkage that occurs during the initial stage of tempering is almost sufficient to return the steel to its original size when it has been tempered at the proper temperature.

The high carbon-high chromium steels (type D) are frequently used for dies. This type contains about 12 percent of chromium and 1.5 or 2.2 percent of carbon, the lower carbon steel being air hardening. These steels also are nondeforming, are more resistant to wear, and may be used at higher temperatures than the manganese nondeforming steels. They have the disadvantage of requiring higher hardening temperatures (about $\left.1,800^{\circ} \mathrm{F}\right)$.

\subsection{Stainless and Heat Resisting Steels}

Steels for high-temperature service must resist scaling and have high creep strength, that is, resistance to deformation under prolonged stress at elevated temperatures. Resistance to scaling is aided by the presence of chromium, aluminum, or silicon, and heat-resistant steels invariably contain one or more of these elements. Resistance to creep is aided by elements that form stable carbides, such as tungsten, vanadium, molybdenum, and chromium.

The stainless steels, often called corrosion-resistant steels, contain appreciable amounts of chromium ( $12 \%$ or more), either with or without other elements, the most important of which is nickel. The heat-resistant and corrosion-resistant steels all belong to the same family, the terminology frequently being dictated by the temperature of use. By common consent, this dividing temperature is taken at about $1200^{\circ} \mathrm{F}$.

The three general groups of stainless steels have markedly different characteristics, as follows:

\section{a. Group I - Hardenable Chromium Steels (Martensitic and Magnetic)}

The significant characteristic of this group is that the steels respond to heat treatment in a manner similar to most lower alloy steels. The steels possess a pearlitic structure on slow cooling and a martensitic (hardened) structure on rapid cooling from within the austenitic field. The chromium content varies from about 12 to 18 percent and the carbon content from less than 0.1 to over 1.0 percent; the higher chromium content demands the higher carbon.

The mechanical properties of this group of steels are markedly improved by heat treatment and heat treatment is essential to realize their corrosion-resistant properties. The only exceptions are the low carbon, low chromium steels (types 403, 410, 416) which are corrosion resistant in the annealed condition, although heat treatment decidedly improves mechanical properties.

Finishing of the martensitic steels has an important effect on corrosion resistance, since maximum corrosion resistance is obtained only with highly finished surfaces. Grinding should be done carefully, using a sharp wheel, light cuts, and plenty of coolant. Grinding burrs and embedded scale serve as focal points for corrosion.

As a group, the martensitic stainless steels resist many types of corrosive environments, including the atmosphere, fresh water, mine water, steam, food acids, carbonic acid, crude oil, gasoline, blood, perspiration, ammonia, and sterilizing solutions.

Type 410 stainless is a general purpose steel suitable for numerous applications where severe corrosion is not a problem. Types 416 and $416 \mathrm{~L}$ are free-machining varieties of type 410 . The higher hardness of type 420 makes it suitable for such uses as cutlery, surgical instruments, valves, ball bearings, magnets, etc. Type $420 \mathrm{~F}$ is its free-machining counterpart. Where still greater hardness is required, type $440 \mathrm{~A}, \mathrm{~B}$, or $\mathrm{C}$ may be used; the last is the hardest of all the stainless steels. Types 420 and 440 should be used only in the hardened and stress-relieved conditions. Type 431 is a structural stainless steel capable of being used in the strength range of 200,000 psi. 


\section{b. Group II-Nonhardenable Chromium Steels (Fer- ritic and Magnetic)}

The distinguishing characteristic of this group is that these steels are ferritic at all temperatures and, therefore, incapable of being hardened by heat treatment. They can, however, be strengthened by cold working.

The ferritic steels develop coarse grained structures when subjected to temperatures above $1650^{\circ} \mathrm{F}$ for varying lengths of time. This grain growth, frequently objectionable because of concomitant brittleness, cannot be eliminated by heat treatment alone. It can be corrected to some extent by cold working, followed by annealing.

The ferritic steels have lower strength at elevated temperatures than the martensitic steels, but resistance to scaling and corrosion is generally better. As a class, the ferritic stainless steels resist corrosion from food products, organic acids, salt water, nitric acid, many fused salts and molten nonferrous metals.

Type 430 stainless finds extensive use in automobile trim, chemical equipment, food containers, and furnace parts. If ease of machining is important, type $430 \mathrm{~F}$ or $430 \mathrm{~F}$ Se may be substituted. Where greater resistance to corrosion or oxidation is required, type 446 may be used.

\section{c. Group III-Nonhardenable Chromium-Nickel and Chromium-Nickel-Manganese Steels (Austenitic and Nonmagnetic)}

The steels in this group are austenitic at room temperature and, hence, both nonhardenable by heat treatment and nonmagnetic. They can, however, be strengthened appreciably by cold work. Depending upon the amount of cold work, the tensile strength varies from about 80,000 psi for fully annealed material to as high as 300,000 psi for severely work hardened steel; the highest strengths can be secured only with small cross sections. A stress-relieving treatment of about $1 \mathrm{hr}$ at $750^{\circ}$ to $800^{\circ} \mathrm{F}$ after severe cold working improves elastic properties without any adverse effect upon ductility. Cold work causes partial transformation of austenite to ferrite, with consequent appearance of magnetism, in some of these steels.

The austenitic steels have excellent coldforming properties and are extremely tough and ductile, even at low temperatures. Their toughness makes machining of all but the free-machining varieties difficult.

As a group, the ausenitic stainless steels are the most corrosion resistant of all the stainless steels. They have excellent resistance to acetic, nitric, and citric acids (liquid), foodstuffs, sterilizing solutions, most of the organic chemicals and dyestuffs, and a wide variety of inorganic chemicals. Typical applications are for outdoor trim, kitchen equipment, dairy utensils, soda fountains, and light weight transportation such as aircraft.

This group of stainless steels should not be discussed without some mention of intergranular embrittlement. If maintained in the temperature range of about $800^{\circ}$ to $1,400^{\circ} \mathrm{F}$, or if slowly cooled through this range after annealing, some of these steels precipitate carbides at the grain boundaries. This is not deleterious unless the steel is either simultaneously or subsequently exposed to acidified corrosive conditions, causing intergranular corrosion. When this occurs, the steels lose their metallic ring and become quite brittle.

Type 302 stainless, with its higher carbon content, is more prone to carbide precipitation than is 304 , which in turn is more susceptible than $304 \mathrm{~L}$.

Type 301 , because of its lower alloy content, is quite susceptible to work hardening and is used largely in the cold rolled or cold drawn form of sheet, strip, and wire. Types 201 and 202 are quite similar to types 301 and 302 in properties. The former were developed primarily to conserve nickel, then in short supply.

Types 305, 308, 309, and 310 contain progressively higher amounts of chromium and nickel and are, therefore, superior to the lower alloy steels in corrosion and heat resistance.

Types 316 and 317 contain molybdenum. The incorporation of this element increases resistance to corrosion, particularly of the "pitting" type.

Types 321 and 347 were developed specifically to resist intergranular corrosion. This property of the titanium-bearing steel (type 321 ) is generally enhanced by a stabilizing heat treatment. This treatment is not particularly necessary for the columbium-bearing steels (types 347 and 348).

\section{d. Semi-Austenitic Stainless Steels}

The semi-austenitic stainless steels, also called precipitation hardening stainless steels, constitute a special group for which no standard specifications have as yet been adopted by AISI. These steels are of sufficient commercial importance, however, to warrant some mention.

Essentially, the semi-austenitic stainless steels are steels in which, by careful control of composition and heat treatment, an austenite can be produced having a stability intermediate between that of the austenitic and martensitic types. After a solution heat treatment these steels are austenitic at room temperature and, therefore, readily amenable to severe forming and working operations. Following fabrication, exposure to a relatively low temperature conditions the austenite for transformation to martensite on subsequent cooling, with a marked increase in strength. Depending on the composition and final properties desired, the low temperature treatment may be a two-step operation. The transformation of the austenite to martensite in the first step results in hardening of the matrix. In some compositions, the matrix also contains elements that are in supersaturated solid solution after this treatment. The second operation, therefore, is designed to allow the solute elements to precipitate and to temper the martensite.

As these are proprietary steels, the manufacturers should be consulted for details of chemical compositions, recommended heat treatments, typical properties, and uses. 
In preparing this monograph, the authors have drawn liberally from the field of common knowledge and published information, especially from the Metals Handbook, published by the American Society for Metals, and the Steel Product Manuals of the American Iron and Steel Institute. Grateful acknowledgment is due to all metallurgists, both known and unknown, whose work and study have transformed the art of heat treating into a science. The various photomicrographs used were prepared by Carolyn R. Irish, a member of the staff of the National Bureau of Standards.

\section{Selected References}

The following is a selected, but by no means complete, list of books that contain information pertaining to the subject of this Monograph. In addition, many manufacturers of steels and of equipment related to heat treating have available excellent pamphlets and books.

American Foundrymen's Society, The cast metals handbook, Am. Foundrymen's Soc., Chicago, Ill. (1957) 316 pages.

American Iron and Steel Institute Steel Products Manuals, as follows: Carbon steel: Semi-finished for forging; Hot rolled and cold finished bars; Hot rolled deformed concrete reinforcing bars, July 1957; Suppl. Dec. 1957; Alloy steel: Semi-finished; hot rolled and cold finished bars, July 1955; Suppl. July 1958; Tool steels, Apr. 1955; Suppl. Sept. 1959; Stainless and heat resisting steels, June 1957; Suppl. Sept. 1959, Am. Iron and Steel Inst., New York, N.Y.

American Society for Metals, Metals handbook, Am. Soc. Metals, Novelty, Ohio (1948) 1444 pages; with 1954 and 1955 supplements.

Edgar C. Bain, Functions of the alloying elements in steel, Am. Soc. Metals, Novelty, Ohio (1939) 312 pages.

R. M. Brick and Arthur Phillips, Structure and properties of alloys (McGraw-Hill Book Co., Inc., New York, N.Y., 1949) 485 pages.
Malcolm S. Burton, Applied metallurgy for engineers (McGraw-Hill Book Co., Inc., New York, N.Y., 1956) 407 pages.

J. M. Camp and C. B. Francis, The making, shaping and treating of steel, 7th edition U.S. Steel Corp., Pittsburgh, Pa. (1957) 1048 pages.

Walter Crafts and John L. Lamont, Hardenability and steel selection (Pitman and Sons, New York, N.Y., 1949) 279 pages.

John C. Everhart, et al, Mechanical properties of metals and alloys, NBS Circ. C447 (1943) 481 pages. J. P. Gill, et al, Tool steels, Am. Soc. Metals, Novelty, Ohio (1944) 577 pages.

M. A. Grossmann, Principles of heat treatment, Am. Soc. Metals, Novelty, Ohio (1953) 303 pages.

A. W. Grosvenor, Editor, Basic metallurgy, vol. I, Am. Soc. Metals, Novelty, Ohio (1954) 697 pages.

J. H. Hollomon and L. D. Jaffe, Ferrous metallurgical design (John Wiley and Sons, Inc., New York, N.Y., 1947) 346 pages.

Samuel L. Hoyt, Metal Data (Reinhold Publishing Corp., New York, N.Y., 1952) 526 pages.

Carl A. Keyser, Basic engineering metallurgy, 2d edition (Prentice-Hall, Inc., Englewood Cliffs, N.J., 1959) 507 pages.

Frank R. Palmer and George V. Luerssen, Tool steel simplified, Carpenter Steel Co., Reading, Pa. (1948) 564 pages.

George Sachs and Kent R. Van Horn, Practical metallurgy, Am. Soc. Metals, Novelty, Ohio (1940) 567 pages. Carl H. Samans, Engineering metals and their alloys, (Macmillan Co., New York, N.Y., 1949) 913 pages. Bradley Stoughton, Allison Butts, and Ardrey M. Bounds, Engineering metallurgy (McGraw-Hill Book Co.. Inc., New York. N.Y., 1953) 479 pages.

E. J. Teichert, Ferrous Metallurgy, vol. I - Introduction to ferrous metallurgy, 484 pages; vol. II - The manufacture and fabrication of steel, 487 pages; vol. III-Metallography and heat treatment of steel, 577 pages (McGrawHill Book Co., Inc., New York, N.Y., 1944).

Carl A. Zapffe, Stainless steels, Am. Soc. Metals, Novelty, Ohio (1949) 368 pages.

Washington, D.C. (March 18, 1960) 


\section{THE NATIONAL BUREAU OF STANDARDS}

The scope of activities of the National Bureau of Standards at its major laboratories, in Washington, D.C., and Boulder, Colo., is suggested in the following listing of the divisions and sections engaged in technical work. In general, each section carries out specialized research, development, and ongineering in the field indicated by its title. A brief description of the activities, and of the resultant publications, appears on the inside front cover.

WASHINGTON, D.C.

Electricity and Electronics. Resistance and Reactance. Electron Devices. Electrical Instruments. Magnetic Measurements. Dielectrics. Engineering Electronics. Electronic Instrumentation. Electrochemistry.

Optics and Metrology. Photometry and Colorimetry. Optical Instruments. Photographic Technology. Length. Engineering Metrology.

Heat. Temperature Physics. Thermodynamics. Cryogenic Physics. Rheology. Molecular Kinetics. Free Radicals Research.

Atomic Physics. Spectroscopy. Radiometry. Mass Spectrometry. Solid State Physics. Electron Physics. Atomic Physics.

Radiation Physics Neutron Physics. Radiation Theory. Radioactivity. X-ray. High Energy Radiation. Nucleonic Instrumentation. Radiological Equipment.

Chemistry. Organic Coatings. Surface Chemistry. Organic Chemistry. Analytical Chemistry Inorganic Chemistry. Electrodeposition. Molecular Structure and Properties of Gases Physical Chemistry. Thermochemistry. Spectrochemistry. Pure Substances.

Mechanics. Sound. Mechanical Instruments. Fluid Mechanics. Engineering Mechanics. Mass and Scale. Capacity, Density, and Fluid Meters. Combustion Controls.

Organic and Fibrous Materials. Rubber. Textiles. Paper. Leather. Testing and Specifications. Polymer Structure. Plastics. Dental Research.

Metallurgy. Thermal Metallurgy. Chemical Metallurgy. Mechanical Metallurgy. Corrosion. Metal Physics.

Mineral Products. Engineering Ceramics. Glass. Refractories. Enameled Metals. Constitution and Microstructure.

Building Technology. Structural Engineering. Fire Protection. Air Conditioning. Heating and Refrigeration. Floor, Roof, and Wall Coverings. Codes and Safety Standards. Heat Transfer. Concreting Materials.

Applied Mathematics. Numerical Analysis. Computation. Statistical Engineering. Mathematical Physics.

Data Processing Systems. SEAC Engineering Group. Components and Techniques. Digital Circuitry. Digital Systems. Analog Systems. Applications Engineering.

- Office of Basic Instrumentation.

- Office of Weights and Measures.

\section{BOULDER, COLORADO}

Cryogenic Engineering. Cryogenic Equipment. Cryogenic Processes. Properties of Materials. Gas Liquefaction.

Radio Propagation Physics. Upper Atmosphere Research. Ionosphere Research. Regular Prediction Services. Sun-Earth Relationships. VHF Research. Radio Warning Services. Airglow and Aurora. Radio Astronomy and Arctic Propagation.

Radio Propagation Engineering. Data Reduction Instrumentation. Radio Noise. Tropospheric Measurements. Trophospheric Analysis. Propagation-Terrain Effects. Radio-Meteorology. Lower Atmosphere Physics.

Radio Standards. High-Frequency Electrical Standards. Radio Broadcast Service. Radio and Microwave Materials. Atomic Frequency and Time Standards. Electronic Calibration Center. Mienowave Circuit Standards.

Radio Communication and Systems. Low Frequency and Very Low Frequency Research. High Frequency and Very High Frequency Research. Modulation Systems. Antenna Research. Navigation Systems. Systems Analysis Field Operations. 
